\title{
Full Ensemble and Bench Scale Testing of Fire Fighter Protective Clothing
}

David W. Stroup

Roy A. McLane

William H. Twilley

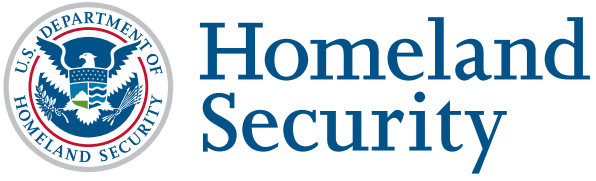

Sponsored in part by Department of Homeland Security

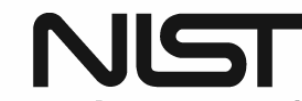

National Institute of Standards and Technology U.S. Department of Commerce 



\title{
Full Ensemble and Bench Scale Testing of Fire Fighter Protective Clothing
}

\author{
David W. Stroup \\ Roy A. McLane \\ William H. Twilley \\ Fire Research Division \\ Building and Fire Research Laboratory \\ National Institute of Standards and Technology \\ Gaithersburg, MD 20899-8661
}

\section{Homeland Security}

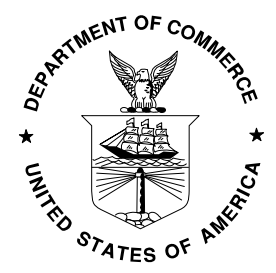

Department of Homeland Security Michael Chertoff, Secretary Federal Emergency Management Agency R. David Paulison, Administrator United States Fire Administration Gregory B. Cade, Assistant Administrator

\author{
U.S. Department of Commerce \\ Carlos M.Gutierrez, Secretary \\ National Institute of Standards and Technology \\ James M. Turner, Acting Director
}


- ii - 
Table of Contents

$\underline{\text { Page }}$

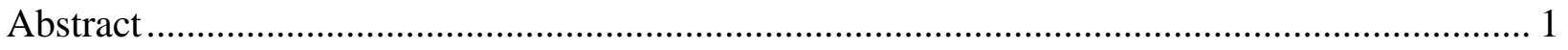

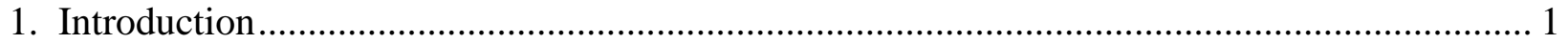

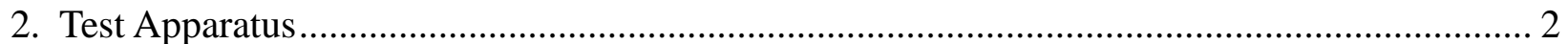

2.1 Bench Scale Apparatus ........................................................................................... 2

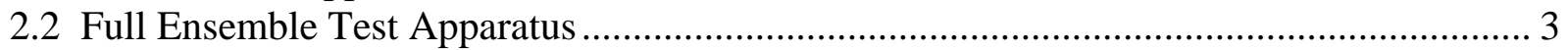

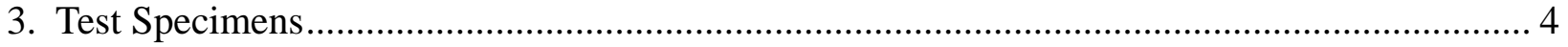

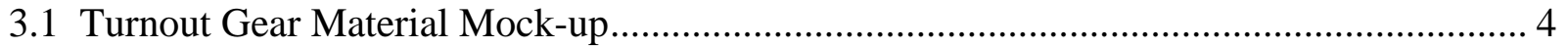

3.2 Fire Fighter Ensemble ....................................................................................... 5

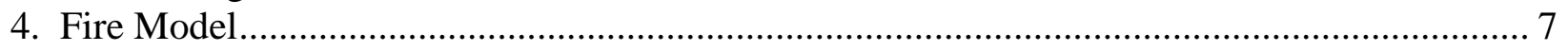

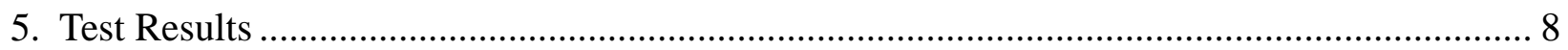

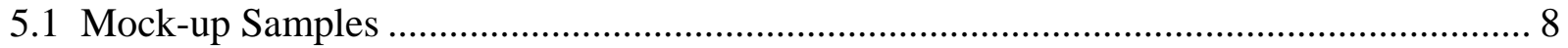

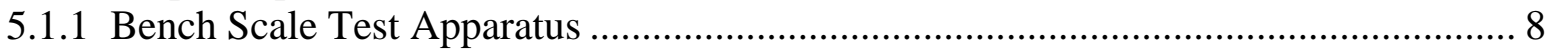

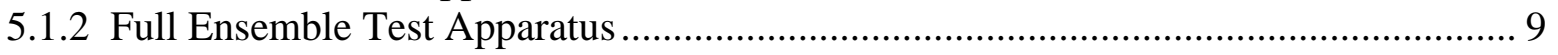

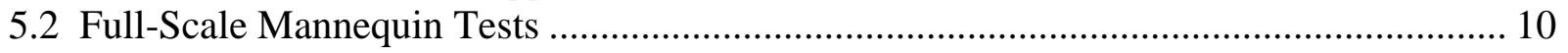

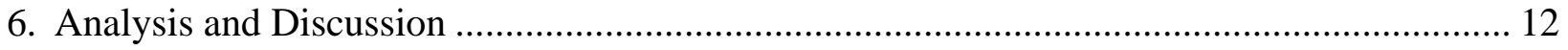

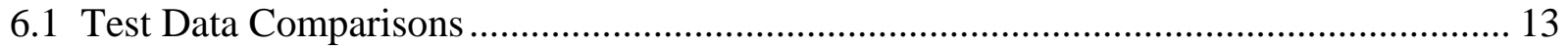

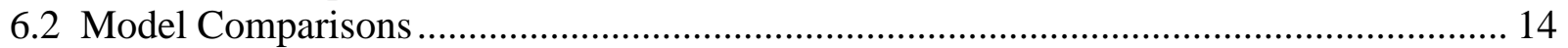

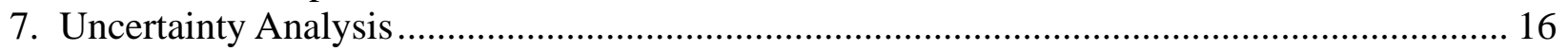

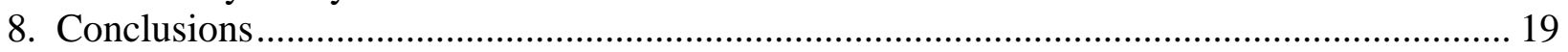

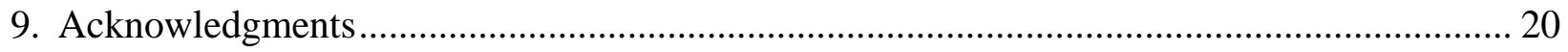

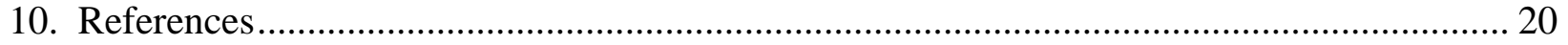




\section{List of Figures}

Page

Figure 1. Photograph of bench scale test apparatus with gas fired radiant panel operating and turn out gear mock-up sample in place ........................................... 22

Figure 2 Sketch showing the bench scale test apparatus......................................................... 23

Figure 3. Plan view of test apparatus including radiant panels and trolley assembly ........... 24

Figure 4. Elevation view of test apparatus including radiant panels and trolley assembly ......................................................................................................... 25

Figure 5. Photograph of radiant panels and radiation shield with trolley mounted heat flux gauge ....................................................................................................... 26

Figure 6. Photograph of the preconditioning chamber..................................................... 27

Figure 7. Photograph of mannequin positioned in front of the radiant panels ...................... 28

Figure 8. Photograph of turnout gear mock-up ................................................................. 29

Figure 9. Drawing of the turnout gear mock-up sample holder ............................................. 30

Figure 10. Photograph of the turnout gear mock-up sample holder with test sample............. 31

Figure 11. Photograph showing mannequin without coat and instrumentation (heat flux gauge and thermocouples).............................................................................. 32

Figure 12. Drawing showing thermocouple locations on the outside of the back of the turnout gear shell (Front Surface) ........................................................................ 33

Figure 13. Drawing showing thermocouple locations on the inside of the turnout coat shell (Mid-Point) .................................................................................................... 34

Figure 14. Drawing showing thermocouple locations on the inside of the thermal liner adjacent to the moisture barrier (Back Surface) .............................................. 35

Figure 15. Drawing showing thermocouple locations on the outside of the

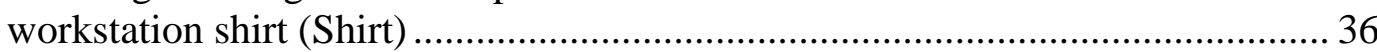

Figure 16. Graph showing temperatures measured on the front of the mock-up shell material for each test conducted using the bench scale test apparatus .................. 37

Figure 17 Graph showing temperatures measured on the back of the mock-up shell material for each test conducted using the bench scale test apparatus .................. 38

Figure 18 Graph showing temperatures measured on the front of the mock-up thermal liner material for each test conducted using the bench scale test apparatus

Figure 19. Graph showing temperatures measured on the back of the mock-up thermal liner material for each test conducted using the bench scale test apparatus

Figure 20 Graph showing average temperatures measured for each of the six mockup samples using the bench scale test apparatus (TC2 eliminated for clarity)

Figure 21 Graph showing average temperatures measured through mock-up shell samples using the bench scale test apparatus

Figure 22 Drawings of heat flux gauge and mock-up trolley showing the mock-up in position and the dimensions 
Figure 23. Photograph of radiation shield in place in front of the radiant panels. 44

Figure 24. Graph showing the data from the thermocouple attached to the front of the mock-up shell material for all tests using the full ensemble test apparatus.......... 45

Figure 25. Graph showing the data from the thermocouple attached to the back of the mock-up shell material for all tests using the full ensemble test apparatus.......... 46

Figure 26. Graph showing the data from the thermocouple attached to the front of the mock-up thermal liner material for all tests using the full ensemble test apparatus

Figure 27. Graph showing the data from the thermocouple attached to the back of the mock-up thermal liner material for all tests using the full ensemble test apparatus .....

Figure 28. Graph showing the average temperatures obtained at the four thermocouple locations during the mock-up test using the full ensemble test apparatus

Figure 29. Graphs showing temperatures measured through mock-up samples for the following orientations: vertical at $0.91 \mathrm{~m}(2.97 \mathrm{ft})$, vertical at $0.93 \mathrm{~m}(3.1$ $\mathrm{ft}), 20$ degree angle at $0.91 \mathrm{~m}(2.97 \mathrm{ft})$, and 20 degree angle at $0.93 \mathrm{~m}$ (3.1 $\mathrm{ft})$...

Figure 30. Graph of temperatures through turnout coat and work station shirt for thermocouples associated with external thermocouple \#16 when exposed to an external radiant flux of $2.5 \mathrm{~kW} / \mathrm{m}^{2}$ and no elevated temperature preconditioning.....

Figure 31. Graph of temperatures through turnout coat and work station shirt for thermocouples associated with external thermocouple \#17 when exposed to an external radiant flux of $2.5 \mathrm{~kW} / \mathrm{m}^{2}$ and no elevated temperature preconditioning ..... 52

Figure 32. Graph of temperatures through turnout coat and work station shirt for thermocouples associated with external thermocouple \#18 when exposed to an external radiant flux of $2.5 \mathrm{~kW} / \mathrm{m}^{2}$ and no elevated temperature preconditioning.....

Figure 33. Graph of temperatures through turnout coat and work station shirt for thermocouples associated with external thermocouple \#19 when exposed to an external radiant flux of $2.5 \mathrm{~kW} / \mathrm{m}^{2}$ and no elevated temperature preconditioning.....

Figure 34. Graph of temperatures through turnout coat and work station shirt for thermocouples associated with external thermocouple \#20 when exposed to an external radiant flux of $2.5 \mathrm{~kW} / \mathrm{m}^{2}$ and no elevated temperature preconditioning 55

Figure 35. Graphs of average temperatures through turnout coat and work station shirt for thermocouples associated with the five external thermocouple locations when exposed to an external radiant heat flux of $2.5 \mathrm{~kW} / \mathrm{m}^{2}$ and preconditioned at $60{ }^{\circ} \mathrm{C}$ 56

Figure 36. Graphs of average temperatures through turnout coat and work station shirt for thermocouples associated with the five external thermocouple

$$
\text { - V - }
$$


locations when exposed to an external radiant heat flux of $2.5 \mathrm{~kW} / \mathrm{m}^{2}$ and with no elevated temperature preconditioning...... 57

Figure 37. Graphs of average temperatures through turnout coat and work station shirt for thermocouples associated with the five external thermocouple locations when exposed to an external radiant heat flux of $2.5 \mathrm{~kW} / \mathrm{m}^{2}$ and preconditioned at $50{ }^{\circ} \mathrm{C}$ 58

Figure 38. Graphs of average temperatures through turnout coat and work station shirt for thermocouples associated with the five external thermocouple locations when exposed to an external radiant heat flux of $2.5 \mathrm{~kW} / \mathrm{m}^{2}$ and preconditioned at $60{ }^{\circ} \mathrm{C}$ 59

Figure 39. Graph showing average temperatures obtained at the four thermocouple locations for the mock-up tests using the bench scale apparatus (labeled 224) and the full ensemble test apparatus (labeled 205)....

Figure 40. Graph showing the decay of the flux field with movement in the vertical direction (heat flux source on right side of graph)....

Figure 41. Graph showing the decay of the flux field with movement away from the radiant panels (heat flux source is $0.91 \mathrm{~m}$ away from the panel on right side of graph)

Figure 42. Graph showing comparison between temperatures measured through turnout gear at thermocouple \#16 location and data from mock-up samples in both the full ensemble test apparatus (labeled 205) and the bench scale apparatus (labeled 224)

Figure 43. Graph showing calculated temperatures for a mock-up exposed to a 2.5 $\mathrm{kW} / \mathrm{m}^{2}$ heat flux using the default parameters in the heat transfer model [12].

Figure 44. Graph showing calculated temperatures for a mock-up exposed to a 2.5 $\mathrm{kW} / \mathrm{m}^{2}$ heat flux using the default parameters in the heat transfer model [12] except the air gaps are half the size.

Figure 45. Graph showing calculated temperatures for a mock-up exposed to a 3 $\mathrm{kW} / \mathrm{m}^{2}$ heat flux using the default parameters in the heat transfer model [12].

Figure 46. Graph showing calculated temperatures for a mock-up exposed to a 2.5 $\mathrm{kW} / \mathrm{m}^{2}$ heat flux using the default parameters in the heat transfer model [12] except with a $75^{\circ} \mathrm{C}$ ambient background temperature

Figure 47. Graph comparing measured (Avg TC 16, Avg TC 1) and calculated temperature distributions through a turnout coat when exposed to a 2.5 $\mathrm{kW} / \mathrm{m}^{2}$ heat flux using the full ensemble test apparatus

Figure 48. Graph comparing measured (TC 1, TC 2, TC 3, TC 4) and calculated temperature distributions through a mock-up assembly when exposed to a $2.5 \mathrm{~kW} / \mathrm{m}^{2}$ heat flux using the full ensemble test apparatus 


\section{List of Tables}

$\underline{\text { Page }}$

Table 1. Thermal Properties of Mock-up Materials................................................................... 5

Table 2. Thermal Properties of Fire Fighter Ensemble Materials ............................................ 6

Table 3. Summary of Air and Water Physical Properties ......................................................... 8

Table 4. Estimated Uncertainty in Experimental Data ........................................................ 17

- vii - 
- viii - 


\title{
Full Ensemble and Bench Scale Testing of Fire Fighter Protective Clothing
}

\author{
David W. Stroup, Roy A. McLane, and William H. Twilley
}

\begin{abstract}
The Thermal Protective Performance (TPP) test was developed to quantify the performance of fire fighter protective clothing ensembles under an intense thermal exposure. This test method has certainly helped to improve the thermal protection of fire fighter protective clothing. However, many fire service burn injuries can be traced to significantly lower thermal exposures than are simulated by the TPP test. A bench scale test method has been developed to evaluate the performance of fire fighter protective clothing at low heat fluxes. In addition, a full scale test apparatus capable of exposing both complete fire fighter ensembles and samples similar to those used in the bench scale test to various heat flux levels is under development. Both of these tests provide temperature measurements on the surface of the outer shell, at locations between the fabric or moisture barrier layers inside the protective clothing system, and at the thermal liner surface. When plotted, these temperature measurements show a detailed picture of how a protective clothing system performs when exposed to a given thermal environment. This report describes comparisons of results obtained using the bench scale test with data from the full-scale test apparatus. The data are also compared to results from a fire fighter protective clothing heat transfer model.
\end{abstract}

Key Words: burns (injuries); fire fighters; fire fighting equipment; heat transfer; large scale fire tests; mannequins; protective clothing; test methods; thermal protective performance (TPP) test

\section{Introduction}

Every year, approximately 100 fire fighters die in the line of duty, and 90000 to 100000 are injured [1]. In 1999, the United States Fire Administration estimated that approximately half of these fatalities were caused by stress and heart attacks [2]. While not the leading cause of fatalities, burns do represent a significant number of fatalities and injuries. Recent reports on fire fighter deaths and injuries indicate that burns accounted for approximately $7 \%$ of fire fighter fatalities [3] and $8.5 \%$ of fire fighter injuries [4].

Fire fighter protective clothing is designed to provide the wearer with a limited amount of protection from burn injury. Burn injuries can occur from exposure to the heat produced by a fire through contact with flames, hot combustion gases, steam, burning items, or any combination of these conditions. Fire fighters can also receive burn injuries when their protective garments become compressed as a result of contact with hot objects or when movement compresses clothing material against the skin [5]. Test methods that quantify the 
thermal performance of fire fighter protective clothing are specified in Standard on Protective Ensembles for Structural Firefighting and Proximity Fire Fighting, NFPA1971 [6]. Two thermal performance test methods found in NFPA 1971 have had a significant impact on improving the performance of fire fighters protective clothing. The Fabric Flammability Test (FFT) has resulted in the development of protective garments that resist flaming ignition. The second test, the Thermal Protective Performance (TPP) method has helped in the design of protective garments that reduce the rate of heat flow from a fire-fighting environment through the protective clothing.

The TPP test measures heat flow through a garment while exposed to a heat flux of approximately $83 \mathrm{~kW} / \mathrm{m}^{2}$ that is intended to simulate exposure to a flashover fire. A single copper calorimeter is used to measure heat transfer through a protective clothing assembly. Work by Krasny et al., suggests that fire fighters will likely receive serious burn injuries in less than 10 seconds when exposed to a heat flux of $83 \mathrm{~kW} / \mathrm{m}^{2}$ [7]. Fortunately, very few fire fighters are exposed to flashover conditions. Most fire fighter burn injuries appear to result from thermal exposures much less severe than the flashover conditions used by the TPP test. In addition, many of these burn injuries appear to result from relatively long duration exposures to low or moderate heat fluxes [8].

As part of a project funded by the United States Fire Administration, the Building and Fire Research Laboratory (BFRL) at National Institute of Standards and Technology (NIST) is exploring the feasibility of developing new apparatus for evaluation of the thermal performance of fire fighter protective clothing. This test apparatus would be capable of measuring the thermal performance of fire fighters' protective clothing over a wide range of thermal environmental conditions and over extended time periods. A bench scale test apparatus, using combinations of protective clothing material approximately $0.38 \mathrm{~m}(1.3 \mathrm{ft})$ square, has been developed [8]. A full scale apparatus that utilizes the full ensemble of protective clothing mounted on a mannequin to more effectively examine the complex geometric interactions of the protective clothing and the potential for various burn injuries is under development.

This report presents the results of tests conducted using turn out gear mock-ups in both the bench scale apparatus and the full scale test apparatus. In addition, data obtained from the mock-up tests is evaluated against results from tests of complete fire fighter ensembles in the full scale test apparatus. Finally, the experimental data are compared to calculations from a mathematical computer model of heat transfer through fire fighter protective clothing systems.

\section{Test Apparatus}

\subsection{Bench Scale Apparatus}

A bench scale test apparatus has been developed that allows for eva1uating the thermal performance of protective clothing systems exposed to heat flux environments ranging from $1.5 \mathrm{~kW} / \mathrm{m}^{2}$ to $50 \mathrm{~kW} / \mathrm{m}^{2}$ [8]. A photograph of the test apparatus is shown in Figure 1 . A side 
view sketch of the apparatus is shown in Figure 2. The heat flux exposure is provided by a premixed air/natural gas fueled radiant panel with a radiating surface measuring $305 \mathrm{~mm}$ by $457 \mathrm{~mm}$ (12 in by $18 \mathrm{in}$ ). The radiant panel is normally operated at an average surface blackbody temperature of $670{ }^{\circ} \mathrm{C}\left(1238^{\circ} \mathrm{F}\right)$. The apparatus has a propane fueled pilot flame that may also be directed onto a test specimen to evaluate thermal performance associated with direct flame contact. The flame height (length) may be adjusted to a low level for determining if fabrics or surface finishes will ignite or the height may be increased to sweep across a specimen's complete surface. Thermocouples are used to measure temperatures at any location of interest on or inside the test specimen assembly during the test time period. Test specimens are mounted on a movable trolley assembly that is attached to the radiant panel test frame. Positioning of the trolley allows for adjustment of radiant flux exposures and provides the ability to expose test specimens to radiant energy environments that can be increased or decreased during a test. The apparatus has the ability to test wet clothing so that the effects of moisture can be studied.

\section{$\underline{2.2 \text { Full Ensemble Test Apparatus }}$}

A test apparatus for evaluating the thermal performance of complete fire fighter protective clothing ensembles is being developed. The apparatus consists of two radiant panels, a trolley assembly, and a preconditioning chamber. The radiant panels and trolley assembly are shown in plan and elevation views in Figures 3 and 4, respectively. The radiant panels with a trolley mounted heat flux gauge positioned in front of them are shown in Figure 5. The preconditioning chamber is shown in Figure 6.

The preconditioning chamber is a commercially manufactured convection oven that has been modified to accommodate the mannequin and trolley assembly. The preconditioning chamber has a heat input of $30 \mathrm{~kW}$ and a maximum temperature rating of $340{ }^{\circ} \mathrm{C}\left(650{ }^{\circ} \mathrm{F}\right)$. Outside

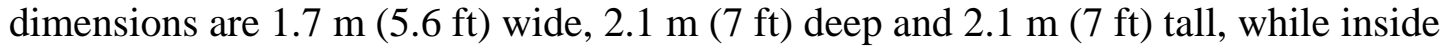
dimensions are $1.2 \mathrm{~m}(4 \mathrm{ft})$ wide, $1.2 \mathrm{~m}(4 \mathrm{ft})$ deep, and $1.9 \mathrm{~m}(6.3 \mathrm{ft})$ tall. To facilitate a uniform temperature within the chamber a variable speed motor operates a fan inside the chamber, providing a constant circulation of interior air. Two electric resistance heating panels, each measuring $2.0 \mathrm{~m}(6.6 \mathrm{ft})$ high by $0.3 \mathrm{~m}$ wide $(1.0 \mathrm{ft})$, produce the radiant energy used to expose the mannequin. A radiation shield (Figure 5) is placed in front of the two radiant panels to completely block the radiant energy from reaching the mannequin while it travels from inside the preconditioning chamber to the test position. This radiation shield consists of two thin aluminum sheets $0.5 \mathrm{~mm}(0.020 \mathrm{in})$ thick, mounted on an aluminum frame $0.66 \mathrm{~m}(2.2 \mathrm{ft})$ by $2.2 \mathrm{~m}(7.2 \mathrm{ft})$. This frame is designed with an air gap between the two aluminum sheets of $0.044 \mathrm{~m}(0.1 \mathrm{ft})$. Two hinged arms attached to this frame and base support tubes allow this panel to be moved quickly from in front of the radiant panels. The trolley assembly, used to move the mannequin from the preconditioning chamber to the test, consists of an aluminum plate $0.71 \mathrm{~m}$ $(2.3 \mathrm{ft})$ by $0.71 \mathrm{~m}(2.3 \mathrm{ft})$ with four aluminum wheels attached. Two of these wheels have angled cuts into their circumference which engage a corresponding reverse angle on the trolley way. The trolley rides atop one aluminum rail made of flat stock $0.05 \mathrm{~m}(0.17 \mathrm{ft})$ wide and a second rail made from an inverted aluminum angle that mates with the inverted angle wheel to guide the mannequin trolley. 
A complete fire fighter ensemble including self contained breathing apparatus (SCBA), if desired, can be mounted on a full sized commercial clothing store mannequin (Figure 7) for

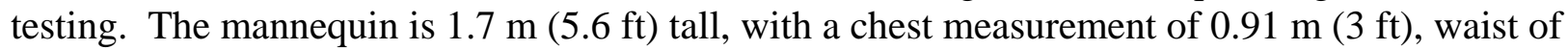
$0.81 \mathrm{~m}(2.7 \mathrm{ft})$, sleeve length of $.0 .81 \mathrm{~m}(2.7 \mathrm{ft})$, and an inseam of $0.71 \mathrm{~m}(2.3 \mathrm{ft})$. The mannequin and clothing ensemble can be thermally preconditioned from $25^{\circ} \mathrm{C}\left(77^{\circ} \mathrm{F}\right)$ to $100{ }^{\circ} \mathrm{C}$ $\left(21{ }^{\circ} \mathrm{F}\right.$ ) before being exposed to a radiant heat flux ranging from $1.5 \mathrm{~kW} / \mathrm{m}^{2}$ to $10 \mathrm{~kW} / \mathrm{m}^{2}$.

Measurement data obtained using this test apparatus can provide a time/temperature response history for components of the protective clothing ensemble. Thermocouples are used to measure temperature at various locations of interest on or inside the clothing ensemble. The data obtained from this test can also be used for determining the latent heat or amount of energy stored in the garment ensemble, when exposed to a heat flux. Mock-up ensembles can be evaluated on this apparatus and can be correlated with the same mock-up ensembles tested on the bench scale test apparatus.

\section{Test Specimens}

\subsection{Turnout Gear Material Mock-up}

One type of test specimen can be used in both the bench scale test apparatus and the full ensemble test apparatus. This test specimen consisted of a three layer mock-up of a fire fighter clothing ensemble (Figure 8). The mock-up samples were composed of a flame resistant fabric shell of polybenzimidazole, known commercially as PBI, with an average dry weight of $0.235 \mathrm{~kg} / \mathrm{m}^{2}\left(6.9 \mathrm{oz} / \mathrm{yd}^{2}\right)$, a breathable moisture barrier with an average dry weight of $0.130 \mathrm{~kg} / \mathrm{m}^{2}\left(3.8 \mathrm{oz} / \mathrm{yd}^{2}\right)$, and a quilted thermal liner with an average dry weight of $0.249 \mathrm{~kg} / \mathrm{m}^{2}$ $\left(7.3 \mathrm{oz} / \mathrm{yd}^{2}\right)$. Each material measured $0.280 \mathrm{.m}(0.92 \mathrm{ft})$ x $0.25 . \mathrm{m}(0.83 \mathrm{ft})$. The thermal and optical properties of similar materials used in fire fighter turnout ensembles have been measured [9]. The properties of the materials used in the mock-up samples are summarized in Table 1.

In all of the mock-up tests, type K, Chromel Alumel* thermocouples with a wire diameter of $0.254 \mathrm{~mm}$ (0.010 in) and fiberglass braid insulation were used. These thermocouples were sewn on to the various layers using a procedure previously described [8]. A single thermocouple was sewn on or near the center of the sample on the outer face of the shell material (side closest to the heat source). The exact location of this thermocouple was dictated by the quilting on the thermal liner. The thermocouple on the shell was positioned so as to prevent the thermocouple behind it on the thermal liner from being in the stitching of the quilting pattern. A second thermocouple was sewn onto the backside of the shell material, $4 \mathrm{~mm}(0.160 \mathrm{in})$ to the side of the front thermocouple. No thermocouples were attached to the moisture barrier, as the needle holes

* Certain commercial equipment, instruments, or materials are identified in this paper to foster understanding. Such identification does not imply recommendation or endorsement by the National Institute of Standards and

Technology, nor does it imply that the materials or equipment are necessarily the best available for the purpose. 
might constitute an atypical thermal path through this barrier. A third thermocouple was sewn on the front face of the thermal liner, behind and $4 \mathrm{~mm}(0.160 \mathrm{in})$ below the location of the other two thermocouples. Finally a fourth thermocouple was sewn onto the back of thermal liner $4 \mathrm{~mm}$ ( $0.16 \mathrm{in})$ beside the third thermocouple location. This offsetting pattern of the thermocouples was an effort to minimize any effect the thermocouples might have on the heat transfer.

Table 1. Thermal Properties of Mock-up Materials

\begin{tabular}{|l|c|c|c|}
\hline \multicolumn{1}{|c|}{ Property } & Shell & $\begin{array}{c}\text { Moisture } \\
\text { Barrier }\end{array}$ & $\begin{array}{c}\text { Thermal } \\
\text { Liner }\end{array}$ \\
\hline $\begin{array}{l}\text { Thermal } \\
\text { Conductivity } \\
\left(\mathbf{W} / \mathbf{m}^{\circ} \mathbf{C}\right)\end{array}$ & $0.0007 \mathrm{~T}+0.0354$ & $0.0003 \mathrm{~T}+0.0299$ & $0.0003 \mathrm{~T}+0.0304$ \\
\hline $\begin{array}{l}\text { Specific Heat } \\
\left(\mathbf{J} / \mathbf{g}^{\circ} \mathbf{C}\right)\end{array}$ & $\begin{array}{c}-2 \mathrm{E}-7 \mathrm{~T}^{3}+0.0004 \mathrm{~T}^{2}-0.037 \mathrm{~T} \\
+1.8212\end{array}$ & $\begin{array}{c}2 \mathrm{E}-6 \mathrm{~T}^{3}+7 \mathrm{E}-5 \mathrm{~T}^{2}-0.0274 \mathrm{~T} \\
+2.9263\end{array}$ & $\begin{array}{c}-7 \mathrm{E}-6 \mathrm{~T}^{3}+0.0012 \mathrm{~T}^{2}-0.0446 \mathrm{~T} \\
+1.798\end{array}$ \\
\hline $\begin{array}{l}\text { Thickness } \\
(\mathbf{m m})\end{array}$ & 0.80 & 0.96 & 3.59 \\
\hline Transmissivity & 0.120 & 0.187 & 0.121 \\
\hline Reflectivity & 0.219 & 0.268 & 0.236 \\
\hline Void Fraction & 0.7 & 0.7 & 0.7 \\
\hline Density (kg/m $\left.\mathbf{m}^{3}\right)$ & 321.8 & 143.1 & 74.2 \\
\hline
\end{tabular}

$\mathrm{T}$ - Material Temperature $\left({ }^{\circ} \mathrm{C}\right)$

The three layers of fabric were mounted in a calcium silicate holder $0.36 \mathrm{~m}(1.2 \mathrm{ft}) \mathrm{x} 0.36 \mathrm{~m}$ $(1.2 \mathrm{ft}) \times 0.013 \mathrm{~m}(0.04 \mathrm{ft})$ thick. The center of the holder had been cut $0.25 \mathrm{ft}(0.83 \mathrm{ft}) \times 0.25 \mathrm{ft}$ $(0.83 \mathrm{ft})$ as the area exposed to the radiant heat source (Figures 9 and 10). This calcium silicate frame was then completely covered with one layer of $0.03 \mathrm{~mm}$ thick aluminum foil. The tests were conducted using an open back, i.e., the back of the thermal liner was open to the room air and not in contact with a piece of calcium silicate backing board or other backing material. Tests can be conducted in the bench scale test apparatus using either an open back or closed back specimen holder. The open back configuration allows the test operator to observe both sides of the test specimen for physica1 changes. The closed back configuration reduces heat loss from the backside by replacing the open back portion of the specimen holder with a backing board of calcium silicate. At $23^{\circ} \mathrm{C}$, calcium silicate has a thermal conductivity of $0.111 \mathrm{~W} / \mathrm{m}{ }^{\circ} \mathrm{C}$, a specific heat of $778 \mathrm{~J} / \mathrm{kg}^{\circ} \mathrm{C}$ and an approximate density of $670 \mathrm{~kg} / \mathrm{m}^{3}$. It is estimated that the actual thermal performance of fire fighters protective clothing falls between the open back and closed back configuration.

\subsection{Fire Fighter Ensemble}

For the full ensemble apparatus tests, a complete set of fire fighter bunker gear (helmet, pants coat, boots, gloves, and hood) and a workstation shirt were used. The fire fighting coat was composed of an external shell made from a blend of $40 \% \mathrm{PBI}$ and $60 \%$ Kevlar, a thermal liner made of "Caldura”, and a moisture barrier made of "E-89 Spunlaced”. Bunker pants were also 
fitted to the mannequin although there was no instrumentation in these pants. The bunker pants are considered an integral part of the fire fighters protective ensemble and were included for completeness. The inclusion of pants also helped to ensure that the coat was fitted in a way that was representative of real world fire ground conditions. The bunker pants were composed of a shell material made of $0.255 \mathrm{~kg} / \mathrm{m}^{2}$ (7.5 oz./sq yd.) Nomex III aramid, a moisture barrier coated with polycotton (65 \% Polyester/35 \% cotton), and a thermal liner made of $100 \%$ aramid.

The turnout coat on the mannequin and the mock-up sample materials were not an exact fabric for fabric match, but both the mock-ups and the turnout coat utilize PBI. The thermal and optical properties [9] of the turnout coat materials are summarized in Table 2. The material used as the thermal liner in the fire fighter turnout coat was not tested. This thermal liner material was produced by the same manufacturer that made the material used in the thermal liner portion of the mock-up sample. An examination of available manufacturer's literature suggests that the material has a composition similar to the thermal liner material used for the mock-up tests. With the exception of weight, the materials have similar physical and fire resistance properties. The density of the thermal liner in the fire fighter coat was estimated based on the heavier material and shown in Table 2.

Table 2. Thermal Properties of Fire Fighter Ensemble Materials

\begin{tabular}{|l|c|c|c|}
\hline \multicolumn{1}{|c|}{ Property } & Shell & \multicolumn{1}{c|}{$\begin{array}{c}\text { Moisture } \\
\text { Barrier }\end{array}$} & $\begin{array}{c}\text { Thermal } \\
\text { Liner }\end{array}$ \\
\hline $\begin{array}{l}\text { Thermal } \\
\text { Conductivity } \\
(\mathbf{W} / \mathbf{m} \text { C) }\end{array}$ & $0.0007 \mathrm{~T}+0.0354$ & $0.0003 \mathrm{~T}+0.0299$ & $*$ \\
\hline $\begin{array}{l}\text { Specific Heat } \\
\left(\mathbf{J} / \mathbf{g}^{\circ} \mathbf{C}\right)\end{array}$ & $\begin{array}{c}-2 \mathrm{E}-6 \mathrm{~T}^{3}+0.0004 \mathrm{~T}^{2}-0.037 \mathrm{~T} \\
+1.8212\end{array}$ & $\begin{array}{c}2 \mathrm{E}-6 \mathrm{~T}^{3}+7 \mathrm{E}-5 \mathrm{~T}^{2}-0.0274 \mathrm{~T} \\
+2.9263\end{array}$ & $*$ \\
\hline $\begin{array}{l}\text { Thickness } \\
(\mathbf{m m})\end{array}$ & 0.80 & 0.96 & $*$ \\
\hline Transmissivity & 0.120 & 0.187 & $*$ \\
\hline Reflectivity & 0.219 & 0.268 & $*$ \\
\hline Void Fraction & 0.7 & 0.7 & 83.3 \\
\hline Density (kg/m $\left.\mathbf{m}^{3}\right)$ & 321.8 & 143.1 & $*$ \\
\hline
\end{tabular}

$\mathrm{T}$ - Material Temperature $\left({ }^{\circ} \mathrm{C}\right)$

* - material not tested [9]

A short sleeve workstation uniform shirt was placed on the mannequin underneath the firefighter coat. This workstation shirt was instrumented with thermocouples on the outside which approximately matched the locations of those thermocouples on the firefighter coat. The workstation shirt was composed of 55 \% FFR (Fibrous Flame Retardant fabric) and 45 \% cotton. The workstation shirt complied with the appropriate requirements of NFPA 1975, Station/Work Uniforms for Fire and Emergency Services [10]. Since the bunker pants were not instrumented, it was not necessary to provide any other clothing underneath the pants. 
The workstation uniform shirt, turnout coat and bunker pants were fitted to the mannequin in such a way as to simulate as close as possible how these garments would fit an actual firefighter. The workstation shirt was open at the collar but the rest of the shirt was buttoned and tucked into the bunker pants. There was no "undershirt" or foundation garments. The coat was latched up completely and the collar was up, and all hook and loop fasteners were snugly closed. The head and neck were covered with a Nomex protective hood, which was also tucked into the coat, just as it would normally be used. A fiberglass fire service helmet was strapped to the mannequin's head. A total heat flux gauge had been attached to the helmet and positioned along the centerline (spine) of the mannequin (Figure 11). This gauge was further aligned in the same horizontal plane as that of the thermocouples on the turnout coat.

The time/temperature profile through each test specimen was then monitored using a series of thermocouples. Type K thermocouples with a wire diameter of $0.254 \mathrm{~mm}$ (0.010 in) were carefully sewn onto the surface of the various layers of fabric used to make up the ensemble. The heat flow as tracked by a set of four thermocouples was simultaneously monitored at five different locations. These thermocouples were used to measure heat flow through the firefighter coat and to the surface of the workstation shirt.

The procedure used to prepare and attach the thermocouples to the turnout coat has been described previously [8]. The thermocouple locations on the turnout coat are shown in Figures 12 - 15. As can be seen in Figure 12, there were five thermocouple locations on the back of the coat. At each of these locations, four thermocouples have been attached to the various layers of the coat and workstation shirt. This allowed for the evaluation of the thermal performance at several locations on the coat simultaneously. The first set of thermocouples was attached to the outer shell fabric; this was the outermost portion of the garment. Trim material was present on the outer portion of the coat, but the thermocouples were placed to avoid this additional layer of material. This thermocouple will be referred to as the front surface thermocouple. The second set of thermocouples was attached to the inside surface of the shell material, offset from the centerline of the garment by $5 \mathrm{~mm}$ (0.20 in). This set was identified as the mid-point thermocouples. The third set of thermocouples was attached to the thermal liner on the side closest to the wearer. These thermocouples were identified as the back surface thermocouples. These thermocouples are located on the centerline of the garment $5 \mathrm{~mm}(0.20 \mathrm{in})$ up above the front surface thermocouples. A fourth set of thermocouples was attached to the centerline of the outer surface of the workstation shirt about $10 \mathrm{~mm}$ (0.39 in) above the front surface thermocouples and identified as the shirt thermocouples.

\section{Fire Model}

A mathematical model has been developed to study the performance of fire fighter protective clothing when exposed to thermal radiation [11]. Mell and Lawson developed the first version of this model in 2000 [12]. The model was further developed and enhanced by Prasad, et al. [13]. The latest version of this model tracks the transient movement of heat and moisture through multiple layers of fabric. The model calculates the response of textile fabrics to an applied heat 
exposure. Heat is applied to the fabric as a combination of an external heat flux and an ambient gas temperature. The moisture in the fabric, the ambient environment, material properties and any air gaps are considered in the model.

The model has been successfully compared to several sets of experimental data. Early comparisons indicated that "the model performed well, especially inside the garment" [12]. In the absence of fabric-specific optical properties, the predicted temperatures on the outside of the fire fighter material differed by as much as $24^{\circ} \mathrm{C}$ from the experimental data while the temperatures inside where within $5{ }^{\circ} \mathrm{C}$. A comparison of the improved model with moisture transport indicates agreement between predicted results and experimental data is within $5 \%$. When the model was used to predict results obtained from Thermal Protective Performance Test (TTP) [14], the model was determined to provide "good agreement" with experimental results [15].

In addition to the properties of the fabric materials, the physical properties of air and water must be specified to use the model. The air and water physical properties that were used for the model comparison discussed in this paper are summarized in Table 3 [16].

Table 3. Summary of Air and Water Physical Properties

\begin{tabular}{|c|c|c|}
\hline Property & Air & Water \\
\hline $\begin{array}{l}\text { Thermal Conductivity } \\
\left(\mathrm{W} / \mathrm{m}^{\circ} \mathrm{C}\right)\end{array}$ & $26.3 \times 10^{-3}$ & 0.61 \\
\hline $\begin{array}{l}\text { Specific Heat } \\
\left(\mathrm{J} / \mathrm{g}^{\circ} \mathrm{C}\right)\end{array}$ & 1.006 & 4.18 \\
\hline Density $\left(\mathrm{kg} / \mathrm{m}^{3}\right)$ & 1.177 & 995.8 \\
\hline Viscosity $\left(\mathrm{m}^{2} / \mathrm{s}\right)$ & $15.9 \times 10^{-6}$ & \\
\hline
\end{tabular}

\section{Test Results}

\section{$\underline{5.1 \text { Mock-up Samples }}$}

\subsubsection{Bench Scale Test Apparatus}

A series of tests were conducted using a bench scale test apparatus described previously [8]. These tests were conducted using the established protocol for this test apparatus with three modifications. First, the sample holders used for these tests were made of a single piece of Bakelite plastic with an aluminum clamp to hold the fabrics in place. Second, the total heat flux gauge was not used with a calcium silicate board. The flux gauge was suspended from a rod attached to the trolley assembly in the bench scale apparatus. This configuration more closely resembled how the flux gauge was suspended when setting the radiant panel flux in the full-scale mannequin test apparatus. Third, no water was ever intentionally applied to the mock-up samples. The mock-up samples were environmentally conditioned at $23{ }^{\circ} \mathrm{C}\left(73^{\circ} \mathrm{F}\right)$ and $50 \%$ relative humidity. This did add some moisture to the mock-ups (approx. $5.2 \%$ by weight) but no 
additional water was intentionally added. While the bench-scale test apparatus has the capability to expose the test sample to both a radiative flux and direct flame exposure, the mock-up samples were only exposed to a radiative flux; none were exposed to direct flames. The exposure heat flux was $2.5 \mathrm{~kW} / \mathrm{m}^{2}$.

For these mock-up tests, four thermocouples were attached to the various material surfaces. One thermocouple (\#1) was attached to the outside surface of the shell material closest to the radiant panel. A second thermocouple (\#2) was attached to the inside of the shell. The third thermocouple (\#3) was attached to the surface of the thermal liner closest to the radiant panel, and the last thermocouple (\#4) was attached to the back of the thermal liner. Six "identical" mock-ups (labeled A - F) were used for these tests as well as the mock-up tests conducted in the full ensemble apparatus.

The results for the four thermocouple locations are plotted in Figures 16 - 19. The average results from three replicate tests of each of the six samples (A-F) are shown in Figure 20, and the averages for all tests at each thermocouple location are shown in Figure 21. The temperature measurements on the front and back of the shell material were similar values and so for clarity temperature values from TC \#2 were not plotted in Figure 20. Peak temperatures obtained on the surface of shell ranged from approximately $120^{\circ} \mathrm{C}\left(250^{\circ} \mathrm{F}\right)$ to $125^{\circ} \mathrm{C}\left(260^{\circ} \mathrm{F}\right)$. Peak temperatures on the front surface of the thermal liner were between $78^{\circ} \mathrm{C}\left(170^{\circ} \mathrm{F}\right)$ and $85^{\circ} \mathrm{C}$ $\left(185^{\circ} \mathrm{F}\right)$ while temperatures on the back were approximately $65^{\circ} \mathrm{C}\left(150^{\circ} \mathrm{F}\right)$ to $70^{\circ} \mathrm{C}\left(160^{\circ} \mathrm{F}\right)$. The data appears reproducible between samples and between tests with peak temperatures varying approximately $5{ }^{\circ} \mathrm{C}$ or less than $10 \%$. These small scale experiments did not utilize any elevated temperature preconditioning.

\subsubsection{Full Ensemble Test Apparatus}

Seventeen tests were conducted exposing the mock-up samples to a radiative heat flux of $2.5 \mathrm{~kW} / \mathrm{m}^{2}$ using the full ensemble test apparatus. To allow for testing of the mock-up samples in the full-scale mannequin testing apparatus, the heat flux calibration cart was modified with the addition of two support arms (Figure 22). These arms were attached approximately $0.18 \mathrm{~m}$ $(0.6 \mathrm{ft})$ above and below the normal location of the total heat flux gauge on the calibration cart. The exact location of these support arms is determined by placing one of the mock-up samples in its holder between the two support arms and adjusting them so that the exact center of the exposed mock-up sample corresponds with the location of the total heat flux gauge when it is positioned at the "center point" of the radiative flux field. This "center point" corresponds to a centerline position $0.91 \mathrm{~m}(3.1 \mathrm{ft})$ from the inside heater edge and $1.6 \mathrm{~m}(5.3 \mathrm{ft})$ up from the flat trolley guide rail. The mock-up sample is shown at the start of a test in Figure 23.

Figure 24 presents the data from the thermocouple attached to the front of the mock-up shell material. Figures 25, 26, and Figure 27 show the data obtained for all 17 tests on the inside of the shell material, the front side of the thermal liner, and the back side of the thermal liner, respectively. The average temperatures obtained during the tests at the four thermocouple locations are shown in Figure 28. 
The data for each thermocouple location was very reproducible with the greatest variation occurring at the back of the sample. The mock-up shell surface thermocouple reached a peak value of about $132{ }^{\circ} \mathrm{C}\left(270^{\circ} \mathrm{F}\right)$ at a $2.5 \mathrm{~kW} / \mathrm{m}^{2}$ exposure. The temperature profile obtained on the back of the shell was essentially the same as the front side. The shell material alone has a very small insulating capability. Peak temperatures of approximately $85^{\circ} \mathrm{C}\left(185^{\circ} \mathrm{F}\right)$ and $70{ }^{\circ} \mathrm{C}$ $\left(160^{\circ} \mathrm{F}\right)$ were obtained on the front and back surface of the thermal liner, respectively.

Another set of experiments was conducted to examine the placement of the sample relative to the radiant panels. With the heat flux at the "center point" set at $2.5 \mathrm{~kW} / \mathrm{m}^{2}$, the mock-up and holder were moved away from the radiant panels by $0.025 \mathrm{~m}(0.083 \mathrm{ft})$ or approximately $0.93 \mathrm{~m}$ (3.05 ft) from the radiant panels (Figure 29). These tests did result in a slightly lower peak temperature of approximately $130^{\circ} \mathrm{C}\left(266^{\circ} \mathrm{F}\right)$ as compared to $135^{\circ} \mathrm{C}\left(275^{\circ} \mathrm{F}\right)$ from the test with the mock-up $0.90 \mathrm{~m}(2.95 \mathrm{ft})$ away from the panels.

Additional experiments were conducted in order to characterize the change in surface heating when the angle of the incident radiant flux is something other than perpendicular to the sample face. These experiments involved modifying the arms normally used to hold the mock-up samples in the vertical orientation. The ends of both arms were modified with a hinge system so the holders could accept mock-up samples at angles other than vertical. Modifying the lower arm by cutting it in half and adding a length of tubing between the two sections allowed the angle of the mock-ups to be changed. With these modifications completed, a mock-up sample was inserted in the arms such that the sample was at an angle of about 20 degrees off vertical. The upper edge of the mock-up was farthest away from the panel. Other angled tests involved simply moving the angled sample $0.025 \mathrm{~m}(0.083 \mathrm{ft})$ closer to the radiant panels. This position placed the center point of the tests sample $0.91 \mathrm{~m}(2.97 \mathrm{ft})$ away from radiant panels.

Tests were conducted with the following configurations: vertical at $0.91 \mathrm{~m}(2.97 \mathrm{ft})$ from the radiant panel, vertical at $0.93 \mathrm{~m}(3.1 \mathrm{ft})$ from the radiant panel, 20 degree angle at $0.91 \mathrm{~m}$ $(2.97 \mathrm{ft})$ from the radiant pane, and 20 degree angle at $0.93 \mathrm{~m}(3.1 \mathrm{ft})$ from the radiant pane. Each test was conducted four times to develop an average, and the results are shown in Figure 29. It is interesting to note that peak shell temperatures obtained from the two sloped tests differ by only about $2{ }^{\circ} \mathrm{C}$ to $3{ }^{\circ} \mathrm{C}$ with a change in distance from the radiant panels of $0.025 \mathrm{~m}$ $(0.081 \mathrm{ft})$. The peak shell temperatures in the two vertical tests differed by about $2{ }^{\circ} \mathrm{C}$ for this same $0.025 \mathrm{~m}(0.081 \mathrm{ft})$ change in distance from the radiant panels. Peak surface temperatures changed rather modestly and seem to follow the flux regression curve regardless of the orientation of the mock-up.

\section{$\underline{5.2 \text { Full-Scale Mannequin Tests }}$}

For the full scale mannequin tests, the radiative heat flux exposure was suddenly applied to the ensemble after first being thermally preconditioned at one of four temperatures: $27^{\circ} \mathrm{C}\left(80.6{ }^{\circ} \mathrm{F}\right)$, $37^{\circ} \mathrm{C}\left(98.6^{\circ} \mathrm{F}\right), 50^{\circ} \mathrm{C}\left(122^{\circ} \mathrm{F}\right)$ or $60^{\circ} \mathrm{C}\left(140^{\circ} \mathrm{F}\right)$. These preconditioning temperatures represent a warm summer evening $27^{\circ} \mathrm{C}\left(80.6^{\circ} \mathrm{F}\right)$, a hot summer day or normal body temperature $37^{\circ} \mathrm{C}$ 
(98.6 ${ }^{\circ} \mathrm{F}$ ), an extremely hot summer day in the Arizona desert or the temperature inside a closed automobile on a sunny day $50^{\circ} \mathrm{C}\left(122^{\circ} \mathrm{F}\right)$, and lastly some type of externally applied heat source $60{ }^{\circ} \mathrm{C}\left(140^{\circ} \mathrm{F}\right)$. The preconditioning temperatures were measured at five different locations on the protective clothing ensemble covering the full size mannequin.

For a preconditioned temperature of $27^{\circ} \mathrm{C}\left(80.6^{\circ} \mathrm{F}\right)$, the temperature measurements at each of the thermocouple locations going down the spine of the turnout coat on the mannequin are shown in Figures 30 - 34. Each plot presents the data from five repeat tests for the four locations through the turnout coat (shell surface, inside of shell, body side of thermal liner, and outer surface of workstation shirt). These graphs provide a visual representation of the variation in the thermal profile through the garment and vertically along the centerline of the coat at each of the five thermocouple stations.

While the external heat flux was applied, the temperature on the outside and immediately inside the shell is shown to increase rapidly in the first $200 \mathrm{~s}$. After the first 200s, the increase becomes more gradual changing by approximately $20{ }^{\circ} \mathrm{C}$ over the next $400 \mathrm{~s}$. Consistent with the insulating capabilities of the turnout coat, the temperature increases on the body side of the thermal liner, and the outer surface of the workstation shirt are much more gradual. For the thermal liner, the rate of temperature increase is approximately $0.25{ }^{\circ} \mathrm{C} / \mathrm{s}$ during the first $400 \mathrm{~s}$ and decreases to $0.05^{\circ} \mathrm{C} / \mathrm{s}$ over the next $200 \mathrm{~s}$. For the outer surface of the workstation shirt, the rate of temperature increase is approximately $0.125^{\circ} \mathrm{C} / \mathrm{s}$ during the first 400 s and decreases to $0.05^{\circ} \mathrm{C} / \mathrm{s}$ over the next $200 \mathrm{~s}$. Once the external flux is removed, all of the temperatures begin to decrease rapidly. The inner and outer shell temperatures decrease more rapidly than thermal liner or workstation shirt temperatures. Ultimately, the shell temperatures fall below the thermal liner and workstation shirt temperatures.

For each of the four preheat conditions, the average temperatures for five repeat tests measured at each vertical location on the turnout coat are shown in Figures 35 - 38. These graphs give a simple "snap shot" of the thermal wave moving through the coat portion of the fire fighter protective ensemble for the four preconditioning temperatures. From these graphs, the impact of construction and fit on the thermal wave at the respective locations along and through the turnout coat can be examined.

With the exception of thermocouple \#5, the fabric layers were exactly the same over the test area. The starting temperature and preconditioning are uniform through out the fabric layers, and the total radiant heat flux is uniform over the test area within 3\%. A comparison of the surface thermocouples at the five locations demonstrates that the temperatures associated with \#17, \#18, $\# 19$, and \#20 thermocouple locations were very similar. One thermocouple differs significantly from the other four. This particular thermocouple, \#16, is as much as $21{ }^{\circ} \mathrm{C}$ cooler at the end of the exposure portion of the test than any of the other four surface thermocouples. This phenomenon was observed regardless of the level of thermal preconditioning. Thermocouples inside the ensemble (thermocouple \#11, \#6 and \#1) also show this same trend of significantly lower temperatures when compared with corresponding thermocouples at adjacent locations. 
There could be several possible explanations for this variation. One possibility is that the flux field is not as uniform as the calibration testing has demonstrated. A dramatic flux discontinuity at this particular thermocouple location (thermocouple \# 16) seems very unlikely considering the flux gauge mounted on the mannequin's helmet is only $0.18 \mathrm{~m}(0.59 \mathrm{ft})$ above this thermocouple and is consistently reading $2.5 \mathrm{~kW} / \mathrm{m}^{2}(+/-0.1)$. Another possibility is that the thermocouples are not in the same relative plane as the other four sets of thermocouples. Using a $0.61 \mathrm{~m} \mathrm{(2 \textrm {ft } )}$ level up against the thermocouples along the spine of the mannequin and a meter stick, revealed that four sets of thermocouples were in very close vertical alignment while the fifth set of thermocouples, the one in question, was $0.025 \mathrm{~m}(0.082 \mathrm{ft})$ farther away from those other four sets. In addition, the upper thermocouples were placed on a sloping portion of the turnout gear. It is possible that a plume of heated gases moving up the back of the turnout gear could be cooling the upper thermocouples. This would be a consistent explanation for the large temperature disparity between this string of thermocouples (\#1, \#6, \#11, and \#16) and adjacent thermocouple strings.

\section{Analysis and Discussion}

The two objectives of this work were 1) to compare results from the full ensemble test apparatus, the bench scale test apparatus and a protective clothing heat transfer model and 2) to monitor the thermal wave moving through a protective clothing ensemble when exposed to a known thermal radiant flux. The full ensemble and bench scale data were used to evaluate the performance of the heat transfer model. If the heat transfer model successfully simulates the temperatures, then the model can be a useful tool in examining different combinations of existing materials and help develop new materials/combinations. The thermal wave moving through the ensemble was monitored as the fire fighter protective clothing materials were exposed to a radiant heat flux of $2.5 \mathrm{~kW} / \mathrm{m}^{2}$. This $2.5 \mathrm{~kW} / \mathrm{m}^{2}$ radiant heat flux represented a low to moderate intensity exposure for most fire ground situations. This type of radiant exposure might be encountered some distance away from a fully involved large structure or when a fire fighter moves down a hallway toward a burning room with flames extending a short distance into that hallway. This moderate exposure intensity can be useful in gaining insight into thermal properties of the protective clothing ensemble without degrading the fabrics during repeated exposures.

Both the experimental and calculated results were obtained for a total test time of $900 \mathrm{~s}$. During this time, the protective clothing ensemble was exposed to a radiant heat flux for $600 \mathrm{~s}$. The test ensemble was allowed to cool in ambient temperature air during the remaining $300 \mathrm{~s}$.

All the protective clothing assemblies were tested or modeled in a near dry condition (less than $5 \%$ moisture by weight). The presence of moisture can have a significant effect on the heat transfer through fire fighter protective clothing and its effectiveness [13]. Several studies have documented that moisture in the protective clothing can change its thermal performance properties $[17,18]$. By controlling the moisture in the garment, the propagation of the thermal wave through the fabric layers and the impact of preheating, construction and fit on this thermal 
wave can be investigated. From this information, a realistic method for the evaluation of fullscale fire fighter protective clothing ensembles can be developed.

\section{$\underline{6.1}$ Test Data Comparisons}

The data obtained from the mock-up tests in both the bench scale apparatus and the full ensemble test show similar trends. Data obtained at the four thermocouple locations during tests in both the bench scale and full ensemble tests are shown in Figure 39. The general trend of the data is the same for both test apparatus. The peak temperatures obtained using the full ensemble apparatus are approximately $5{ }^{\circ} \mathrm{C}$ higher than those from the bench scale apparatus. This higher peak temperature is reflected in the measurements obtained throughout the turnout gear mockups. Once the exposure heat flux is stopped, the materials begin cooling at the same rate with all of the temperatures, mock up and full-scale apparatus, following the same curve.

A series of tests were conducted exposing a complete fire fighting ensemble to a $2.5 \mathrm{~kW} / \mathrm{m}^{2}$ heat flux using the full ensemble test apparatus. The fire fighting ensemble was preheated to one of four temperatures, ambient (no preheating), $37^{\circ} \mathrm{C}\left(98.6{ }^{\circ} \mathrm{F}\right), 50 \mathrm{C}\left(122{ }^{\circ} \mathrm{F}\right)$, or $60{ }^{\circ} \mathrm{C}\left(140{ }^{\circ} \mathrm{F}\right)$ using the preconditioning chamber. The average results obtained from the tests at each thermocouple location are shown in Figures 35 - 38. Each graph presents the temperature distribution through the turnout coat at each location as a function of time. The peak temperatures and the rate of increase of temperature appear to be relatively insensitive to the initial temperature of the turnout gear resulting from the preheating. Since the peak temperatures are similar regardless of initial temperature, the temperature profiles through the turnout coat at each location are also similar.

The heat flux profile obtained along a vertical axis at a fixed horizontal distance from the radiant panels is shown in Figure 40. Comparison of the thermocouple locations with the heat flux profile indicates that the thermocouples are all located in an area where the heat flux varies by less than 5\%. The major variation is associated with the thermocouple \#20 position. The thermocouple \#16, \#17, \#18, and \#19 positions fall within $0.1 \mathrm{~m}$ above to $0.2 \mathrm{~m}$ below the centerline. The measured heat flux is almost uniform over this area. Thermocouple \#20 is $0.278 \mathrm{~m}$ below the centerline in a position where the heat flux has decreased to $2.4 \mathrm{~kW} / \mathrm{m}^{2}$.

The peak temperatures obtained on the surface of the turnout coat exposed to the radiant heat flux are very similar between the different locations with the exception of the thermocouple \#16 position. Since the heat flux in the vertical direction is relatively uniform, another possibility for the temperature difference between location \#16 and the other thermocouple locations would be the horizontal distance. Since the radiant heat flux deceases with distance away from the radiant panels as shown in Figure 41, location \#16 is exposed to less radiation. Figure 29 illustrates the impact of moving a turnout gear mock-up away from the radiant panels and sloping it $20^{\circ}$. These changes result in at most a $5{ }^{\circ} \mathrm{C}$ change in peak temperatures. This suggests that the increased distance and sloping orientation may account for some of the temperature difference at thermocouple location \#16, but not all $20^{\circ} \mathrm{C}$ observed when the turnout coat is exposed to a $2.5 \mathrm{~kW} / \mathrm{m}^{2}$ heat flux using the full ensemble apparatus (Figures 35 - 38). 
The peak temperature obtained at thermocouple \#16 in the full ensemble tests compares favorably with the data from the mock-up tests using both the full ensemble apparatus and the bench scale apparatus. The rate of temperature increase on the surface of the exposed shell and the inside of the shell also compare favorable with the mock-up tests. The rate of increase with the turnout gear as indicated by the thermal liner temperature measurements differ significantly from the mock-up tests. In addition, the cooling (time period after $600 \mathrm{~s}$ ) within the turnout gear differs from that obtained using the mock-up samples. Figure 42 shows a comparison between temperature measurements through the turnout gear at the thermocouple \#16 location and data obtained using mock-up samples.

Peak temperatures obtained at the thermocouple \#16 location during the full ensemble tests agree responsibly well with the peak temperatures obtained from the mock-up tests (Figure 42). The peak temperatures at thermocouple \#16 are significantly below those obtained at the other locations of the shell surface during full ensemble testing. In addition, the temperatures on the unexposed side of the shell are seen to increase above the exposed surface temperatures for most of the thermocouple locations regardless of preheat temperature (Figures 35 -38). The lower peak temperatures obtained at thermocouple \#16 and during the mock-up tests are probably the result of two phenomena. Given the location of thermocouple \#16 and the small size of the mock-up samples, it is likely that the thermocouple bead is "viewing" less of the radiant panel and more of the ambient environment. This would result in the thermocouple indicating a lower temperature. It also appears that a convective boundary layer may be cooling the thermocouples along the exposed side of the turnout coat shell. This would account for the crossover of the inner and outer thermocouple temperatures. While these differences may limit comparison of data from the full ensemble and mock-up tests, it should not impact either test as a means to investigate heat transfer through fire fighting ensemble materials.

\section{$\underline{6.2 \text { Model Comparisons }}$}

For comparison purposes, a combination of materials used in a fire fighting coat were exposed to an external heat flux of $2.5 \mathrm{~kW} / \mathrm{m}^{2}$ for $600 \mathrm{~s}$ using the fire fighter clothing heat transfer model. The results are presented in Figure 43 for an air gap of $1 \mathrm{~mm}(0.04 \mathrm{in})$ between each layer. Figure 44 presents the results for the sample model calculations with the air gap between each layer reduced by half. The affects of the reduced air gaps are readily apparent in the decreased difference between the outside and inside temperatures of each of the three layers of material (shell, moisture barrier, and thermal liner). When the original air gaps are used together with an external heat flux of $3 \mathrm{~kW} / \mathrm{m}^{2}$, the peak temperatures increase by approximately $15^{\circ} \mathrm{C}$ (Figure 45). Figure 46 illustrates the impact of an increased external ambient temperature. When the background temperature is increased from $27^{\circ} \mathrm{C}$ to $75^{\circ} \mathrm{C}$, the peak temperatures increase by almost $25{ }^{\circ} \mathrm{C}$.

The model predictions for a set of turnout coat materials exposed to a $2.5 \mathrm{~kW} / \mathrm{m}^{2}$ external heat flux are compared to data obtained from the full ensemble test apparatus in Figure 47. The model prediction for the external part of the shell (Shell-Outside) compares favorably with the 
temperature data obtained on the exterior of the turnout coat Avg TC 16). However, the agreement between the prediction (Cotton_Outside) and the measured values (Avg TC 1) for the outer surface of the workstation shirt is not as good. The peaks are close, but the trends are very different. The almost linear growth of the measured data is consistently evident in the measured data obtained inside the fire fighting ensemble using the full ensemble test apparatus. The agreement between measured data (TC 1, TC 2, TC 3, and TC4) and predicted values (ShellOutside, Shell-Inside Moist_Barrier-Outside, Moist_Barrier-Inside Thermal_Liner-Outside, Thermal_Liner-Inside and Cotton_Outside) is much better throughout the material combination for a turnout gear mock-up (Figure 48).

The comparisons of experimental data and model calculations provide some insight into some of the differences between measurements at various thermocouple locations. It is likely that the higher peak temperatures measured at thermocouple locations \#17, \#18, \#19, \#20 are the result of those thermocouples "viewing" more of the radiant panels. Thermocouple \#16 is located higher on the coat and would view less of the radiant panel area. Similarly, the mock-ups both when exposed to the electric radiant panel and the gas fired radiant panel would see a small portion of the panels relative to the surrounding ambient environment. Using the model with an increased ambient temperature results in peak temperature prediction similar to those obtained at thermocouple locations \#17, \#18, \#19, and \#20. As discussed previously, thermocouple \#16 may represent the best location for comparison with mock-up tests. Any of the thermocouple locations should be useful for analysis of the heat transfer through the turnout gear material.

The almost linear temperature increase within the turnout coat during the full ensemble tests is more difficult to explain. Since this increase is not evident in either the mock-up tests or the model predictions, it is likely that the linear increase is the result of interactions within the turnout coat. These interactions could be difficult to address completely in any model. Non uniform air gaps, material contact, seams, and other issues could impact these results [13].

There are certain underlying assumptions that have been made for all of these mannequin tests. First, the fabric shell, moisture barrier, thermal liner, and workstation uniform are unique and separate layers, but considered to be homogeneous materials throughout each layer within the ensemble. The thermal wave moves through each layer from the surface of the outer shell, through the moisture barrier, thermal liner and to the workstation uniform. As the heat wave moves through the layers, the heat can move within a material layer or through one layer and into the next material layer. Air trapped between different layers can also slow the movement of heat from one layer to another layer. On the other hand, sections where stitching compresses two layers together may allow the heat wave to be conducted more quickly through the gear.

The thermocouples were located such that none of them are shielded by trim or seams or exposed to perforations such as needle holes. Trim and seams are a normal part of all fire fighter protective clothing ensembles. During the installation of the thermocouples on the various layers of fabric, considerable effort was expended to closely align these thermocouples, but not exactly overlap them. This specific slight misalignment was considered necessary to minimize the impacts of the thermally conductive thermocouples on the movement of the heat wave. This 
staggering of the thermocouples was designed to prevent one thermocouple from "shading" an adjacent thermocouple or creating a line of heat sinks.

In addition to the intentional thermocouple offsets, the final location of the thermocouples is also dependant on the shifting of the different layers of the fabric when the mannequin is completely dressed. Effort was made to insure that the thermocouples were in their desired locations when installation was completed.

\section{Uncertainty Analysis}

Uncertainties are grouped into two categories according to the method used to estimate them. Type A uncertainties are those which are evaluated by statistical methods, and Type B are those which are evaluated by other means [19]. Type B analysis of systematic uncertainties involves estimating the upper $(+a)$ and lower $(-a)$ limits for the quantity in question such that the probability that the value would be in the interval $( \pm \mathrm{a})$ is essentially $100 \%$. After estimating uncertainties by either Type A or B analysis, the uncertainties are combined in quadrature to yield the combined standard uncertainty. Multiplying the combined standard uncertainty by a coverage factor of two results in the expanded uncertainty which corresponds to a 95 percent confidence interval (2 $\Phi)$.

There are different components of uncertainty in the gas temperatures and heat flux measurements reported here. Components of uncertainty are summarized in Table 4. For these tests, the main variables that impact the uncertainty of the measurements are: 1) the gas temperatures, 2) the heat flux measurements and 3) the data acquisition equipment. The affect the thermocouples have on the precision of the test can further be broken down into three sub categories: a) variations in thermocouple manufacturing, b) variations in thermocouple attachment, and c) variations in thermocouple response time dependent largely on thermocouple wire and bead size. The total expanded uncertainty for an individual temperature measurement is estimated to be $\pm 18 \%$, and the total heat flux total expanded uncertainty is estimated to be $\pm 17 \%$. The components of uncertainty are tabulated in Table 4 .

Imprecise and inconsistent thermocouple attachment to the various fabric layers can result in inaccurate measurement of temperatures on these fabric surfaces. Reference [8] specifies a specific protocol for the attachment of the thermocouples to the fabric layers. This protocol was followed rigorously when attaching all the thermocouples. The positioning of the thermocouples, the mannequin, and the heat flux gauge could also produce uncertainties in the results. The relative placement of the various instruments and test equipment is estimated to be within $\pm 5 \%$.

Variations in response times of different wire size thermocouples have been documented in other publications [20]. By using a $0.254 \mathrm{~mm}$ (0.010 in) diameter wire in the thermocouples for all of the experiments, a compromise has been made between a very quick response time and the durability and workability of the wire. Temperature lag for this size thermocouple is estimated 
to be on the order of $0.25 \mathrm{~s}$. With a wire size of $0.254 \mathrm{~mm}(0.010 \mathrm{in})$, the typically formed bead size will average about $0.635 \mathrm{~mm}(0.025 \mathrm{in})$. This translates to a thermal radiation correction of approximately $+2.5^{\circ} \mathrm{C}\left(+5.5^{\circ} \mathrm{F}\right)$ during the steady state part of the test. This radiation error represents a temperature correction of about $5 \%$ [20].

\section{Table 4. Estimated Uncertainty in Experimental Data}

\begin{tabular}{|c|c|c|c|}
\hline & $\begin{array}{c}\text { Component } \\
\text { Standard } \\
\text { Uncertainty }\end{array}$ & $\begin{array}{c}\text { Combined } \\
\text { Standard } \\
\text { Uncertainty }\end{array}$ & $\begin{array}{c}\text { Total } \\
\text { Expanded } \\
\text { Uncertainty }\end{array}$ \\
\hline $\begin{array}{l}\text { GasTemperature } \\
\text { Calibration } \\
\text { Position } \\
\text { Bead Size } \\
\text { Radiative Cooling } \\
\text { Radiative Heating } \\
\text { Repeatability }^{1} \\
\text { Random }^{1} \\
\end{array}$ & $\begin{array}{c} \pm 1 \% \\
\pm 5 \% \\
\pm 5 \% \\
-5 \% \text { to }+0 \% \\
-0 \% \text { to }+5 \% \\
\quad \pm 5 \% \\
\pm 3 \%\end{array}$ & $\pm 9 \%$ & $\pm 18 \%$ \\
\hline $\begin{array}{l}\text { Total Heat Flux } \\
\text { Calibration } \\
\text { Zero } \\
\text { Position } \\
\text { Repeatability }^{1} \\
\text { Random }^{1} \\
\end{array}$ & $\begin{array}{l} \pm 3 \% \\
\pm 2 \% \\
\pm 5 \% \\
\pm 5 \% \\
\pm 3 \% \\
\end{array}$ & $\pm 9 \%$ & $\pm 17 \%$ \\
\hline $\begin{array}{c}\text { Data Acquisition } \\
\text { Calibration } \\
\text { Resolution } \\
\text { Repeatability }^{1} \\
\text { Random }^{1} \\
\end{array}$ & $\begin{array}{l} \pm 5 \% \\
\pm 1 \% \\
\pm 3 \% \\
\pm 3 \%\end{array}$ & $\pm 5 \%$ & $\pm 10 \%$ \\
\hline
\end{tabular}

The total heat flux was measured with a commercially manufactured, continuously reading, water-cooled, Schmidt/Boelter type thermopile gauge. This gauge has a maximum non-linearity of $\pm 2 \%$, a repeatability of $\pm 5 \%$, and an accuracy of $\pm 3 \%$. The non-linearity aspect of this gauge is of reduced importance when setting up and doing many repeat experiments, at the same radiant heat flux setting. A repeatability of $\pm 5 \%$ translates into about $\pm 0.1 \mathrm{~kW} / \mathrm{m}^{2}$ for the mannequin test apparatus. The manufacture's statement of accuracy would reflect a $\pm 0.3 \mathrm{~kW} / \mathrm{m}^{2}$. This much divergence from the actual flux reading would be undesirable. To mitigate this problem, this flux gauge was checked against a transfer standard gauge. The two gauges differed by slightly less than $1 \%$ or $0.1 \mathrm{~kW} / \mathrm{m}^{2}$.

The data acquisition equipment has certain limitations in its ability to accurately measure the temperature using a thermocouple. The greatest source of error in the thermocouple temperature measurements are a) the limits of error of the thermocouple wire itself, b) the reference 
temperature determined with the thermistor built into the data logger, c) the accuracy of the voltage measurement, and d) errors in the thermocouple and reference temperature polynomials. Beyond the limits of error of the thermocouple wire itself, the next largest possible source of temperature error is the thermistor (RTD) used to obtain the temperature of the reference junction. This RTD is accurate to $\pm 0.1^{\circ} \mathrm{C}\left(1.8^{\circ} \mathrm{F}\right)$. This RTD device can also be the source of other temperature measuring errors. The RTD is an integral part of the cold junction reference point. If the cold junction reference is not isothermal relative to the thermocouple terminal strip, any deviation from the RTD calculated temperature would show up as an error in the temperature measurement of the thermocouple. Careful placement of the data logger away from hot or cold drafts, and protection from uneven radiative heating will help to minimize this type of error. The environmentally conditioned laboratory space, used to conduct these experiments, should also substantially mitigate this source of temperature error.

The accuracy of the thermocouple voltage measurements in the data loggers used in these experiments is between $0.07 \%$ to $0.10 \%$. For the relatively small $\left(<160{ }^{\circ} \mathrm{C}\right)$ temperature changes developed in these tests, the temperature error due to the voltage measurement error on the order of a $0.02{ }^{\circ} \mathrm{C}$. Another potential source of thermocouple temperature error is in the polynomials used to convert the RTD output and the thermocouple voltage to a temperature. This error is $\pm 0.01{ }^{\circ} \mathrm{C}$ between $-50{ }^{\circ} \mathrm{C}$ and $950{ }^{\circ} \mathrm{C}$. Other potential sources of error in the thermocouple temperature measurement are the rate at which the thermocouples are scanned. Very high data logger scan rates of a very large number of thermocouples as well as switching ranges can result in insufficient settling times between each reading. This phenomenon can cause some degradation of the precise voltage measurement with a corresponding loss of temperature measurement precision. The data loggers used in these experiments were operated at a slow enough speed that this type of error could be assumed to be negligible.

The data logger has some inaccuracy associated with its internal clock. This clock error is about one minute per month. This represents a shift of approximately $\pm 0.3 \mathrm{~s}$ over the $900 \mathrm{~s}$ test interval. With a scan interval of $2 \mathrm{~s}$, this clock error would be insignificant. There are other possible sources of temperature measurement error not directly related to or attributable to the data logger equipment. Such things as extraneous electro magnetic radiation inducing stray voltages on to the thermocouple circuits are an example of this type of nonspecifically induced temperature measurement errors. The data logger does have a mechanism to cope with the most common type of electro magnetic interference, that being the typical 60-hertz found on the AC power lines. Other nonspecific electro magnetic interference inducing errors are difficult to quantify. Prevention and suppression of these interference sources is by far the best method of dealing with them. 


\section{Conclusions}

The full ensemble test apparatus provides a means for examining the thermal performance of fire fighter protection clothing. The apparatus can be used to measure the heat transfer through a complete fire fighting ensemble when exposed to a wide range of external heat flux values. The apparatus can be operated for extended periods of time simulating exposure times that could occur during fire fighting operations. Testing of complete ensembles is a vital supplement to the bench scale testing of mock-up samples. As additional work is undertaken to incorporate a fire fighter submodel into various computer-based fire models such as the Fire Dynamics Simulator [21], results from this full ensemble test apparatus will be critical for development and verification.

Test results are reasonably reproducible for a given test scenario (apparatus type, turn out gear materials, and mock-up or full ensemble arrangement). Data from fire fighter turnout gear mock-up tests using the full ensemble apparatus compare favorably with similar materials tested in the bench scale apparatus. Peak temperatures obtained when the materials are exposed to a $2.5 \mathrm{~kW} / \mathrm{m}^{2}$ heat flux are similar for mock-up samples tested in both the bench scale apparatus and the full ensemble test apparatus. Peak temperatures obtained using a complete ensemble differ from both the mock-up sample tests and at different locations on the ensemble when exposed to the same heat flux. These differences indicate the importance of clothing lay and air gaps in determining the transmission of heat through the turn out gear ensemble. In addition, the testing of mock-up samples with an open back sample holder appears to impact the heat transfer within the samples.

Given the location of the higher thermocouple and the small size of the mock-up samples, it is likely that the thermocouple bead would be "viewing" less of the radiant panel and more of the ambient environment. This would result in the thermocouple indicating a lower temperature. It also appears that a convective boundary layer may be cooling the thermocouples along the exposed side of the turnout coat shell. This would account for the crossover of the inner and outer thermocouple temperatures. While these differences may limit comparison of data from the full ensemble and mock-up tests, it should not impact either test as a means to investigate heat transfer through fire fighting ensemble materials.

Data from mock-up sample tests and full ensemble tests have been compared to results obtained from a computer-based mathematical model of heat transfer through fire fighter protective clothing [12]. Measured and calculated temperatures at the shell outer and inner surface agree quite well for the mock-up sample tests. The calculated rate of temperature increase at all of the measurement points is similar to the data obtained from the mock-up tests. However, the measured and predicted temperatures within the material layers are different. The computer model over predicts the temperatures at the various measurement locations when compared to data from the full ensemble tests. 


\section{Acknowledgments}

The authors would like to thank the United States Fire Administration, especially Mr. William Troup and Mr. Robert T. McCarthy, for their sponsorship and support of this important research

\section{References}

[1] Beyler, C.L., "Fire Safety Challenges in the $21^{\text {st }}$ Century,” Journal of Fire Protection Engineering, Vol. 11, No.1, pp. 4-15, 2001.

[2] Fire Fighter Fatalities in the United States in 1999, United States Fire Administration, Emmitsburg, MD, July 2000.

[3] LeBlanc, P.R. and Fahy, R.F., "Firefighter Fatalities in the United States - 2003," National Fire Protection Association, Quincy, MA, June 2004.

[4] Karter, M.J. and Molis, J.L., "U.S. Fire Fighter Injuries - 2002,” National Fire Protection Association, Quincy, MA, November 2003.

[5] Lawson, J.R., "Fire Fighter's Protective Clothing and Thermal Environments of Structural Fire Fighting," NISTIR 5804, National Institute of Standards and Technology, Gaithersburg, MD, August 1996.

[6] National Fire Protection Association, Standard on Protective Ensembles for Structural Fire Fighting and Proximity Fire Fighting, NFPA Standard 1971-2000, National Fire Protection Association, Quincy, MA, 2000.

[7] Krasney, J.F., Rockett, J.A., and Huang, D., "Protecting Fire Fighters Exposed in Room Fires: Comparison of Results of Bench Scale Test for Thermal Protection and Conditions During Room Flashover,” Fire Technology, 24 No. 1, pp. 5-19, 1988.

[8] Lawson, J.R. and Twilley, W.H., "Development of an Apparatus for Measuring the Thermal Performance of Fire Fighters’ Protective Clothing,” NISTIR 6400, National Institute of Standards and Technology, Gaithersburg, MD, October 1999.

[9] Lawson, J.R., Walton, W.D., Bryner, N.P., and Amon, F.K., "Estimates of Thermal Properties for Fire Fighters’ Protective Clothing Materials,” NISTIR 7282, National Institute of Standards and Technology, Gaithersburg, MD, June 2005.

[10] National Fire Protection Association, Station/Work Uniforms for Fire and Emergency Services, NFPA Standard 1975-2004, National Fire Protection Association, Quincy, MA, 2004.

[11] Prasad, K., Ho Dac, H.M., and Kukuck, S., "Thermal Performance of Fire Fighters' Protective Clothing. 2. Protective Clothing Performance Simulator - User’s Manual,” NISTIR 6901, National Institute of Standards and Technology, Gaithersburg, MD, January 2003.

[12] Mell, W.E., and Lawson, J.R., "Heat Transfer Model for Fire Fighters' Protective Clothing,” Fire Technology, Vol. 36, No. 1, pp. 39-68, February 2000.

[13] Prasad, K., Twilley, W.H., and Lawson, J.R., "Thermal Performance of Fire Fighters' Protective Clothing. 1. Numerical Study of Transient Heat and Water Vapor Transfer," NISTIR 6881, National Institute of Standards and Technology, Gaithersburg, MD, August 2002. 
[14] International Organization for Standardization, Clothing for protection against heat and flame - Determination of heat transmission on exposure to both flame and radiant heat, ISO Standard 17492, Geneva, Switzerland, 2003.

[15] Kukuck, S., and Prasad, K., "Thermal Performance of Fire Fighters' Protective Clothing. 3. Simulating a TPP Test for Single-Layered Fabrics,” NISTIR 6993, National Institute of Standards and Technology, Gaithersburg, MD, January 2003.

[16] DiNenno, P.J.,” Appendix B - Property Data,” The SFPE Handbook of Fire Protection Engineering, $3^{\text {rd }}$ Edition, Society of Fire Protection Engineers, Bethesda, MD, pp. A-23 to A33, 2002.

[17] Lawson, J.R., “Thermal Performance and Limitations of Bunker Gear,” Fire Engineering, Vol. 151, No. 8, pp. 37, 40, 42, 44, 46, 50 - 52, 55 - 56, August 1998.

[18] North Carolina State University, "Evaluating the Effects of Moisture on the Thermal Protective Performance of Firefighter Protective Clothing in Low Level Heat Exposures,” Annual Report, National Institute of Standards and Technology, Gaithersburg, MD, December 2001.

[19] Taylor, B.N., and Kuyatt, C.E., "Guidelines for Evaluating and Expressing the Uncertainty of NIST Measurements Results," NIST Technical Note 1297, National Institute of Standards and Technology, Gaithersburg, MD, September 1994.

[20] Blevins, L.G., and Pitts, W.M., "Modeling of Bare and Aspirated Thermocouples in Compartment Fires,” Fire Safety Journal, Vol. 33, pp. 239-259, 1999.

[21] McGrattan, K.B., "Fire Dynamics Simulator (Version 4) Technical Reference Guide," NIST SP 1018, NIST Special Publication 1018, National Institute of Standards and Technology, Gaithersburg, MD, July 2004. 


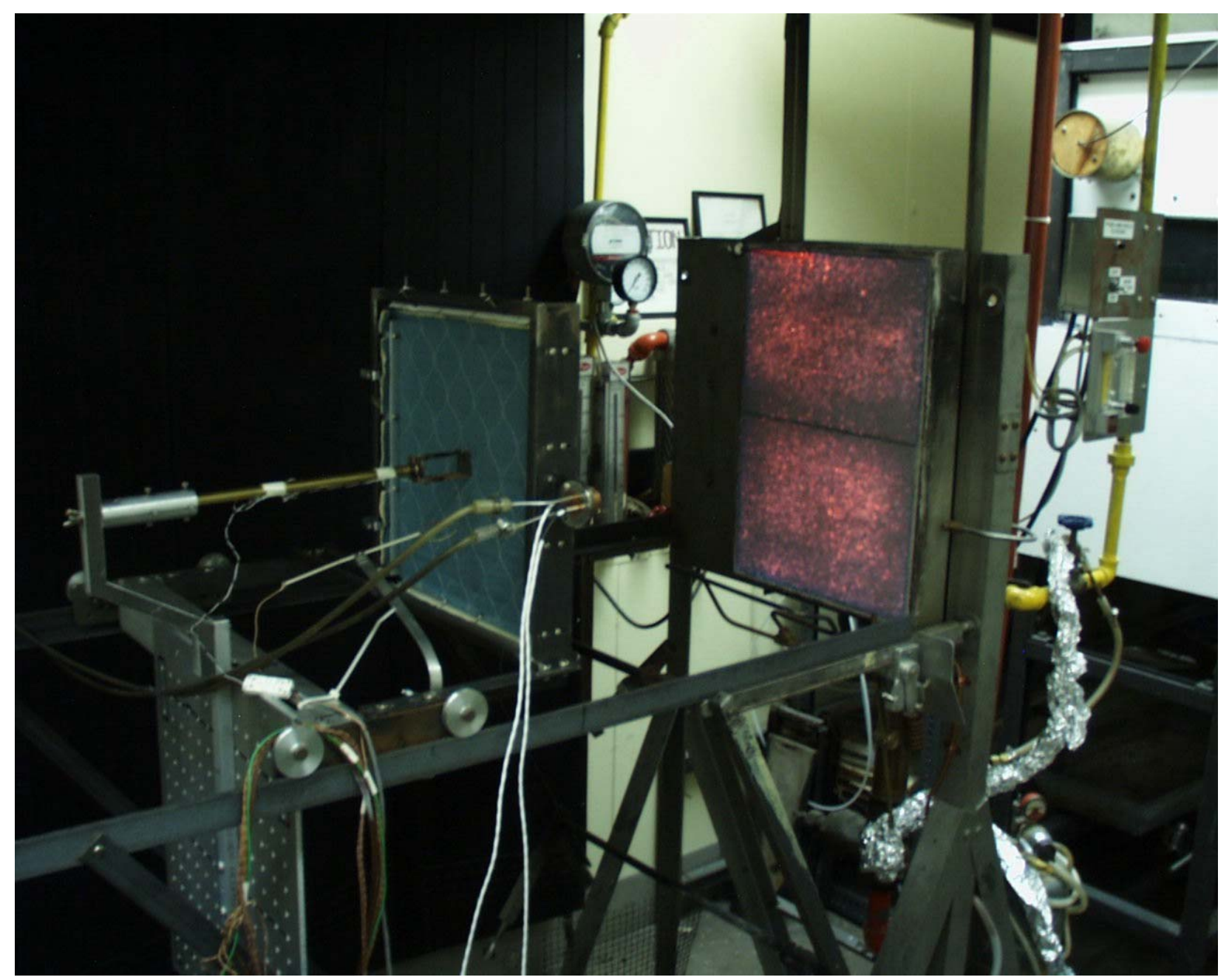

Figure 1. Photograph of bench scale test apparatus with gas fired radiant panel operating and turn out gear mock-up sample in place. 


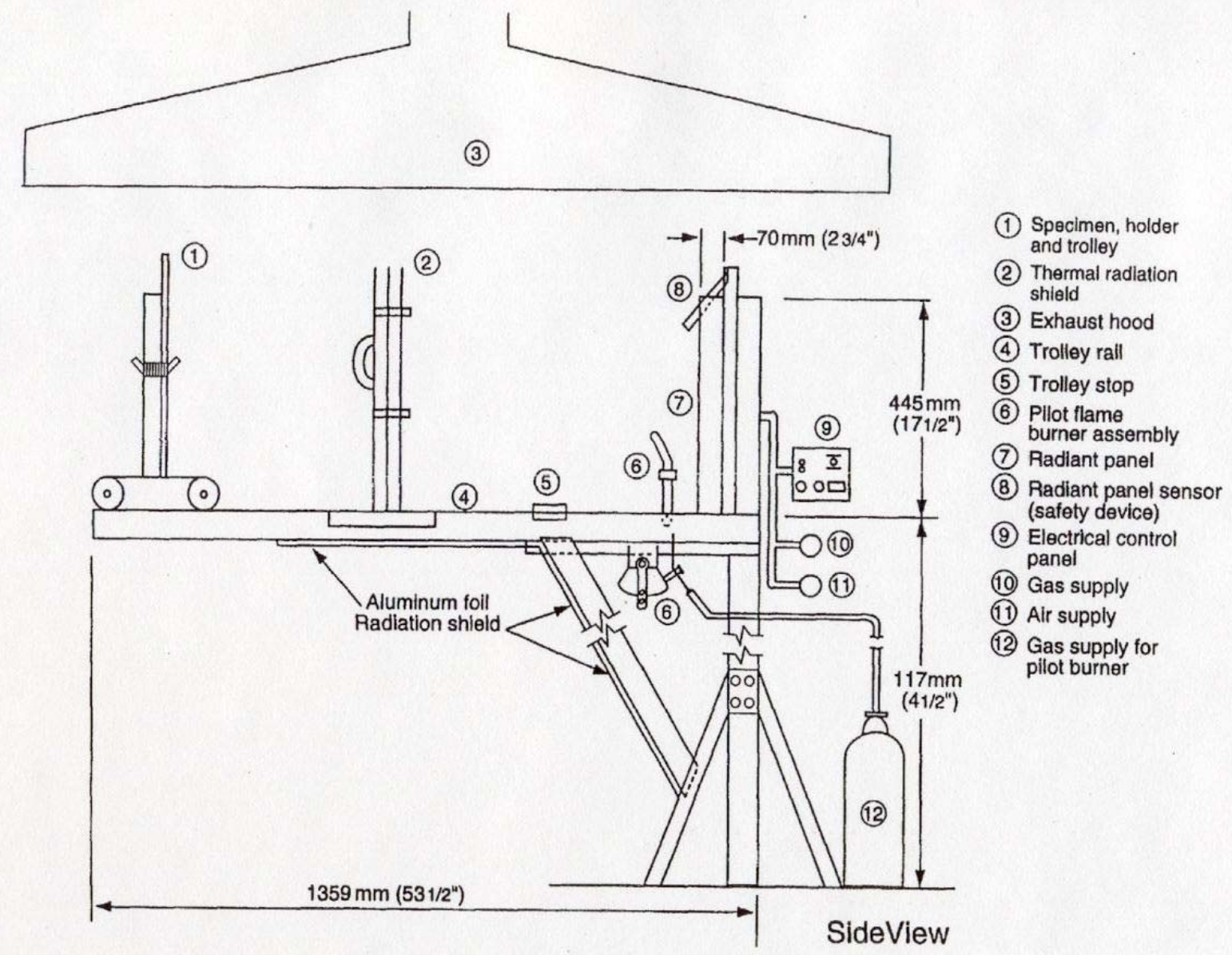

Figure 2. Sketch showing the bench scale test apparatus. 


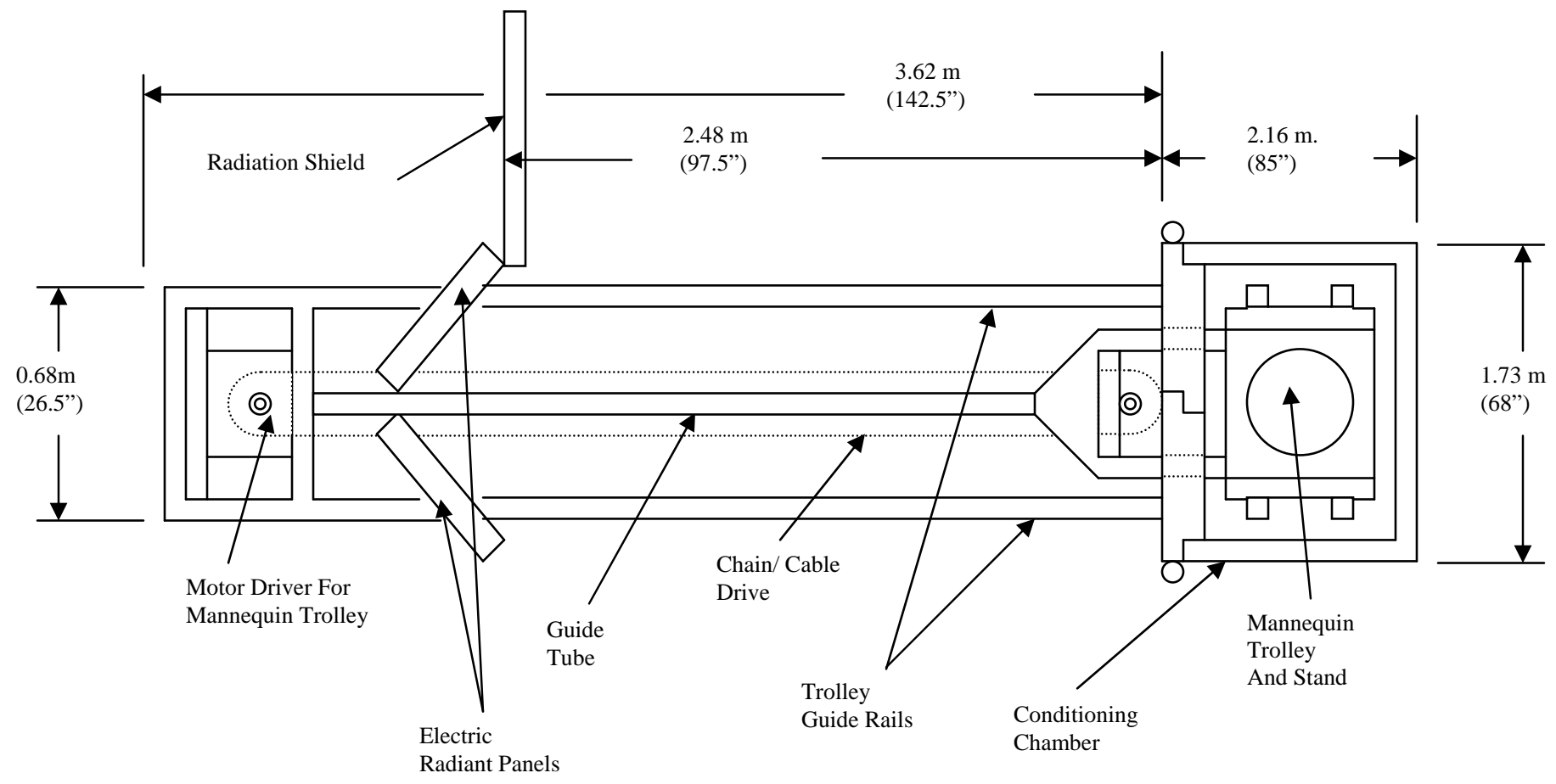

Not To Scale

Figure 3. Plan view of test apparatus including radiant panels and trolley assembly. 


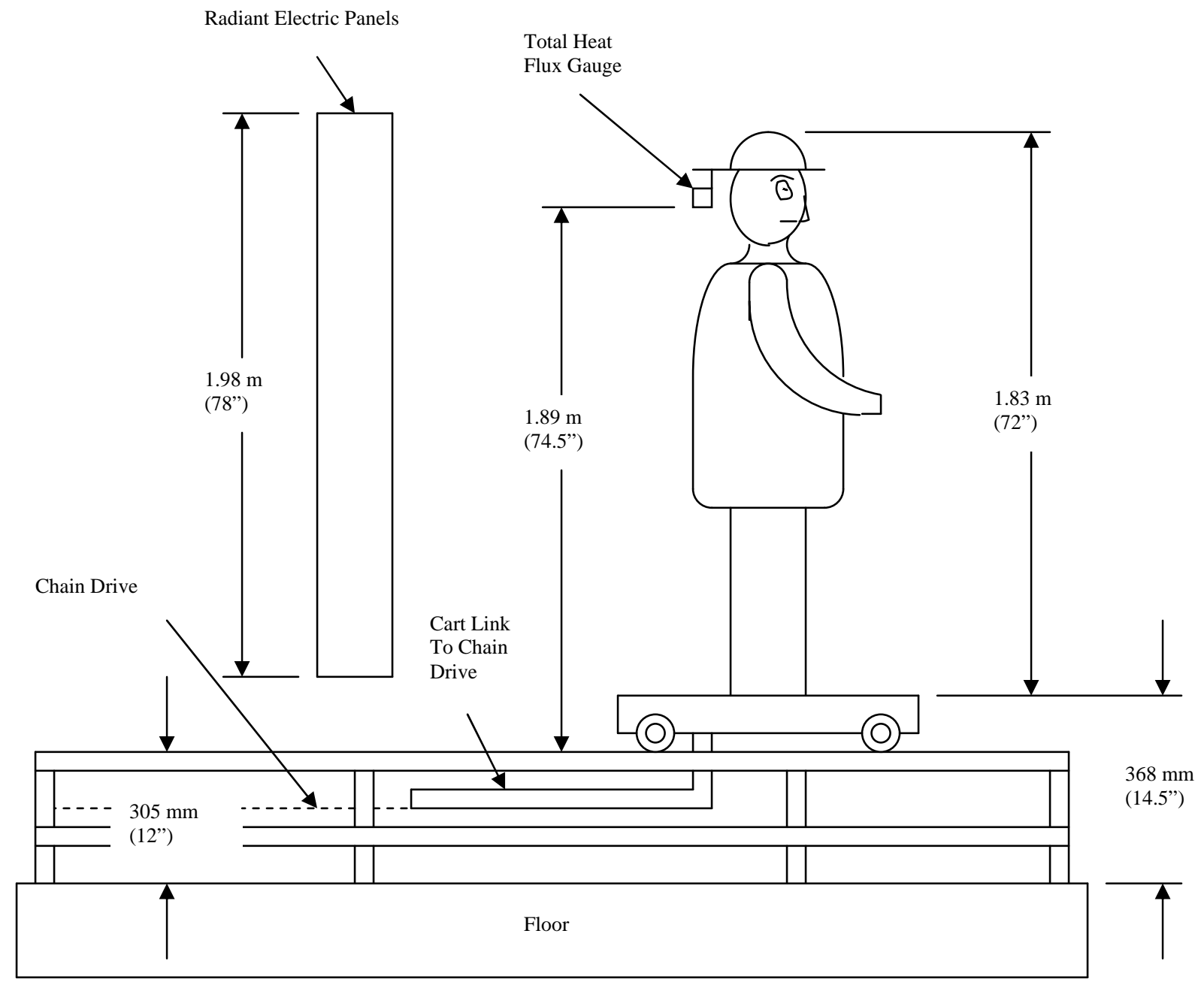

Figure 4. Elevation view of test apparatus including radiant panels and trolley assembly. 


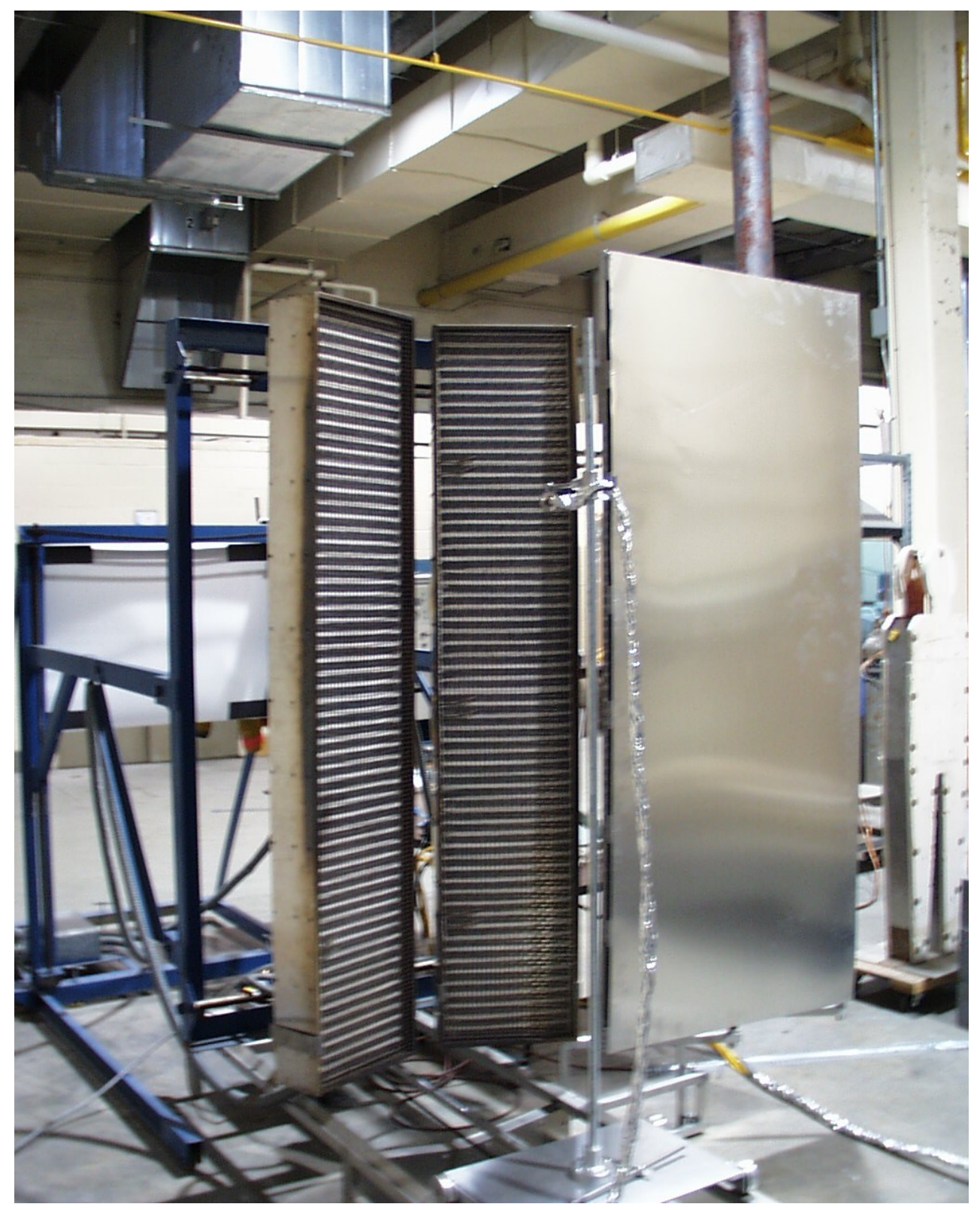

Figure 5. Photograph of radiant panels and radiation shield with trolley mounted heat flux gauge. 


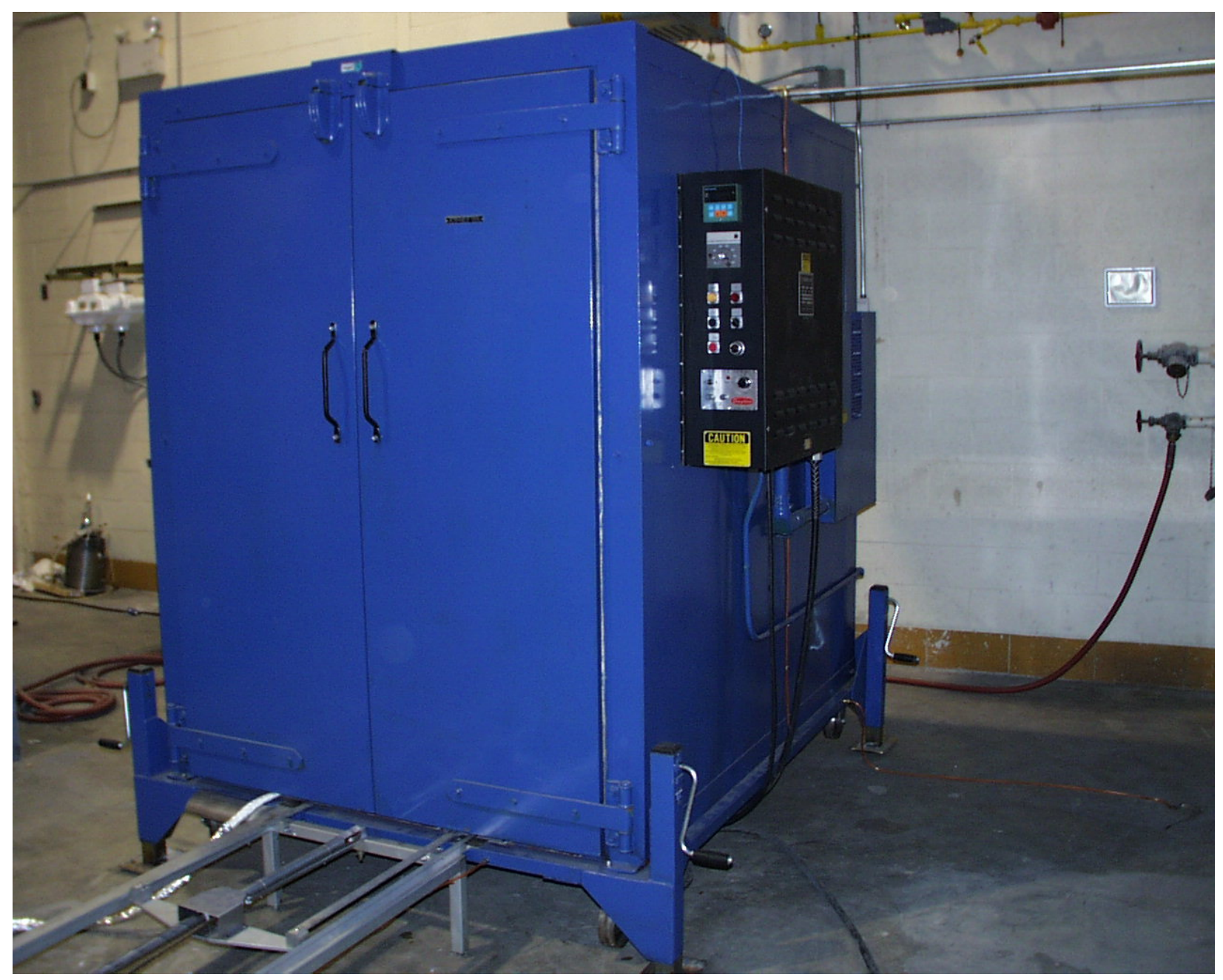

Figure 6. Photograph of the preconditioning chamber. 


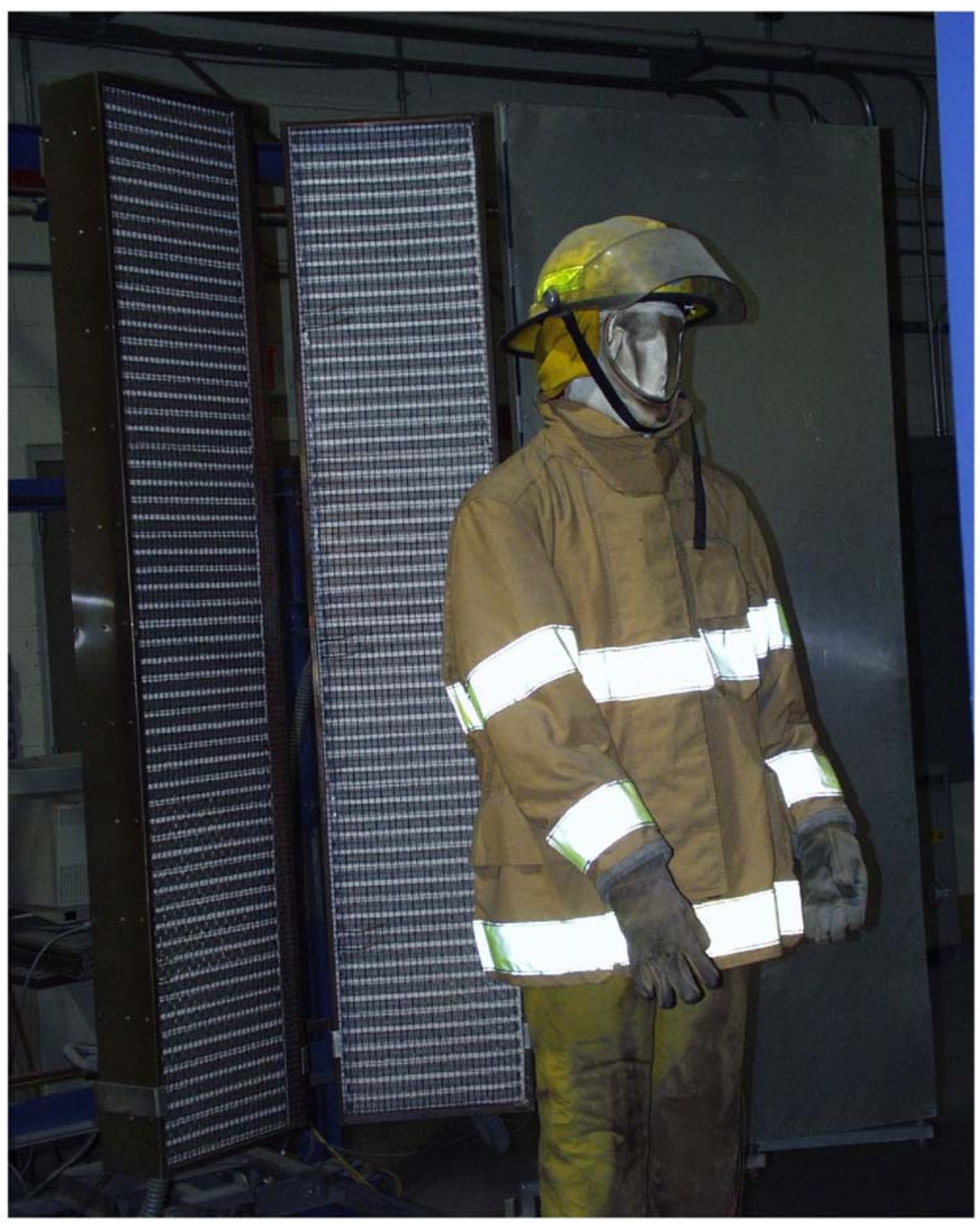

Figure 7. Photograph of mannequin positioned in front of the radiant panels. 


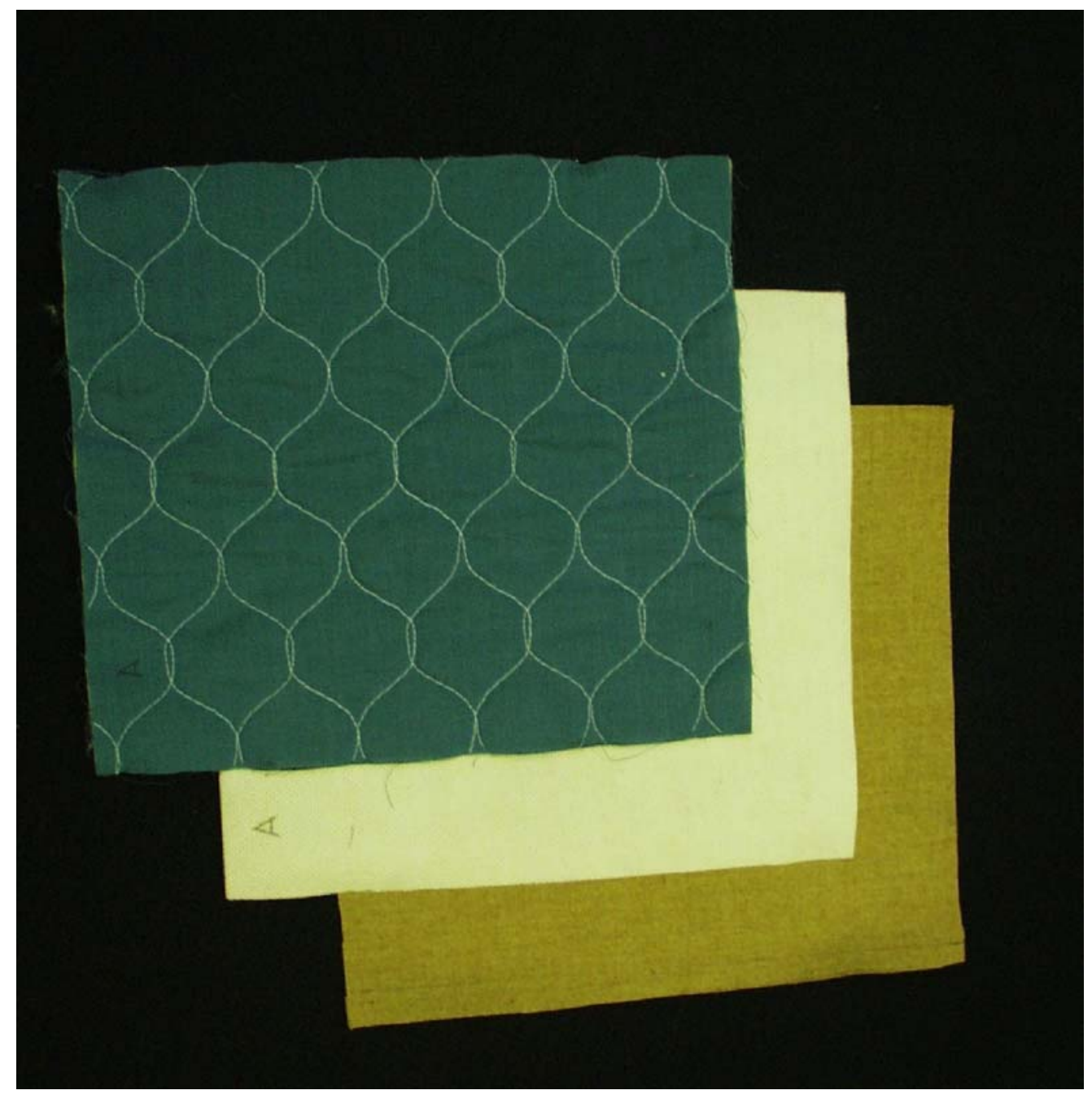

Figure 8. Photograph of turnout gear mock-up. 

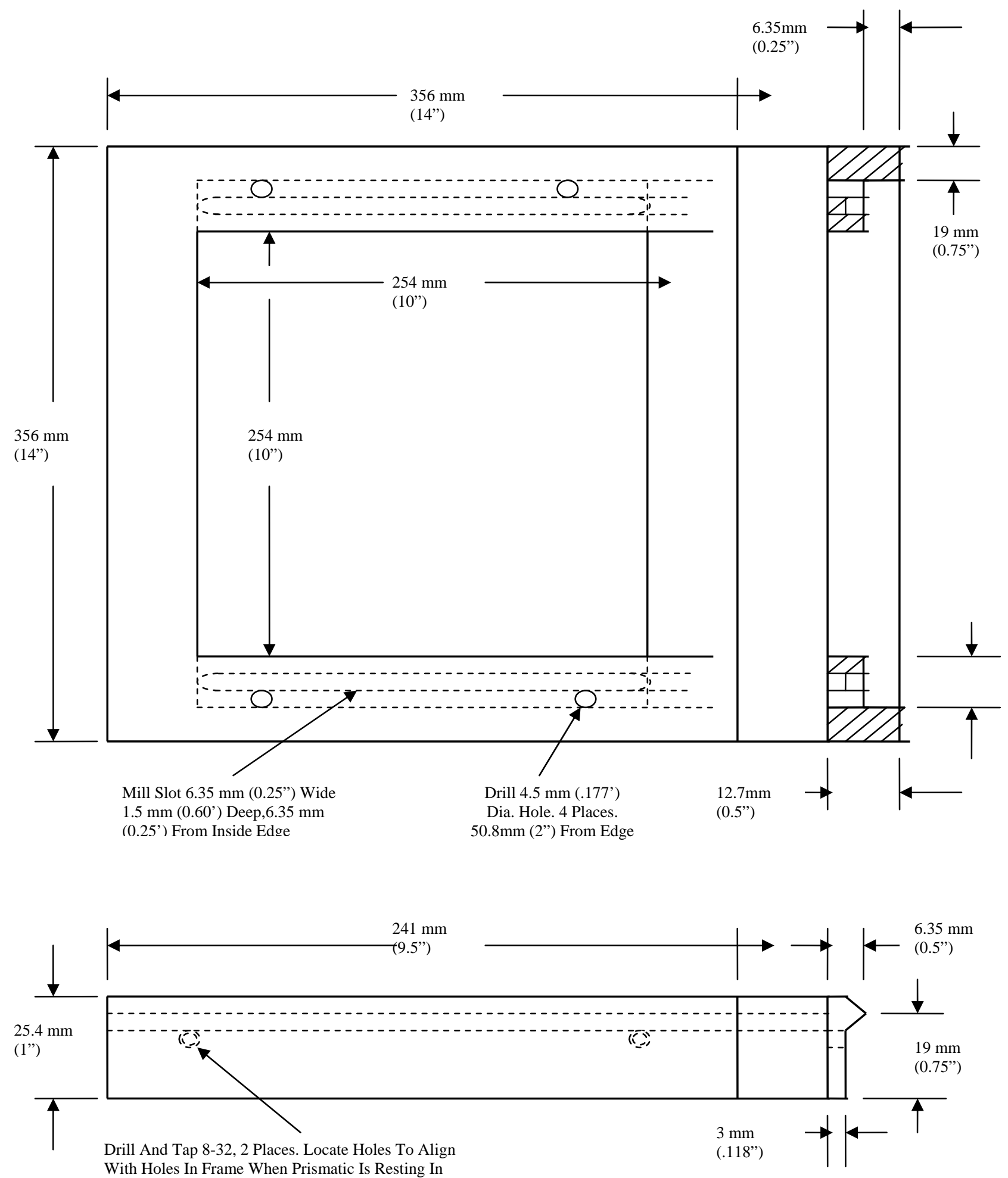

With Holes In Frame When Prismatic Is Resting In Milled Slot

NOT TO SCALE

Figure 9. Drawing of the turnout gear mock-up sample holder. 


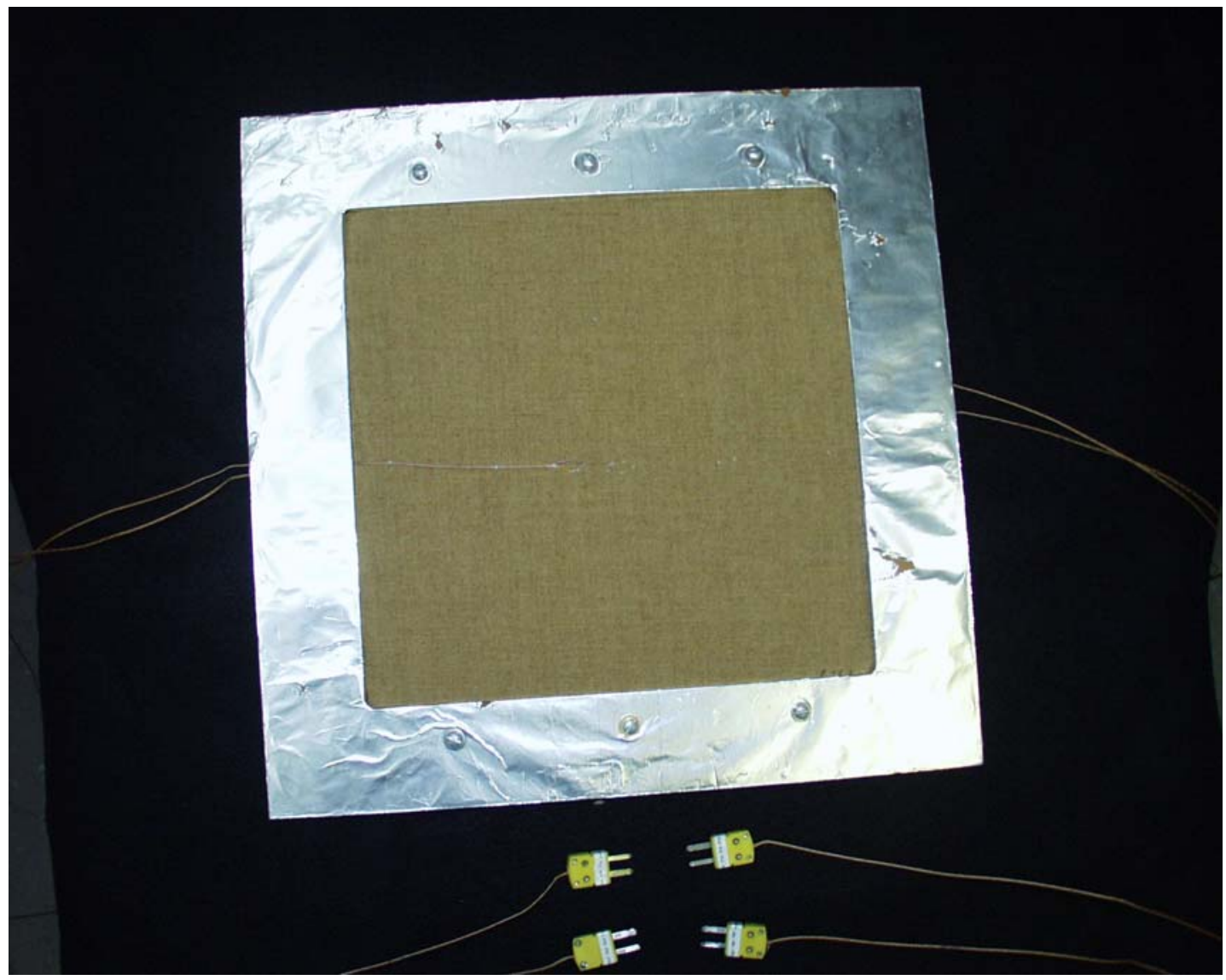

Figure 10. Photograph of the turnout gear mock-up sample holder with test sample. 


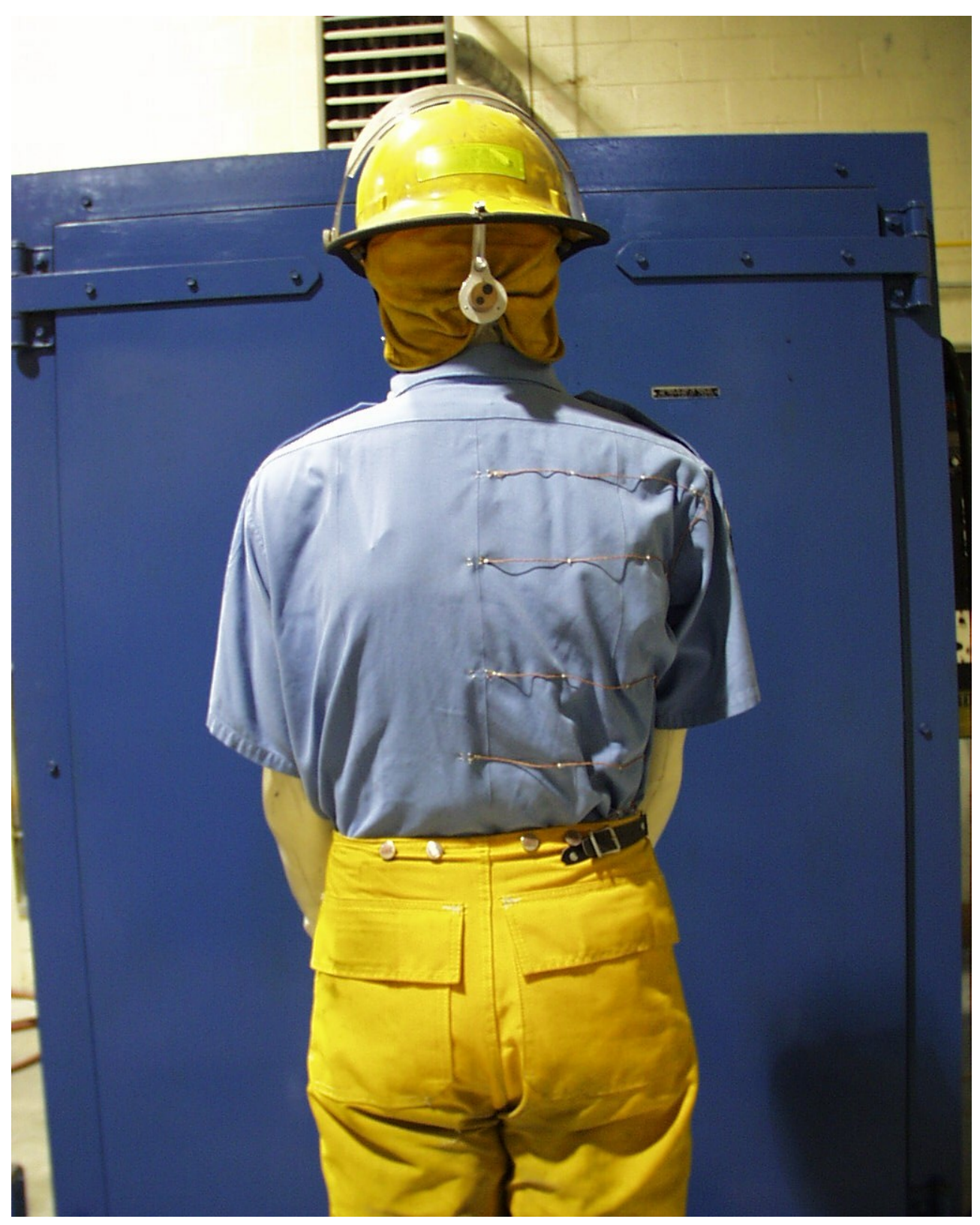

Figure 11. Photograph showing mannequin without coat and instrumentation (heat flux gauge and thermocouples). 


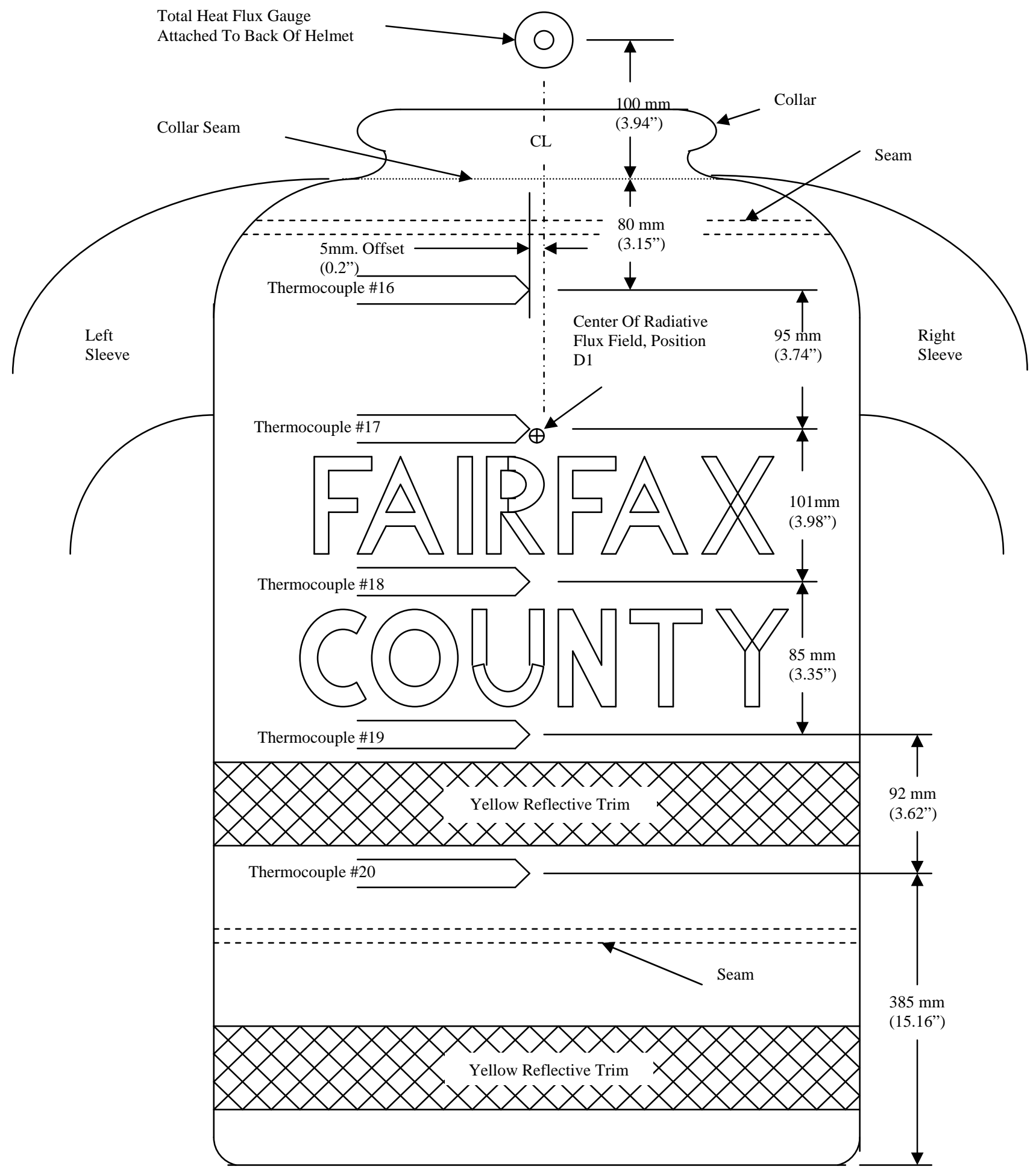

Figure 12. Drawing showing thermocouple locations on the outside of the back of the turnout gear shell (Front Surface). 


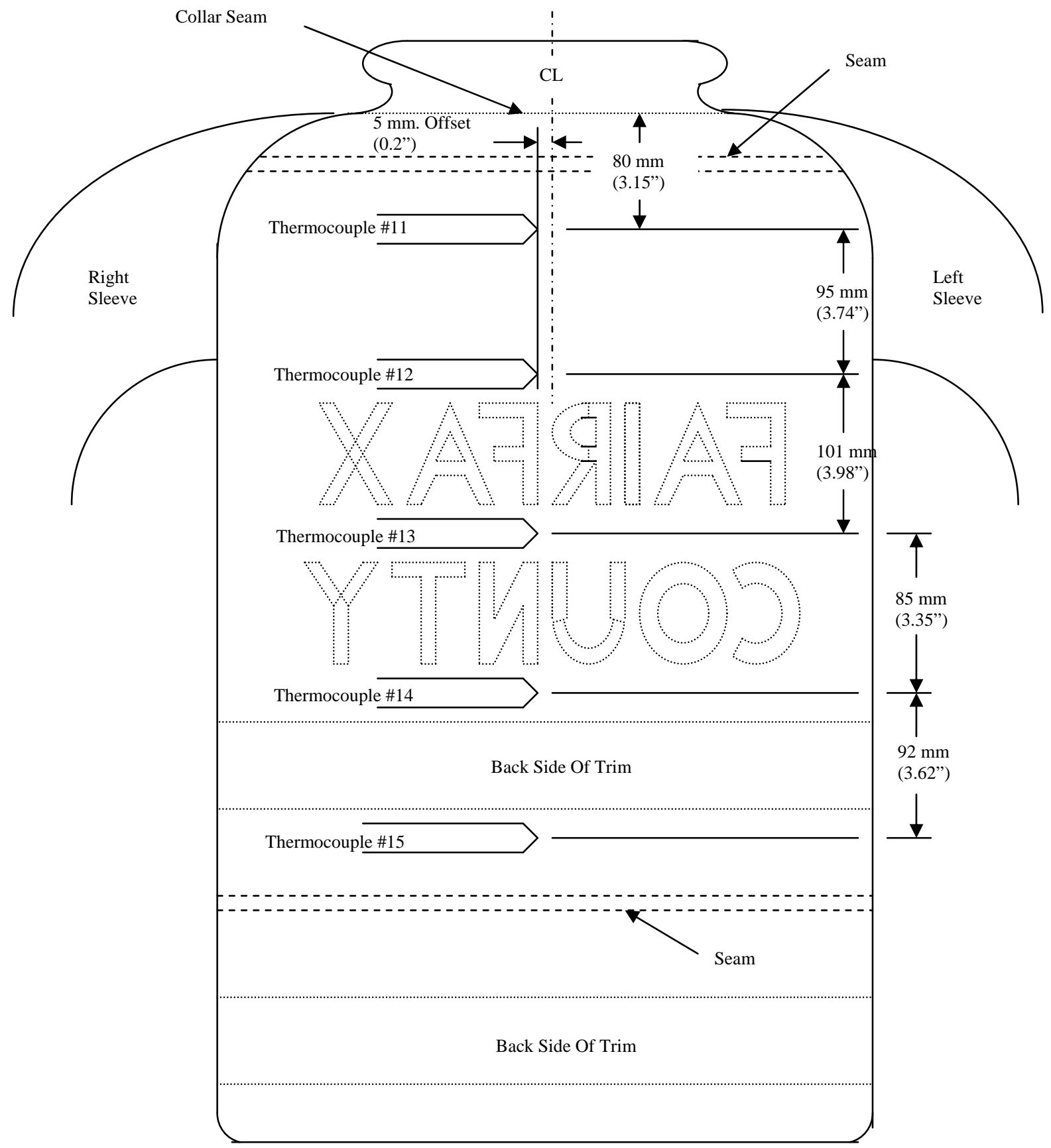

Figure 13. Drawing showing thermocouple locations on the inside of the turnout coat shell (Mid-Point). 


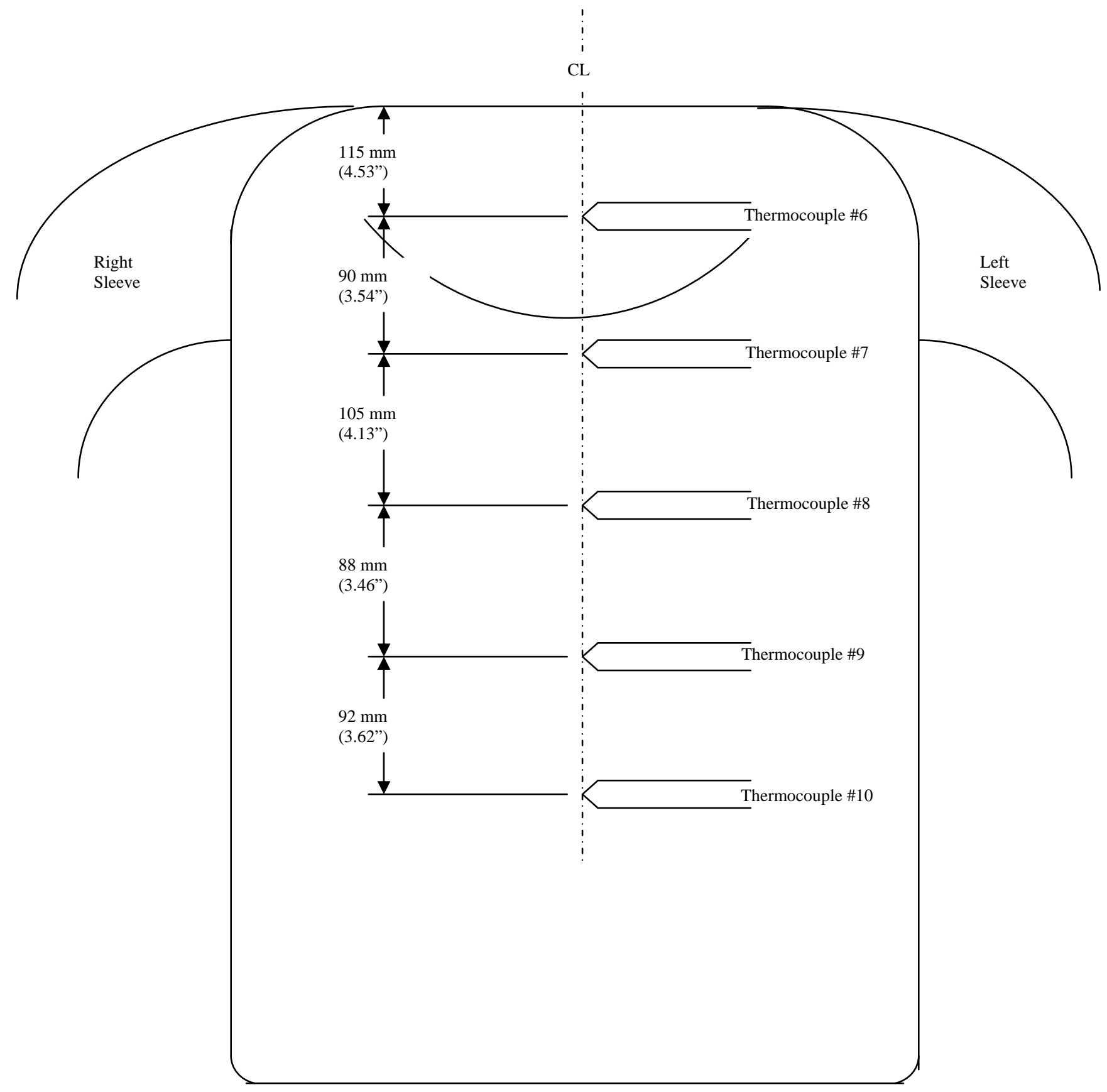

Figure 14. Drawing showing the thermocouple locations on the inside of the thermal liner adjacent to the moisture barrier (Back Surface). 
CL

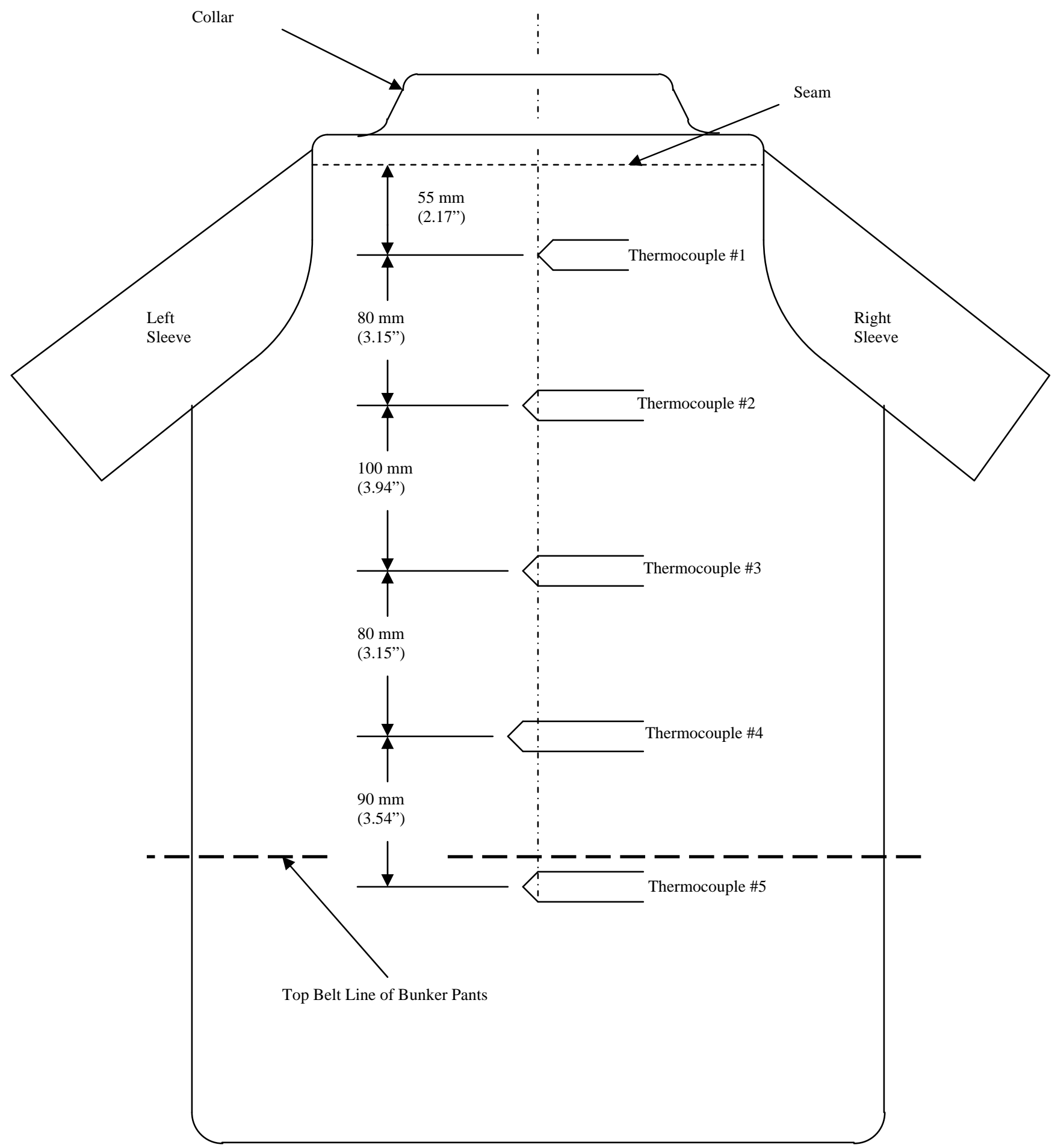

Figure 15. Drawing showing thermocouple locations on the outside of the workstation shirt (Shirt). 


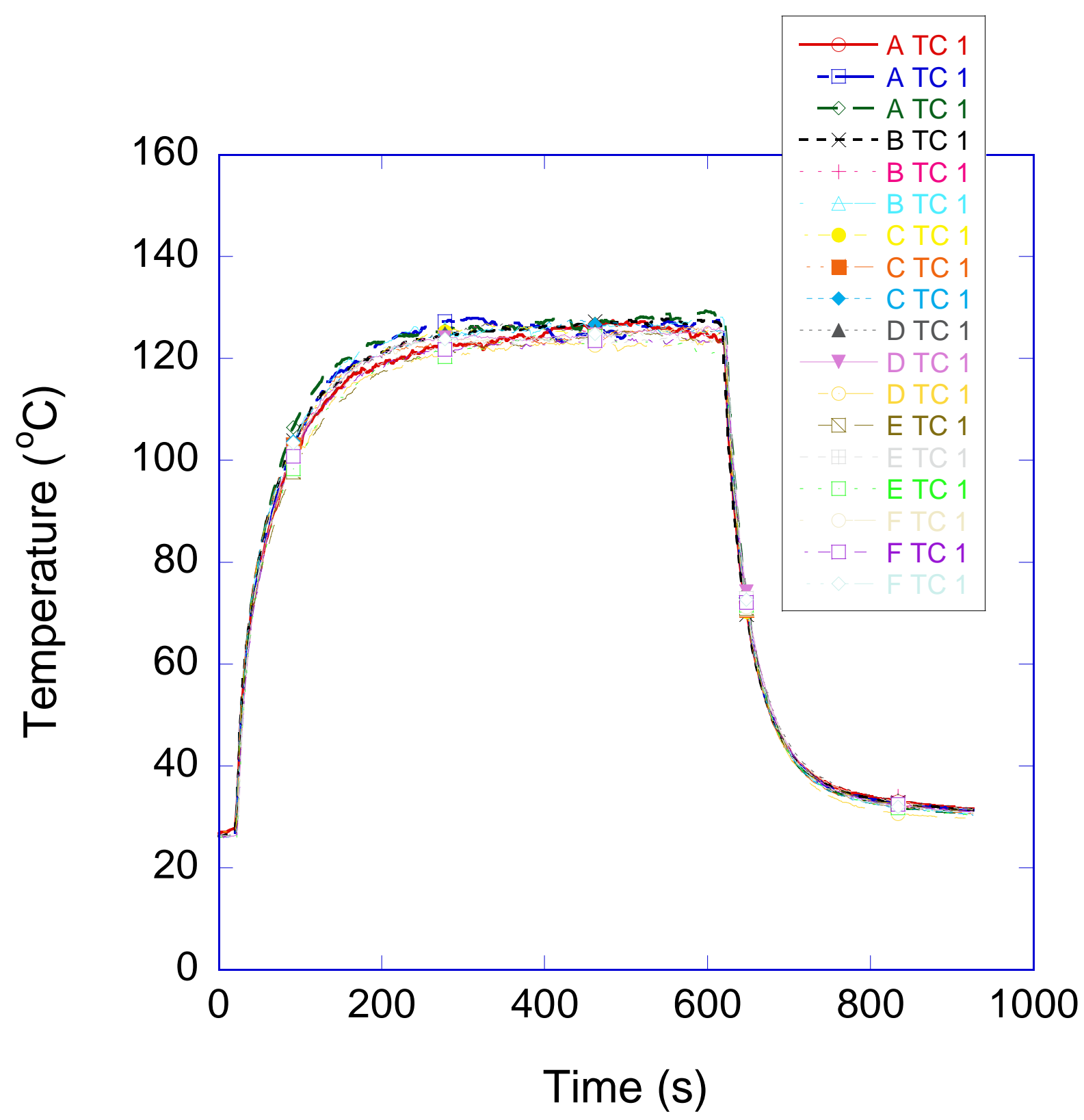

Figure 16. Graph showing temperatures measured on the front of the mock-up shell material for each test conducted using the bench scale test apparatus. 


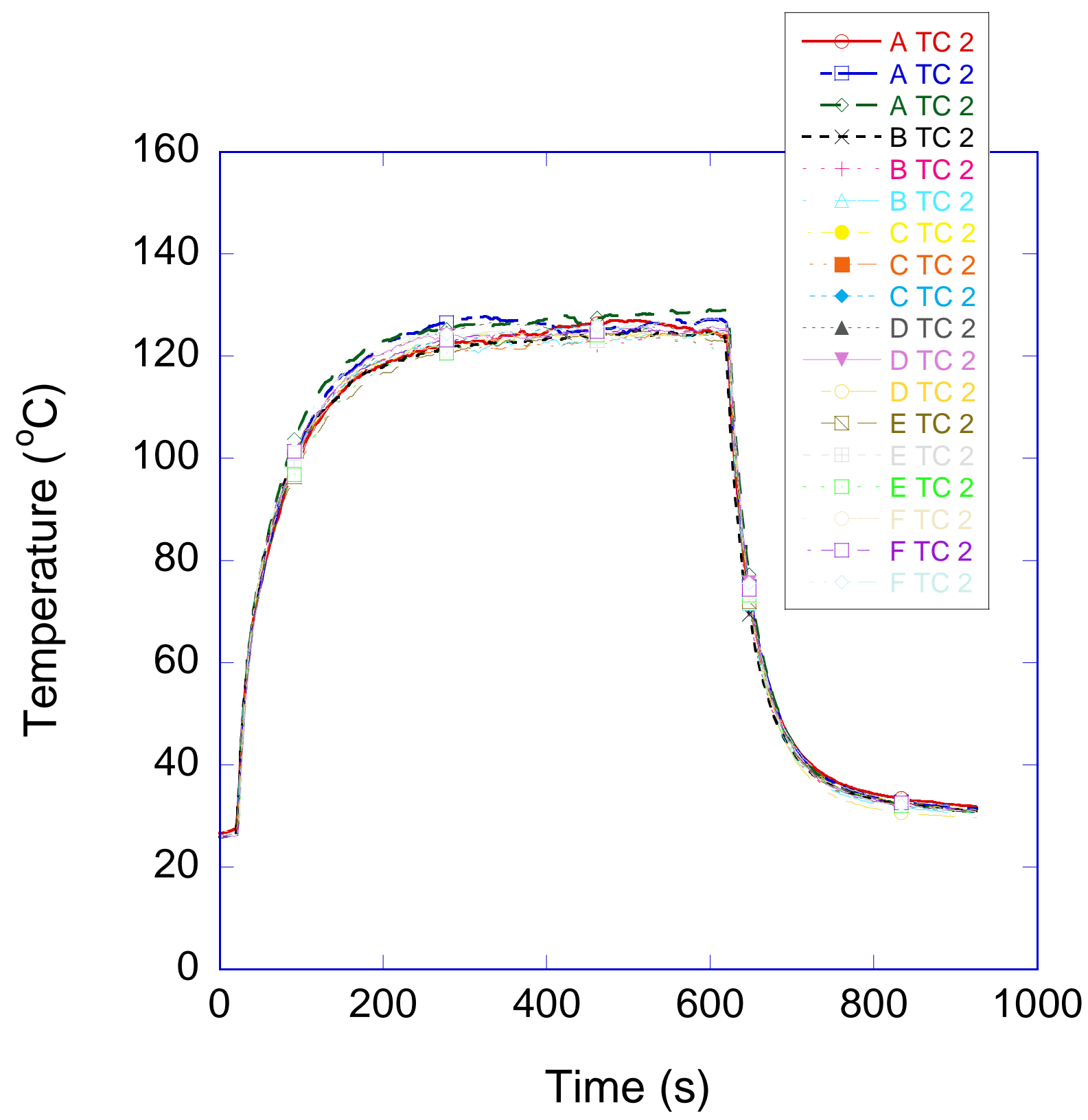

Figure 17. Graph showing temperatures measured on the back of the mock-up shell material for each test conducted using the bench scale test apparatus. 


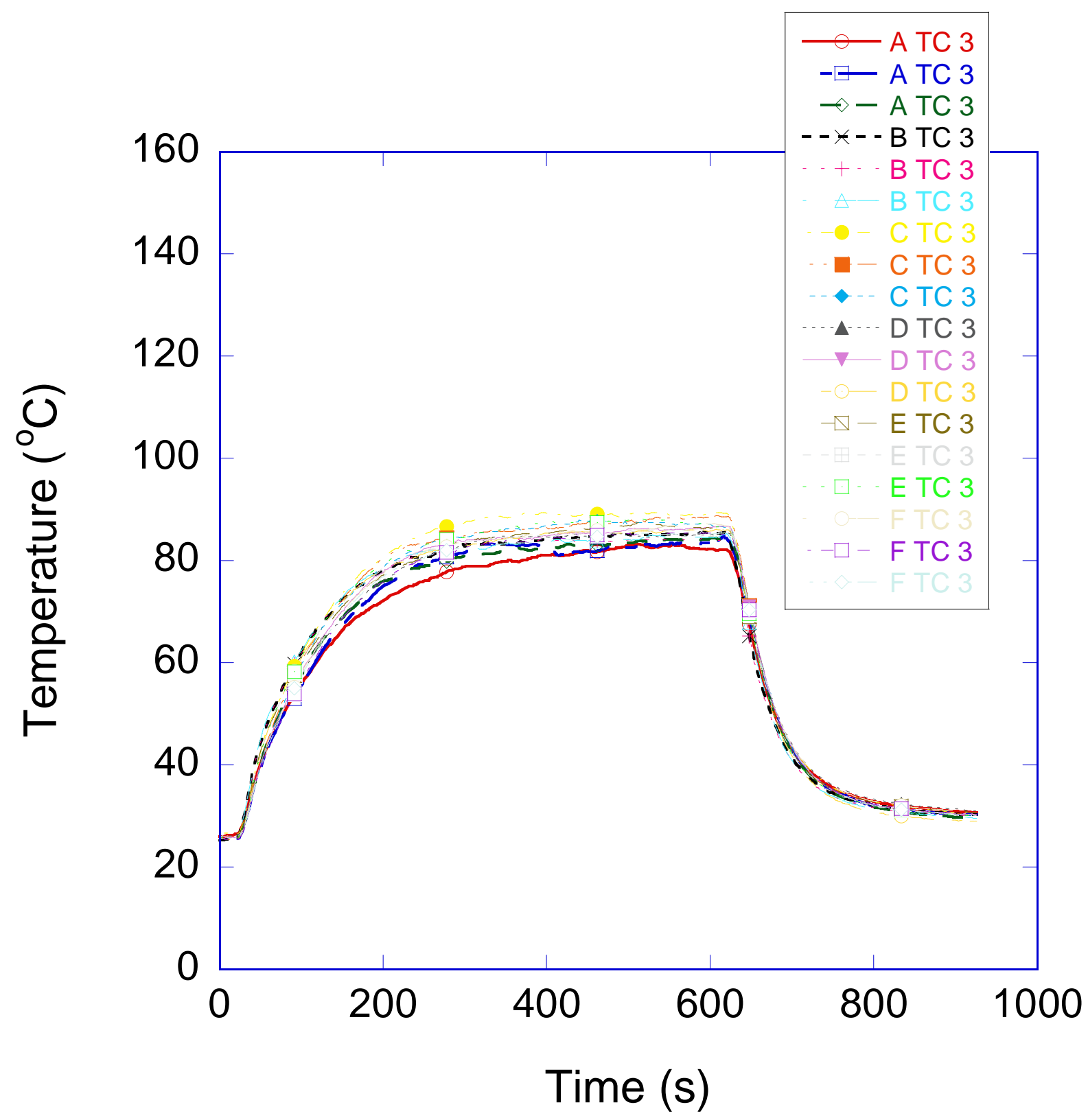

Figure 18. Graph showing temperatures measured on the front of the mock-up thermal liner material for each test conducted using the bench scale test apparatus. 


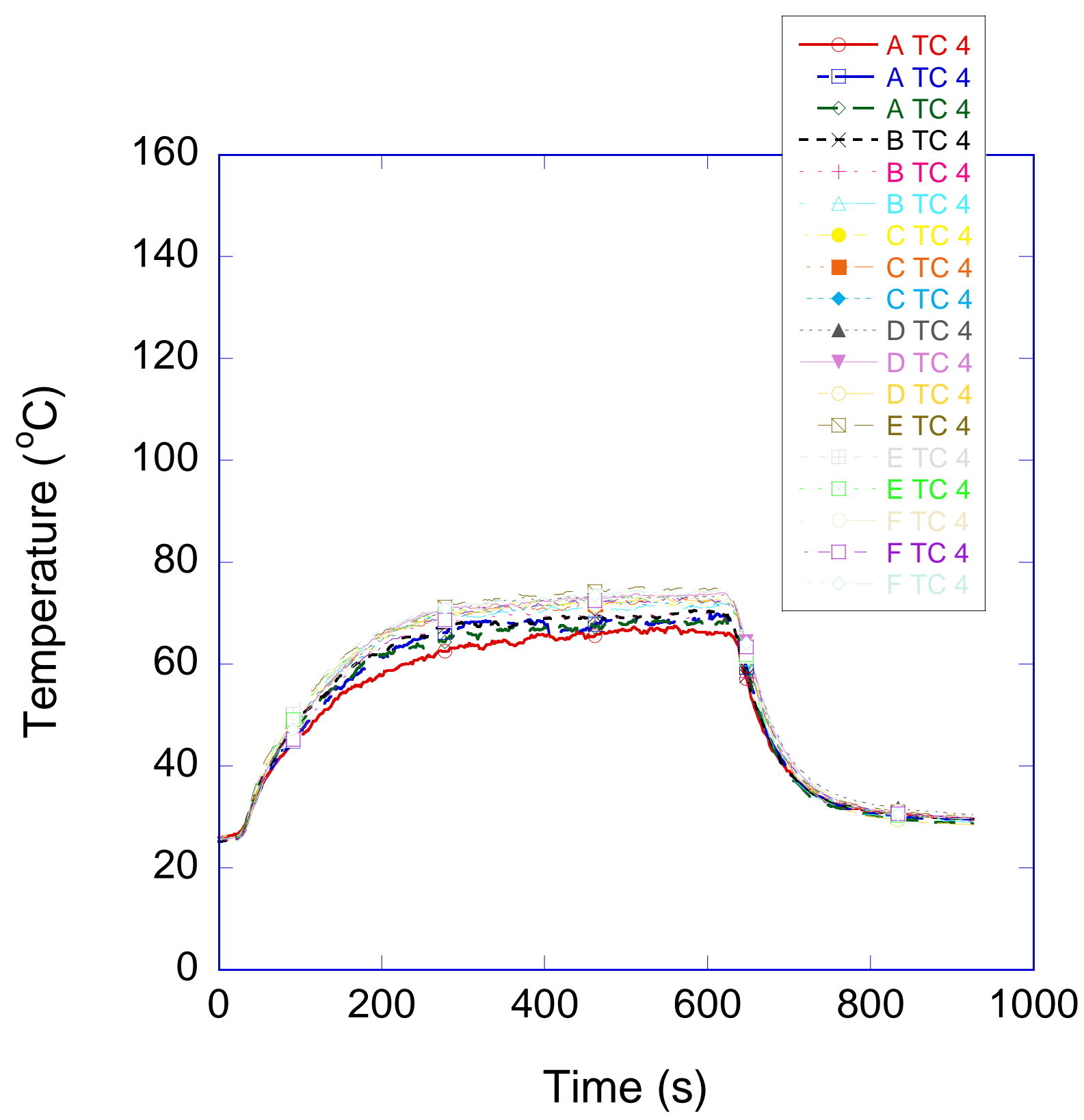

Figure 19. Graph showing temperatures measured on the back of the mock-up thermal liner material for each test conducted using the bench scale test apparatus. 


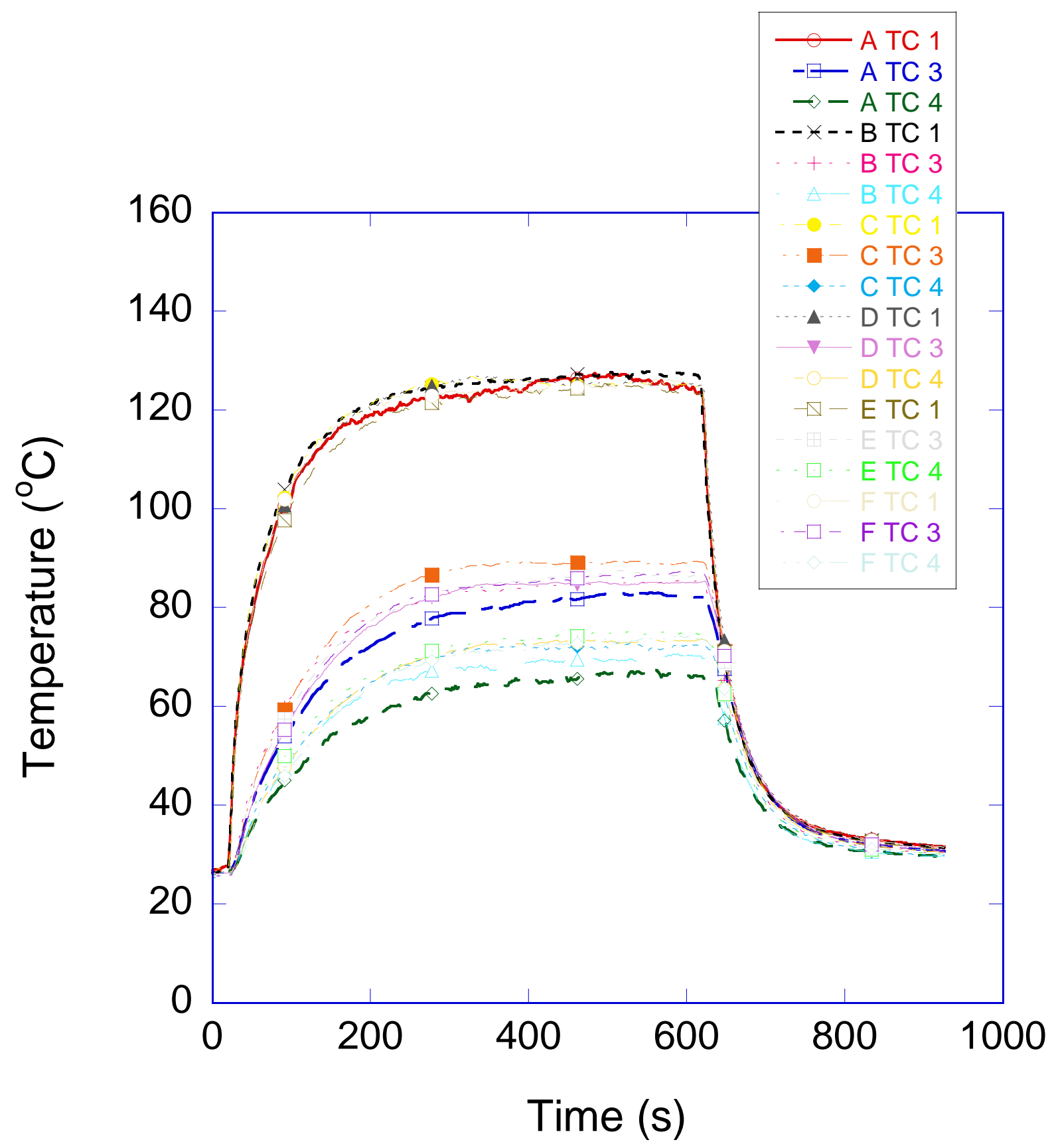

Figure 20. Graph showing average temperatures measured for each of the six mockup samples using a bench scale test apparatus (TC2 eliminated for clarity). 


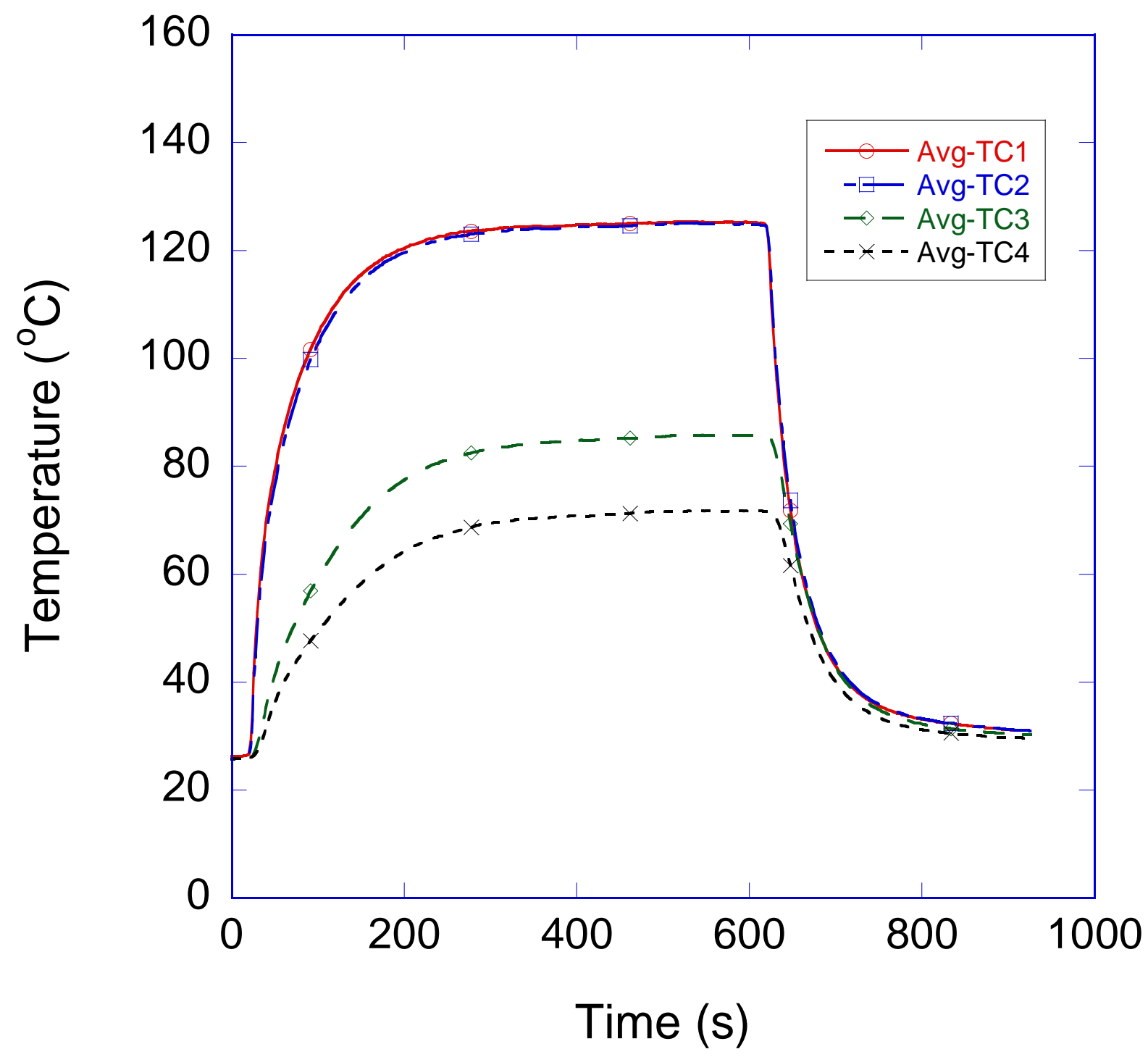

Figure 21. Graph showing average temperatures measured through mock-up samples using a bench scale test apparatus. 

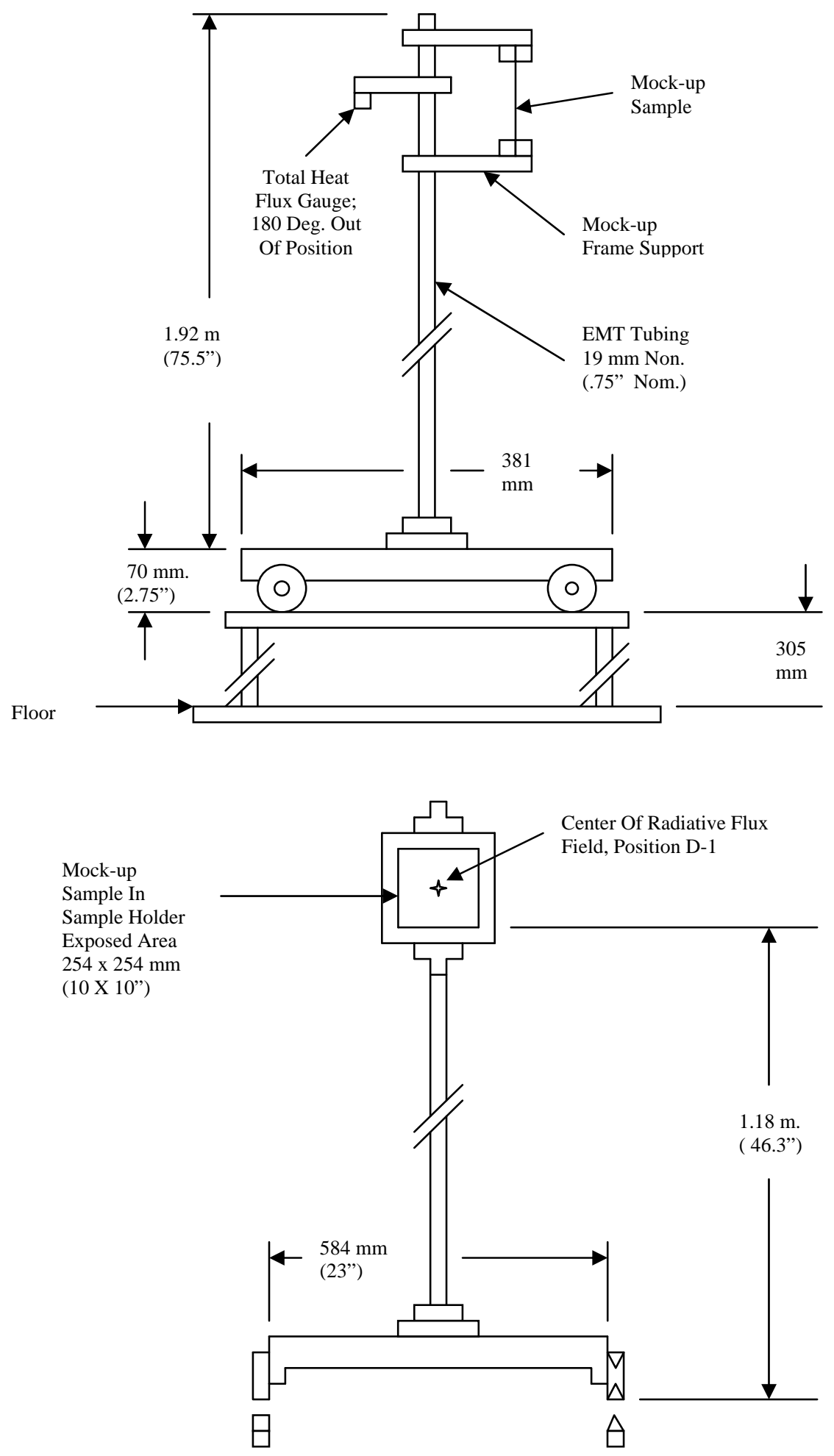

Figure 22. Drawings of heat flux gauge and mock-up trolley showing the mock in position and the dimensions. 


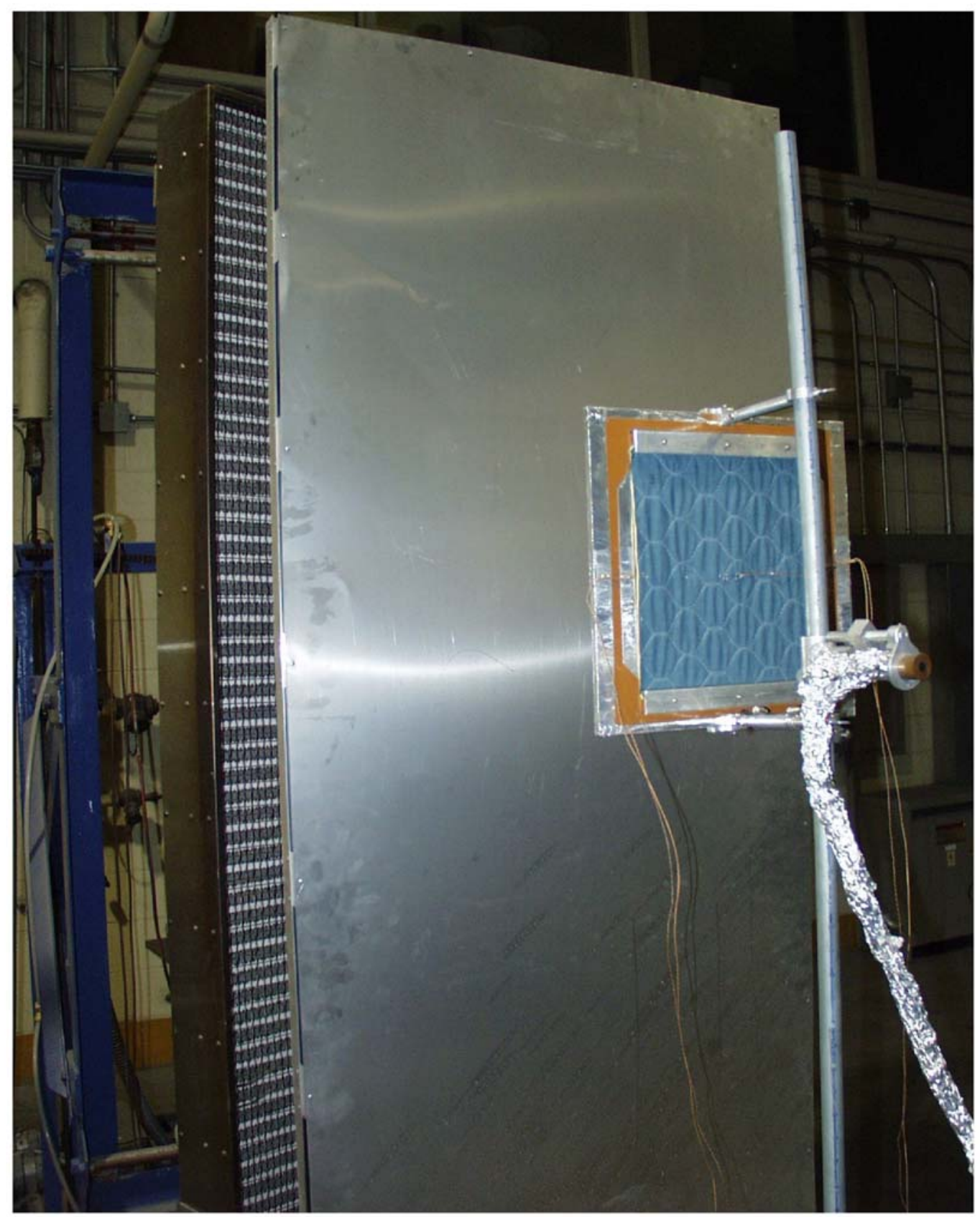

Figure 23. Photograph of the radiation shield in place in front of the radiant panels. 


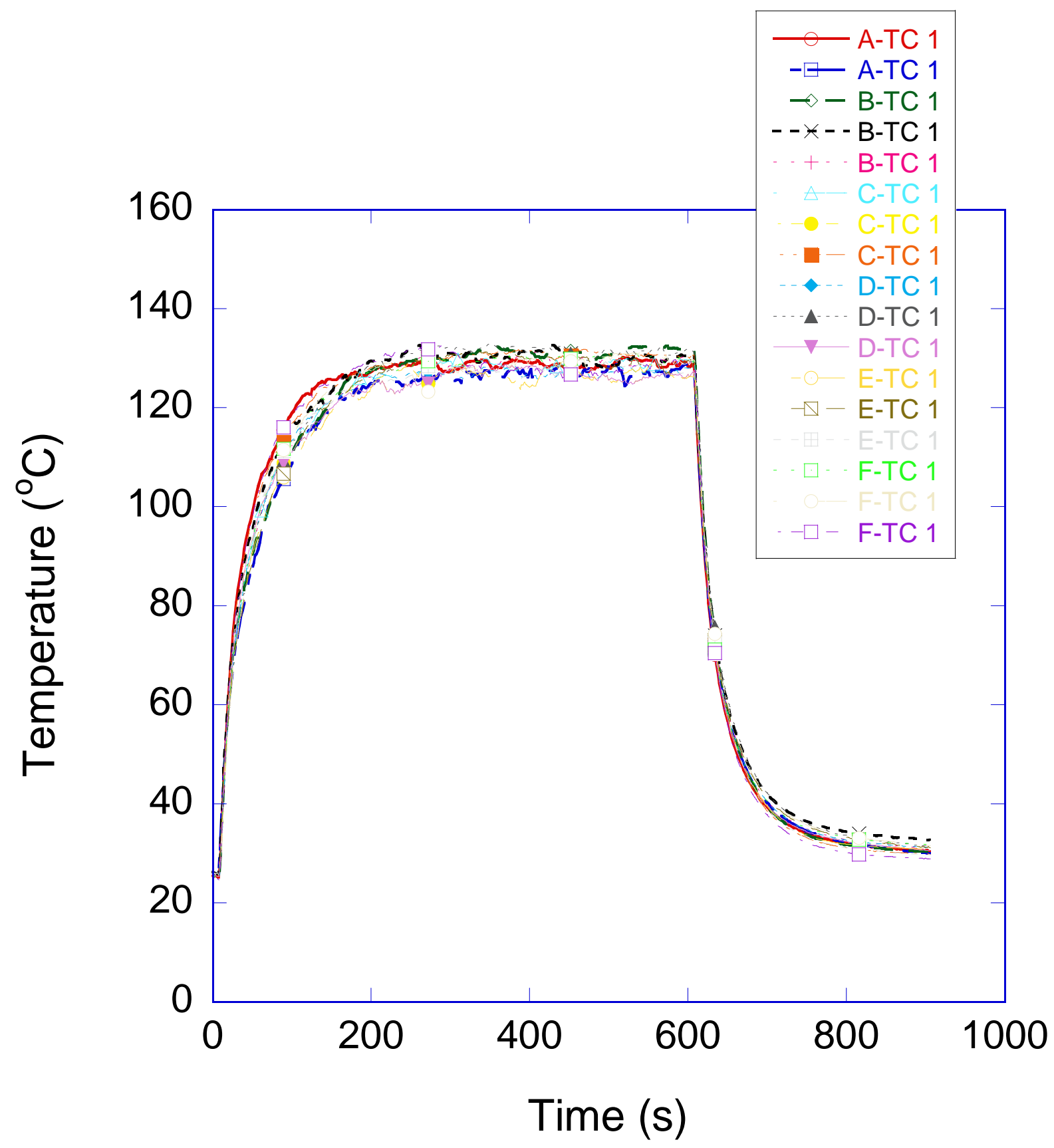

Figure 24. Graph showing the data from the thermocouple attached to the front of the mock-up shell material for all tests using the full ensemble test apparatus. 


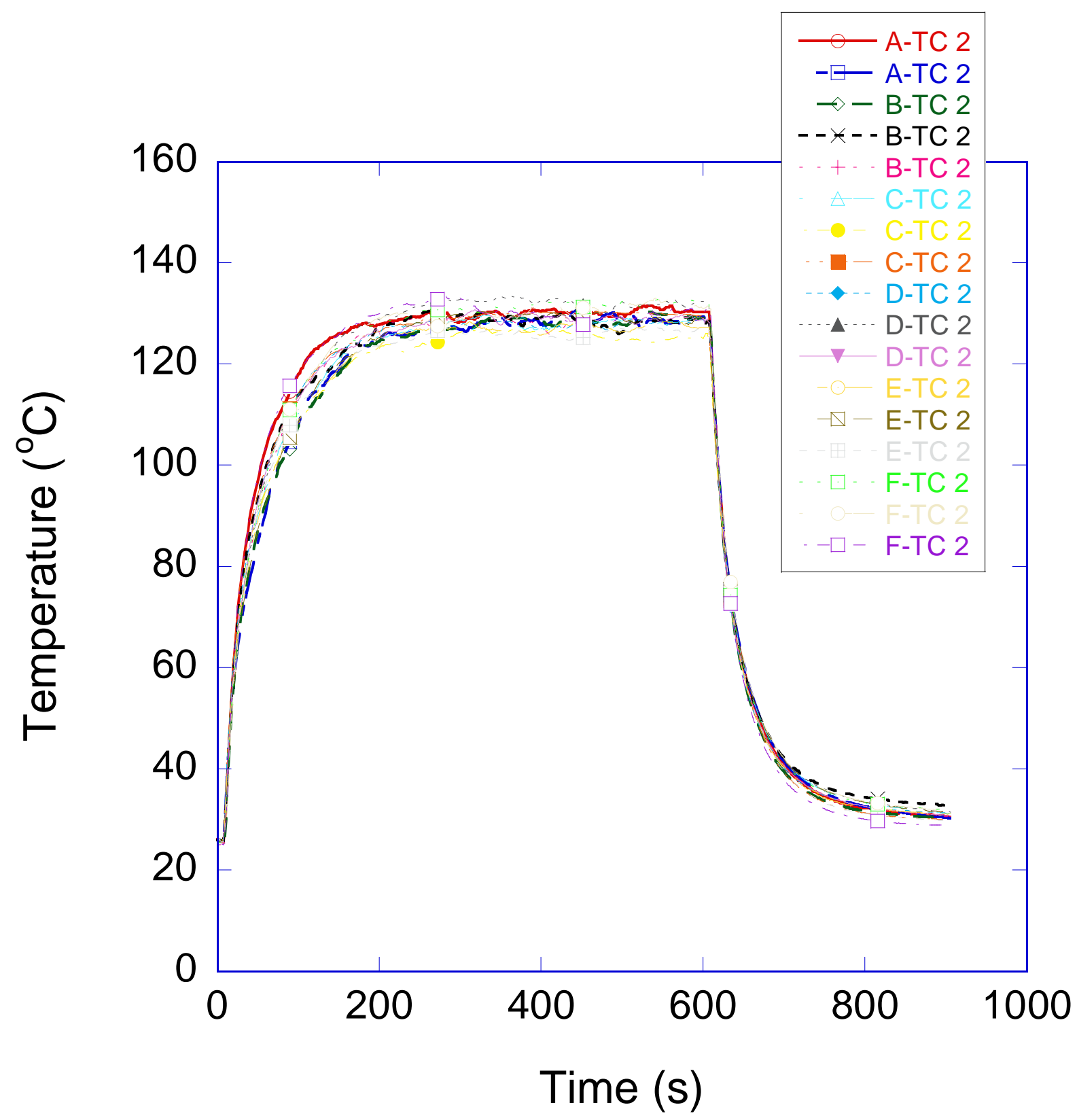

Figure 25. Graph showing the data from the thermocouple attached to the back of the mock-up shell material for all tests using the full ensemble test apparatus. 


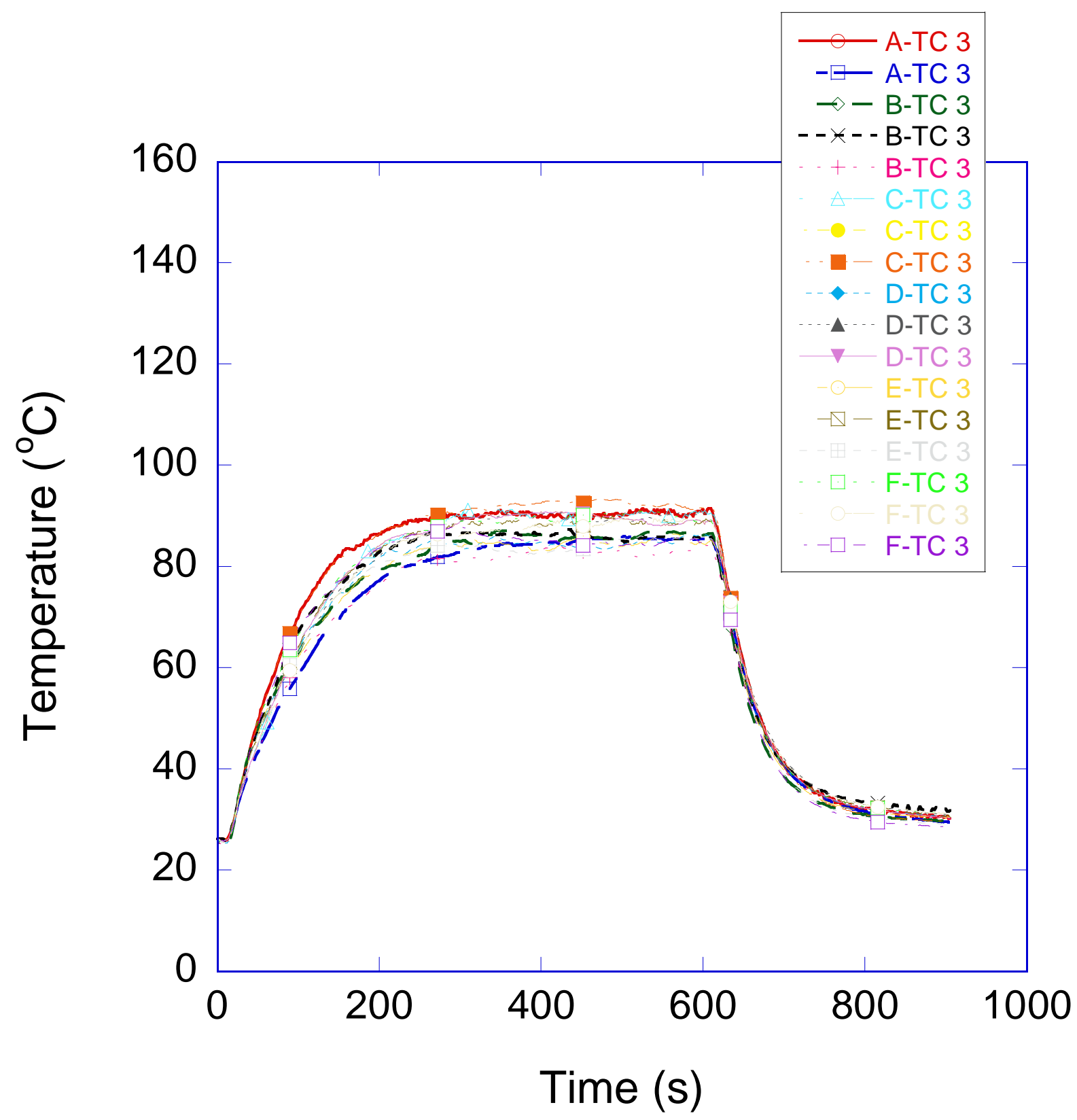

Figure 26 Graph showing the data from the thermocouple attached to the front of the mock-up thermal liner material for all tests using the full ensemble test apparatus. 


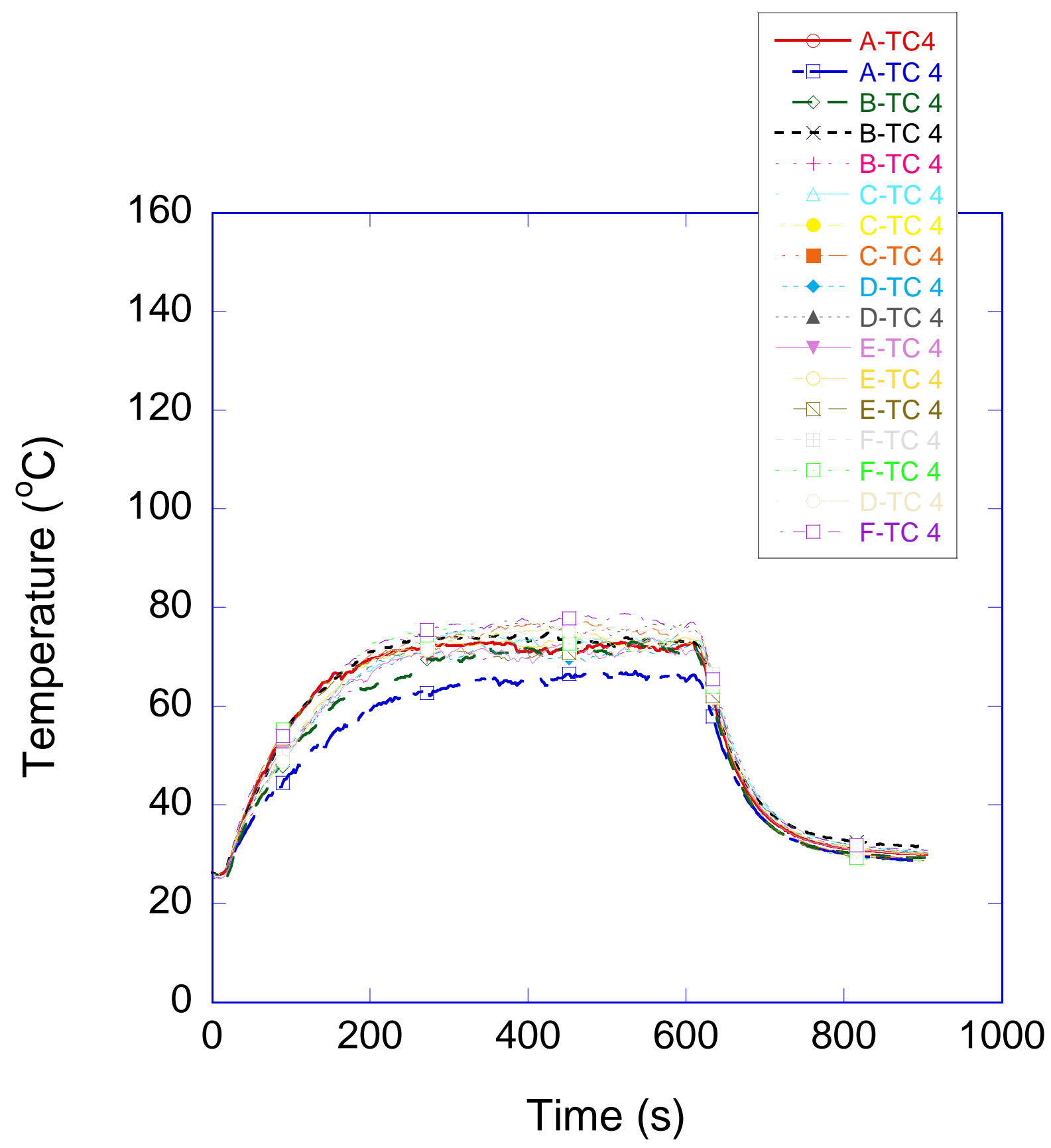

Figure 27. Graph showing the data from the thermocouple attached to the back of the mock-up thermal liner material for all tests using the full ensemble test apparatus. 


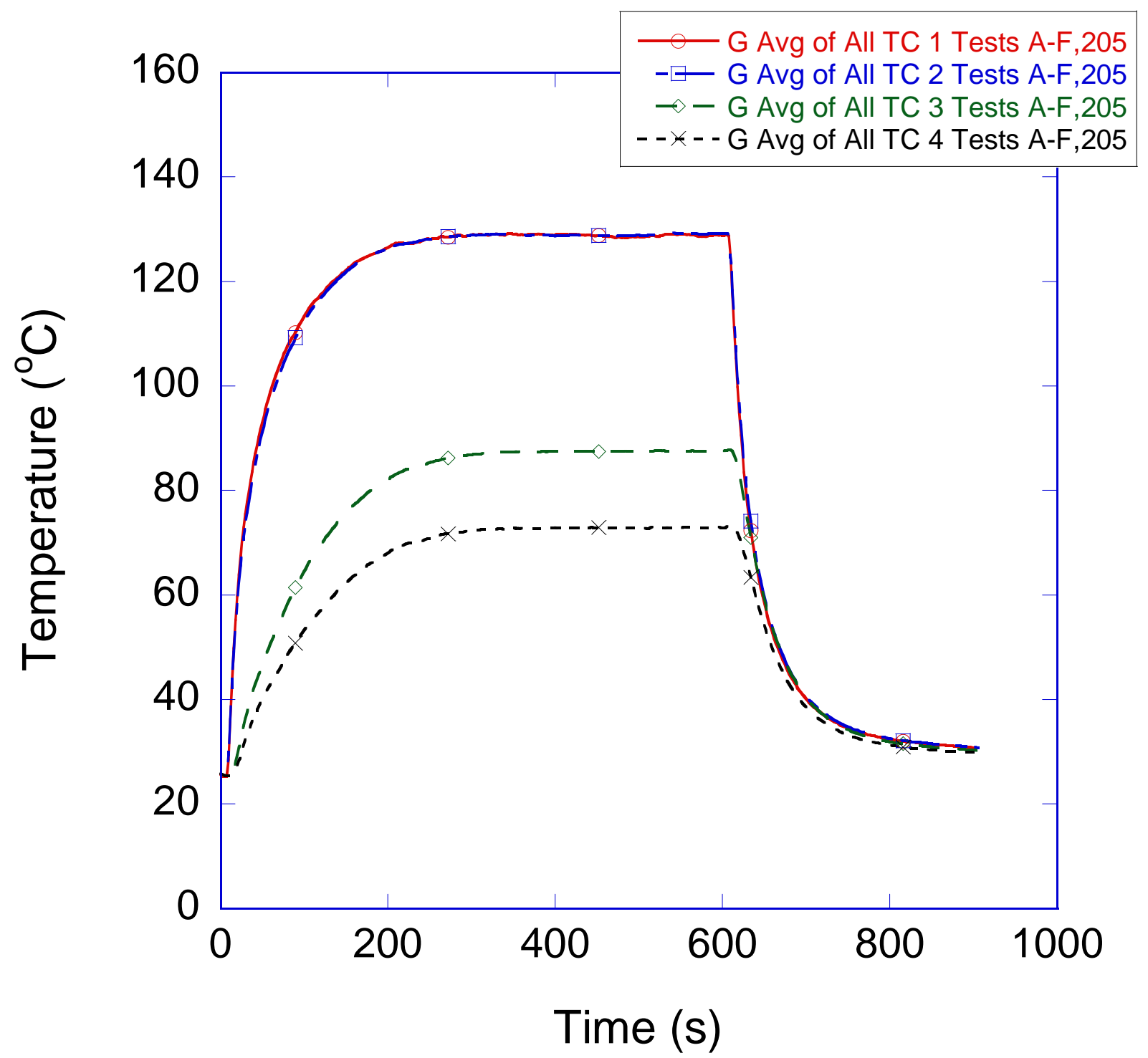

Figure 28. Graph showing the average temperatures obtained at the four thermocouple locations during the mock-up tests using the full ensemble test apparatus. 

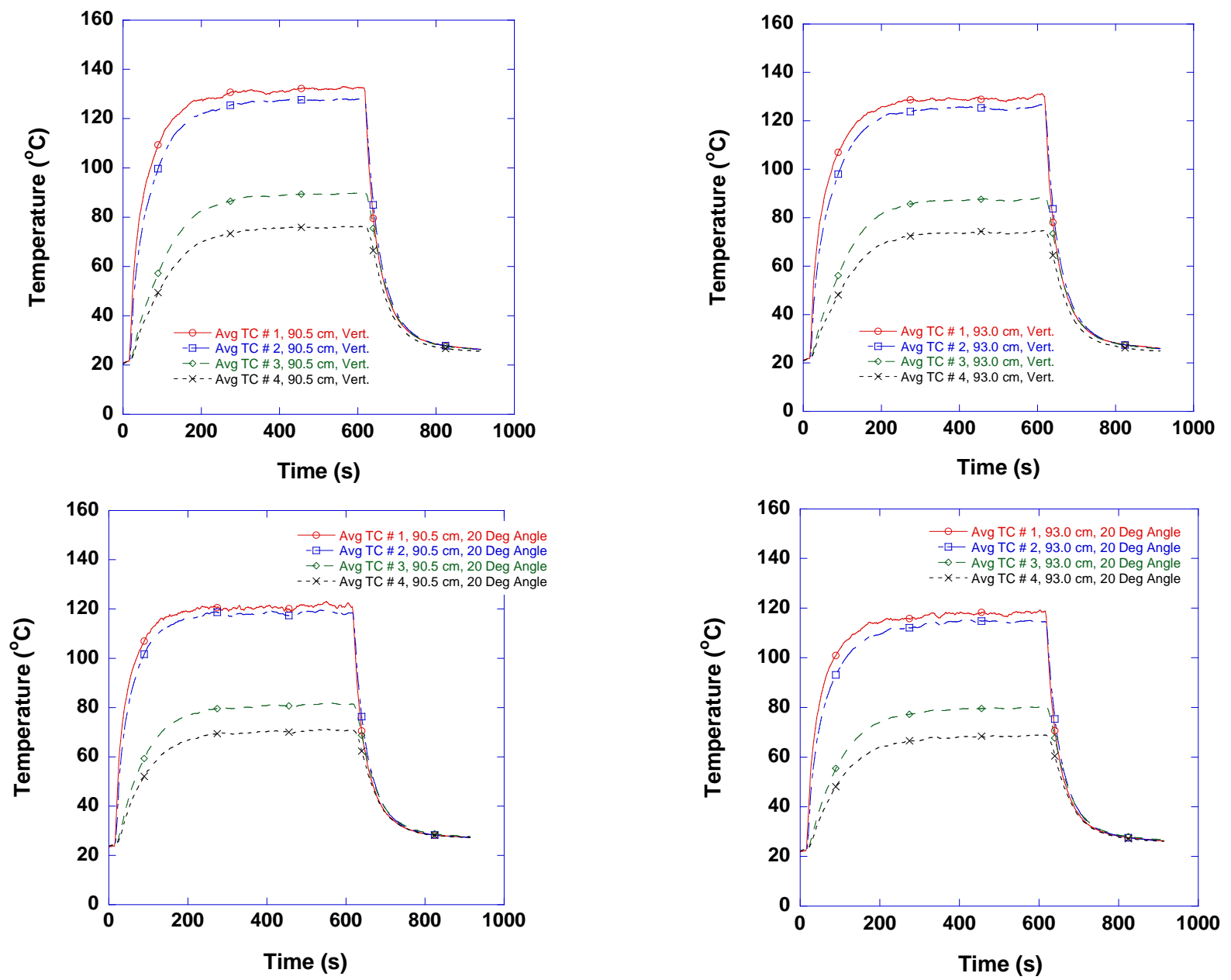

Figure 29. Graphs showing temperatures measured through mock-up samples for the following orientations: vertical at $0.91 \mathrm{~m}(2.97 \mathrm{ft})$, vertical at $0.93 \mathrm{~m}(3.1$ $\mathrm{ft}), 20 \mathrm{deg}$. angle at $0.91 \mathrm{~m}(2.97 \mathrm{ft})$, and $20 \mathrm{deg}$. angle at $0.93 \mathrm{~m}(3.1 \mathrm{ft})$. 


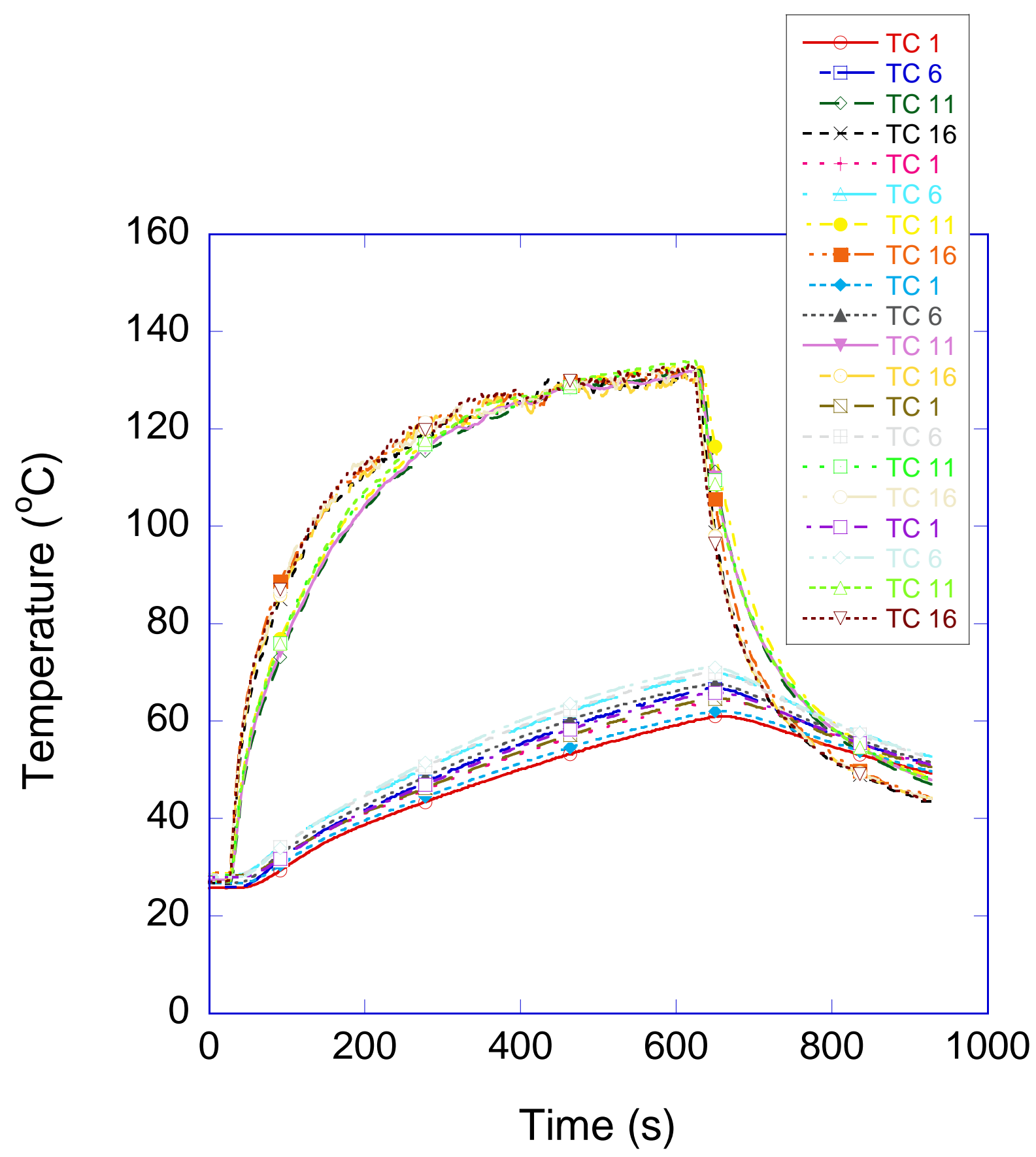

Figure 30. Graph of temperatures through turnout coat and work station shirt for thermocouples associated with external thermocouple \#16 when exposed to an external radiant flux of $2.5 \mathrm{~kW} / \mathrm{m}^{2}$ and no elevated temperature preconditioning. 


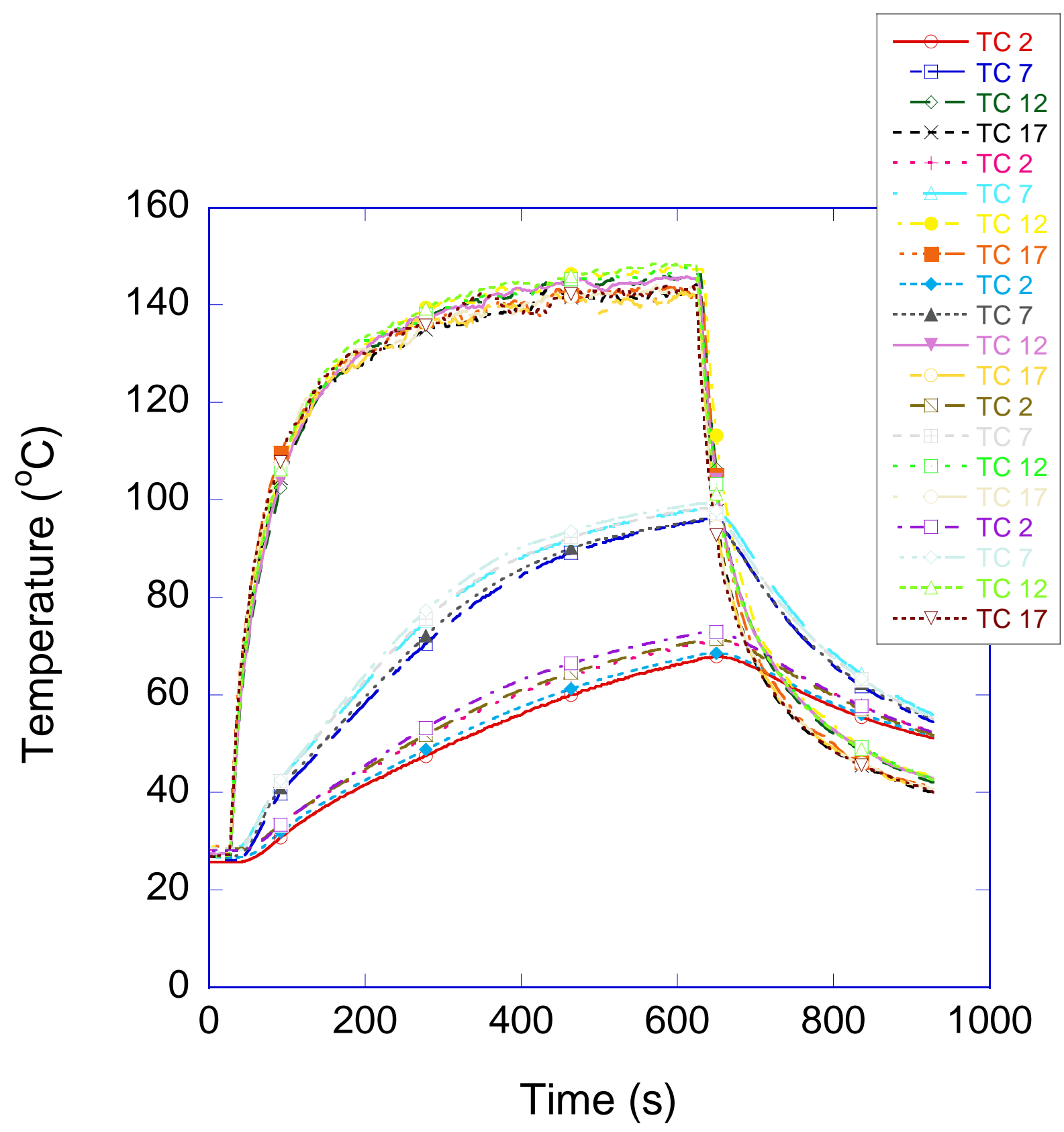

Figure 31. Graph of temperatures through turnout coat and work station shirt for thermocouples associated with external thermocouple \#17 when exposed to an external radiant flux of $2.5 \mathrm{~kW} / \mathrm{m}^{2}$ and no elevated temperature preconditioning. 


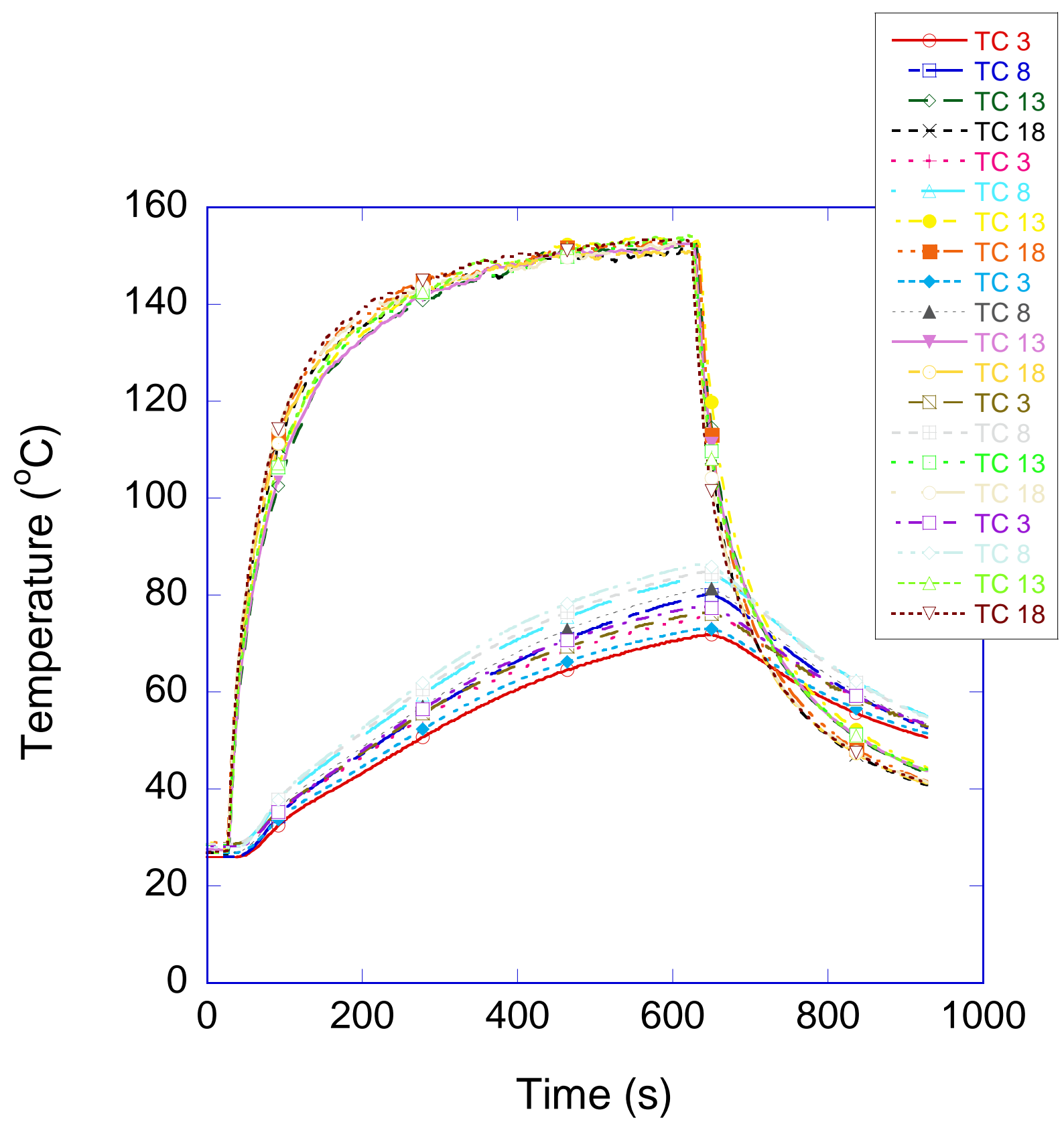

Figure 32. Graph of temperatures through turnout coat and work station shirt for thermocouples associated with external thermocouple \#18 when exposed to an external radiant flux of $2.5 \mathrm{~kW} / \mathrm{m}^{2}$ and no elevated temperature preconditioning. 


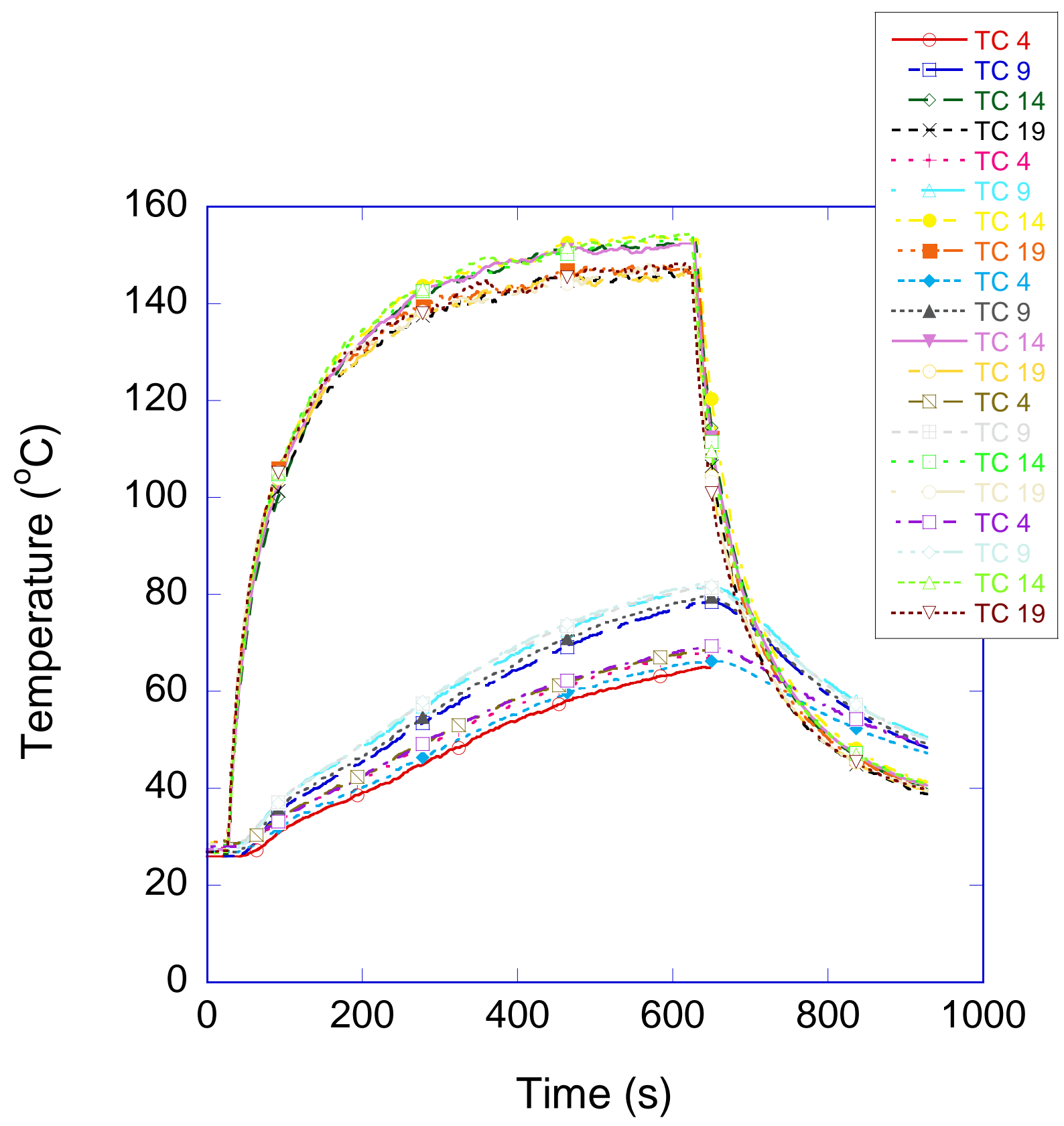

Figure 33. Graph of temperatures through turnout coat and work station shirt for thermocouples associated with external thermocouple \#19 when exposed to an external radiant flux of $2.5 \mathrm{~kW} / \mathrm{m}^{2}$ and no elevated temperature preconditioning. 


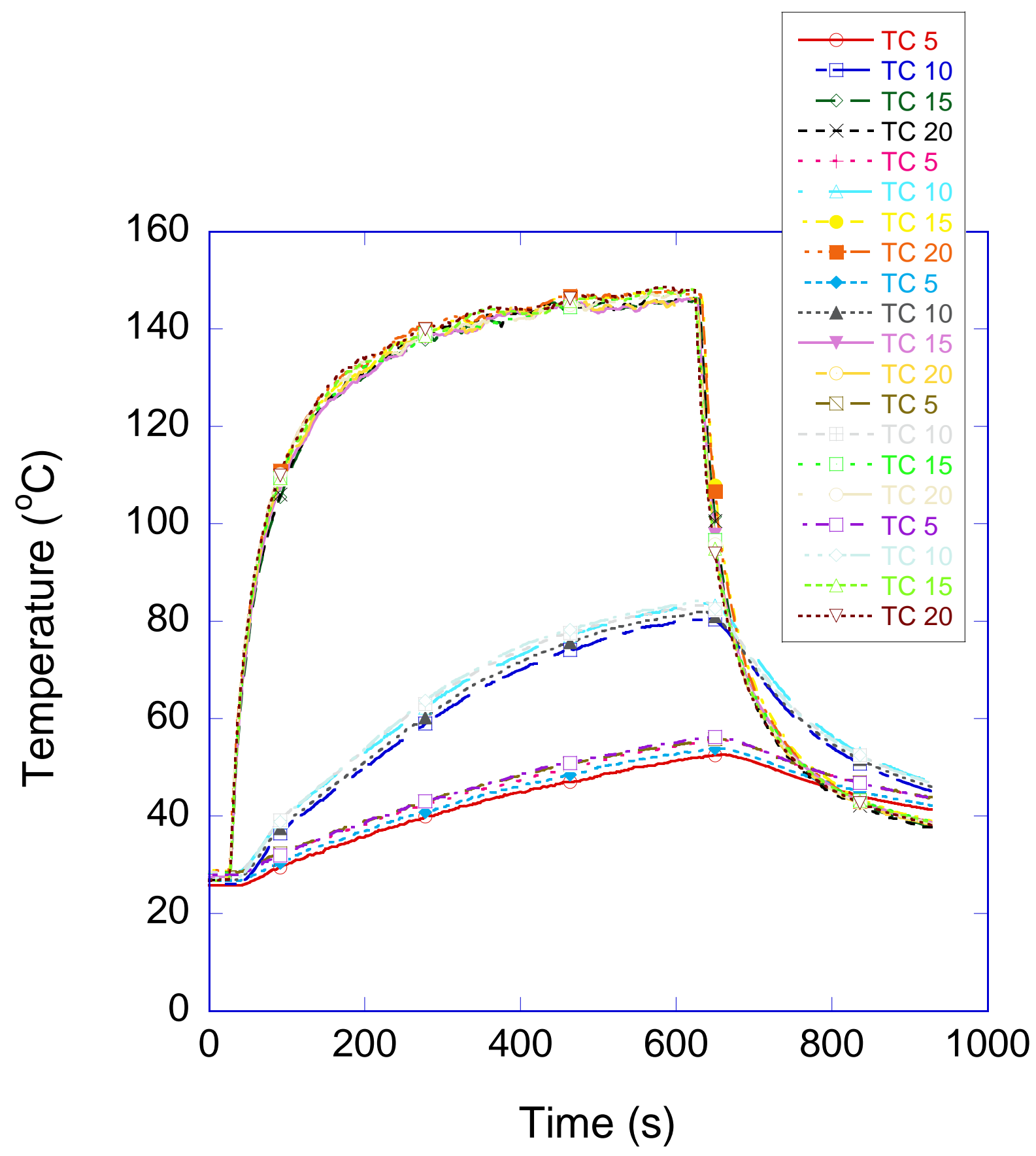

Figure 34. Graph of temperatures through turnout coat and work station shirt for thermocouples associated with external thermocouple \#20 when exposed to an external radiant flux of $2.5 \mathrm{~kW} / \mathrm{m}^{2}$ and no elevated temperature preconditioning. 

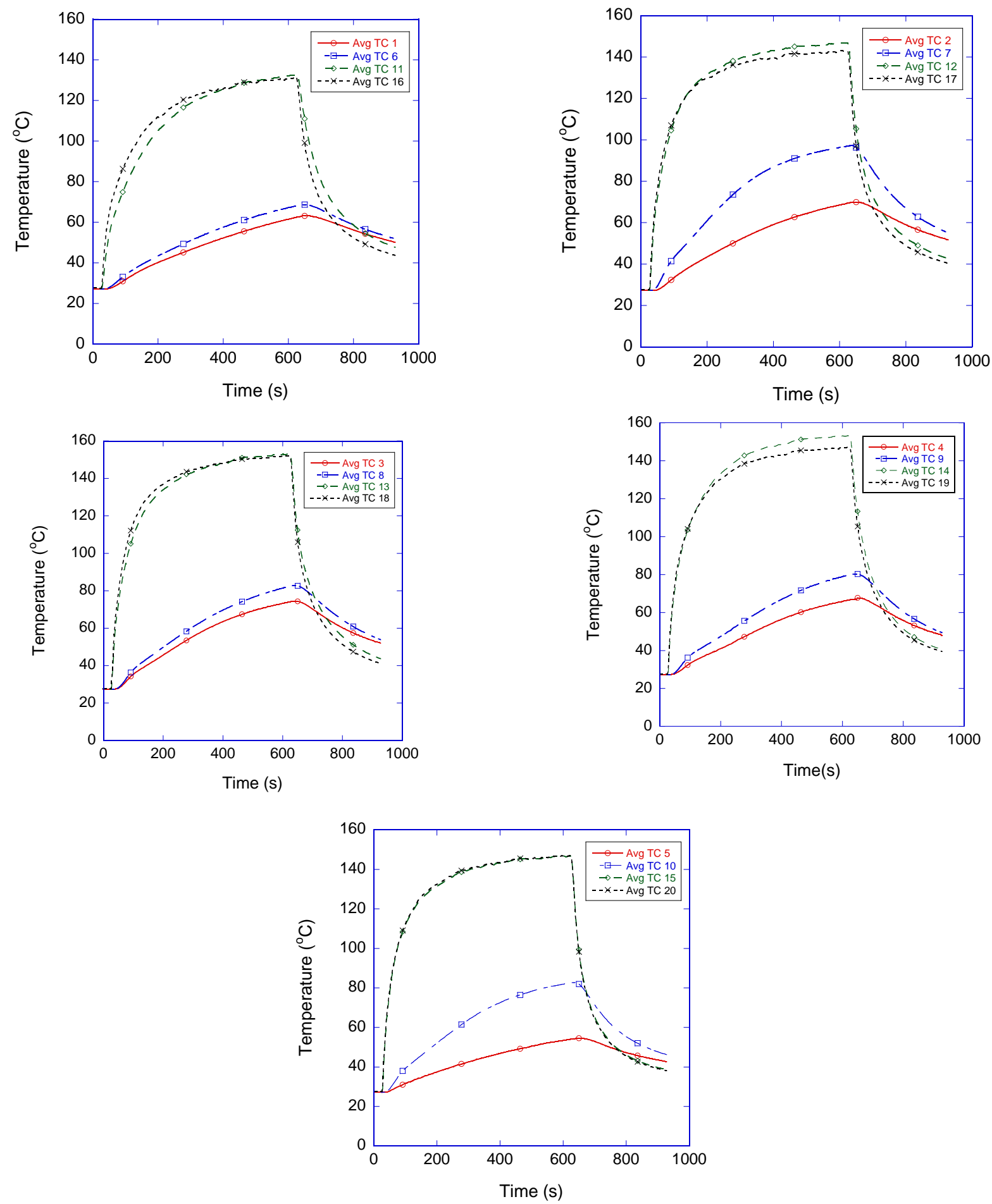

Figure 35. Graphs of average temperatures through turnout coat and work station shirt for thermocouples associated with the five external thermocouple locations when exposed to an external radiant heat flux of $2.5 \mathrm{~kW} / \mathrm{m}^{2}$ and no elevated temperature preconditioning.

$$
-56 \text { - }
$$



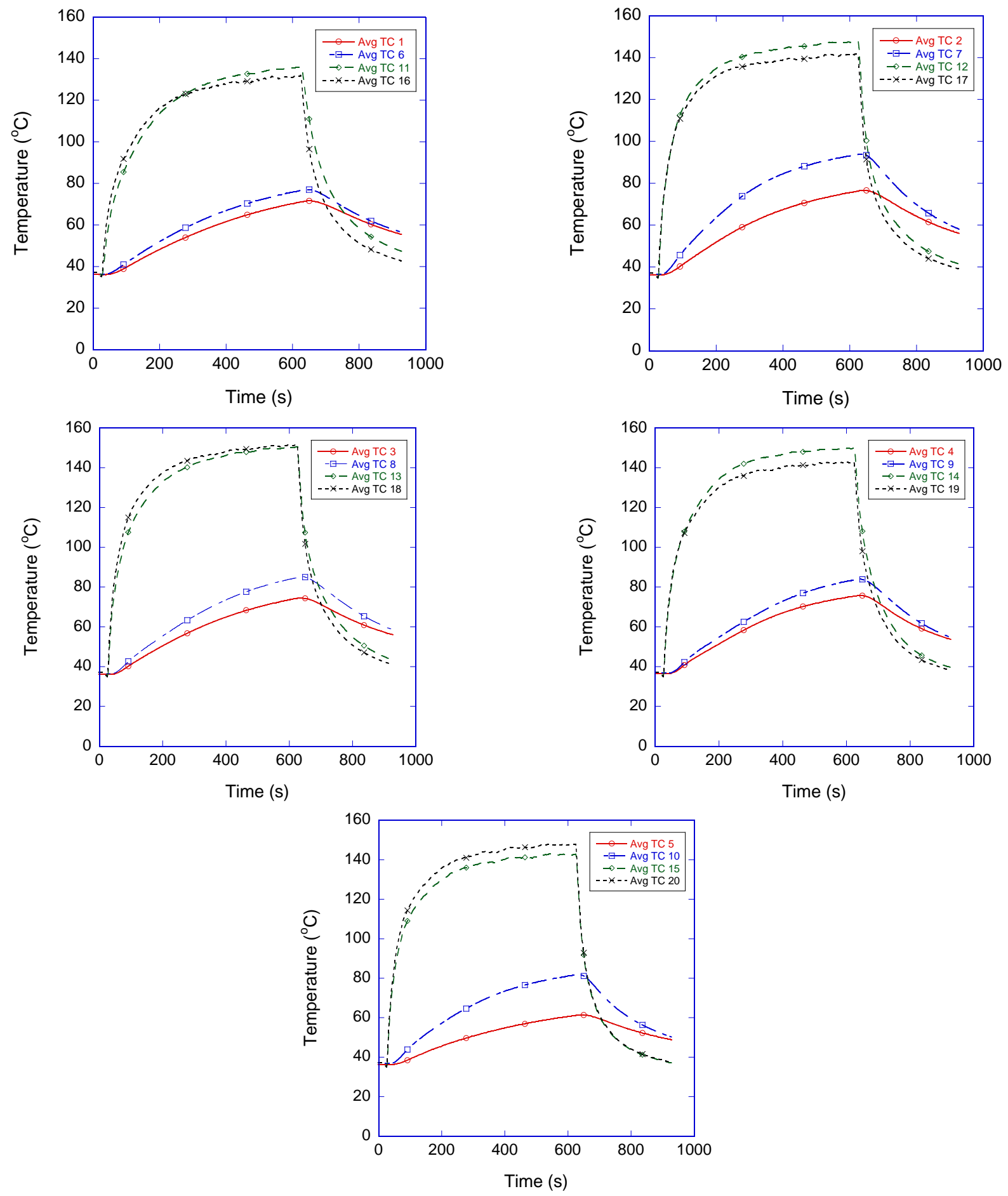

Figure 36. Graphs of average temperatures through turnout coat and work station shirt for thermocouples associated with the five external thermocouple locations when exposed to an external radiant heat flux of $2.5 \mathrm{~kW} / \mathrm{m}^{2}$ and preconditioned at $37^{\circ} \mathrm{C}$. 

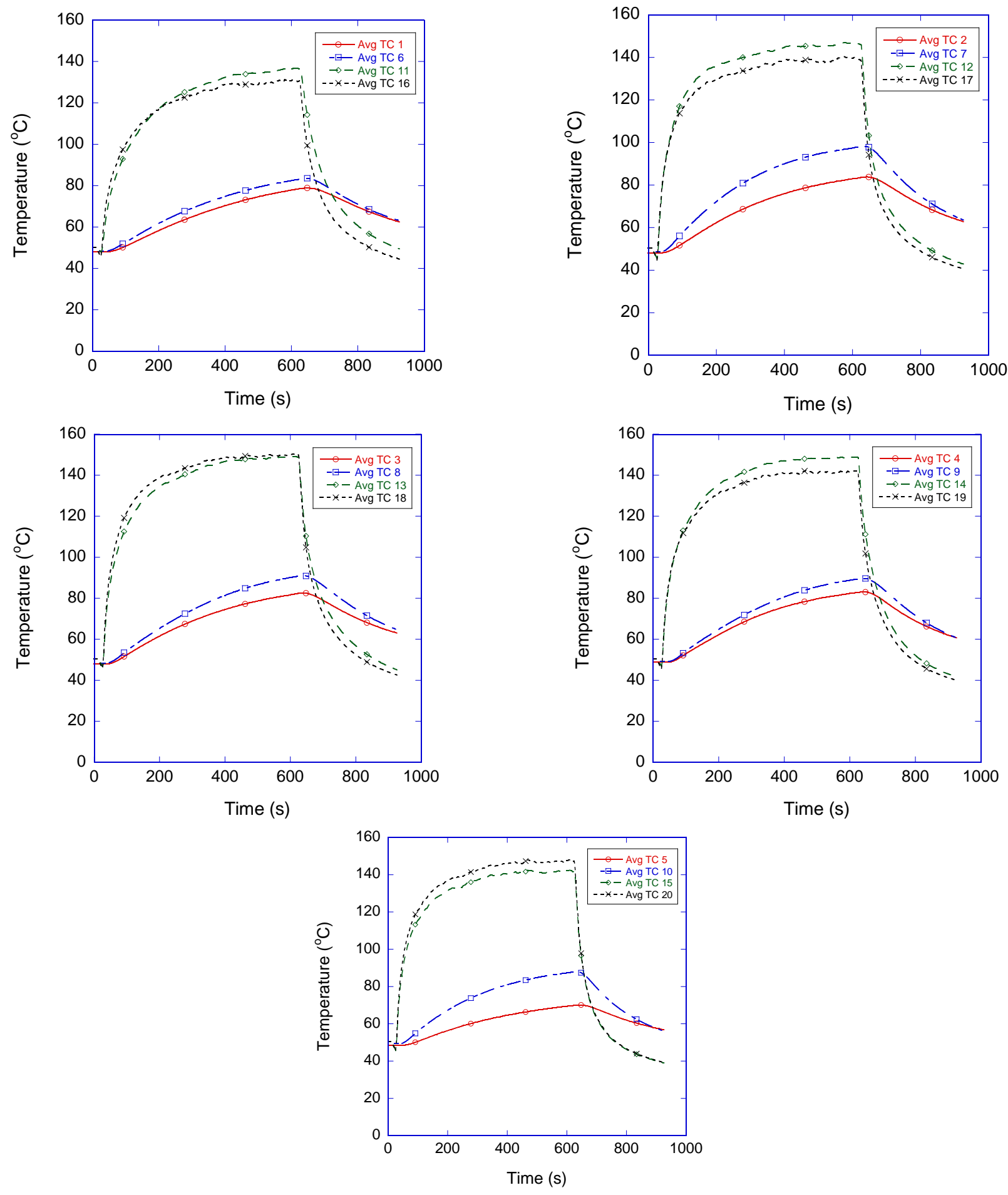

Figure 37. Graphs of average temperatures through turnout coat and work station shirt for thermocouples associated with the five external thermocouple locations when exposed to an external radiant heat flux of $2.5 \mathrm{~kW} / \mathrm{m}^{2}$ and preconditioned at $50{ }^{\circ} \mathrm{C}$. 

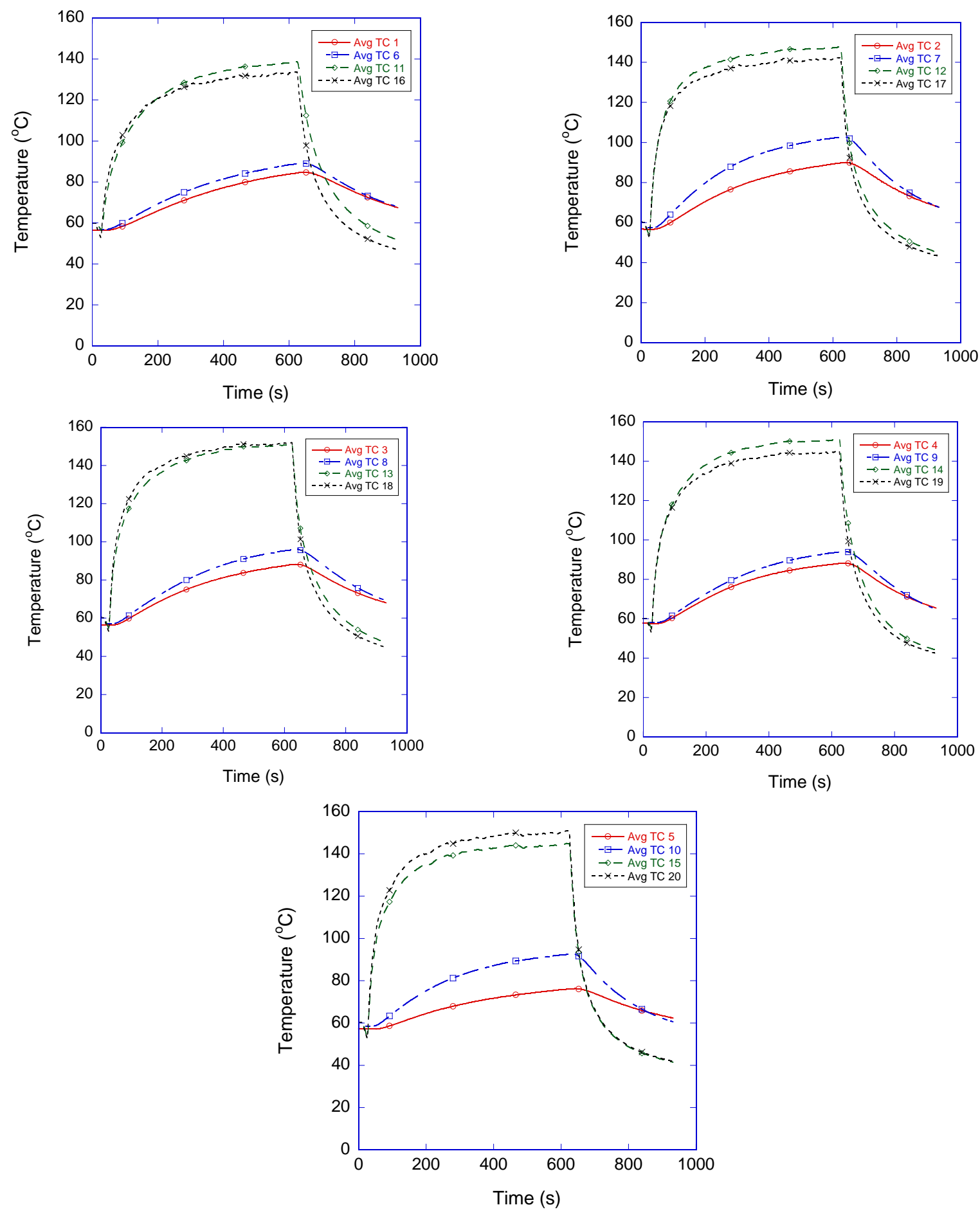

Figure 38. Graphs of average temperatures through turnout coat and work station shirt for thermocouples associated with the five external thermocouple locations when exposed to an external radiant heat flux of $2.5 \mathrm{~kW} / \mathrm{m}^{2}$ and preconditioned at $60^{\circ} \mathrm{C}$. 


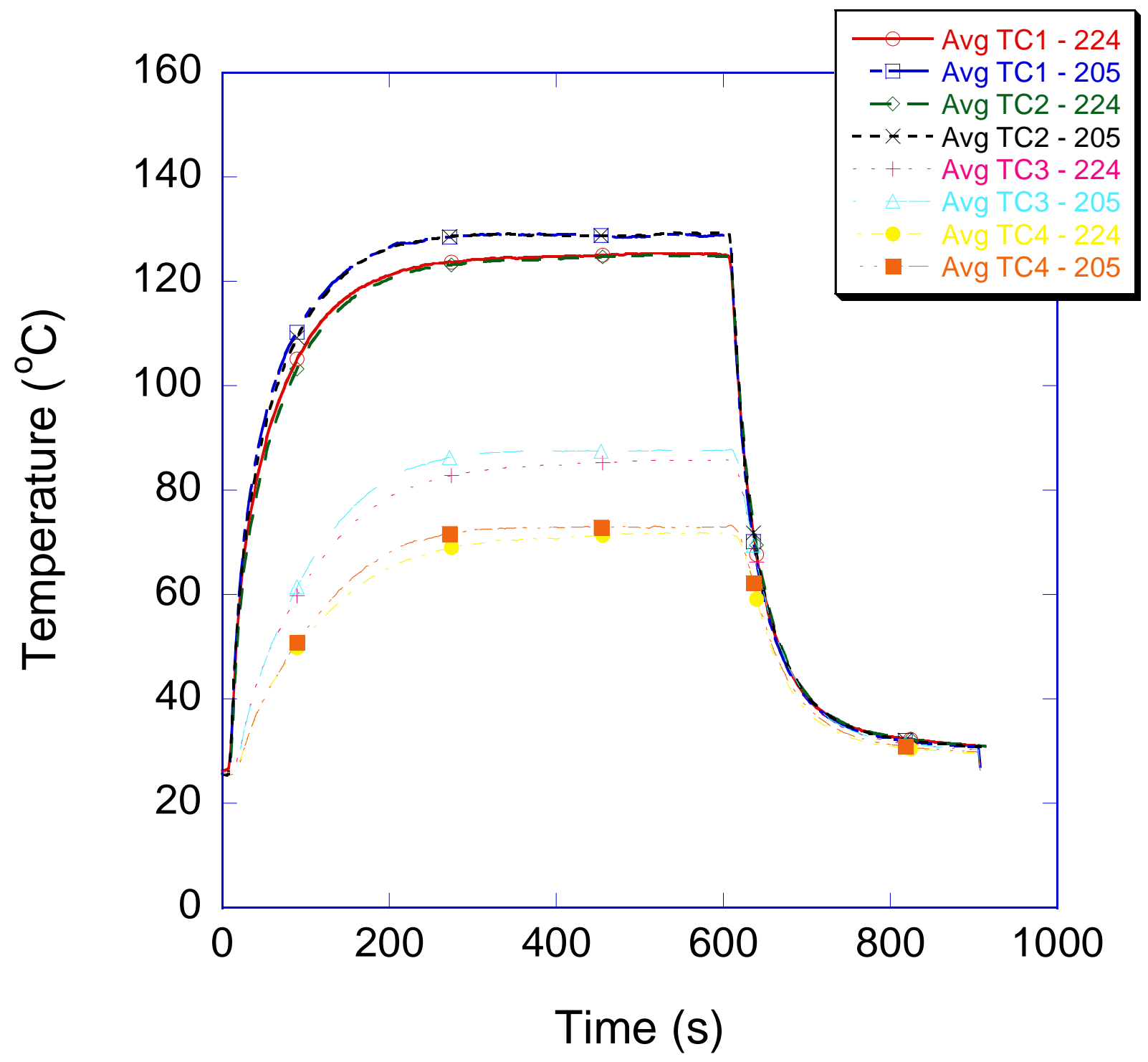

Figure 39. Graph showing average temperatures obtained at the four thermocouple locations for the mock-up tests using the bench scale apparatus (labeled 224) and the full ensemble test apparatus (labeled 205). 


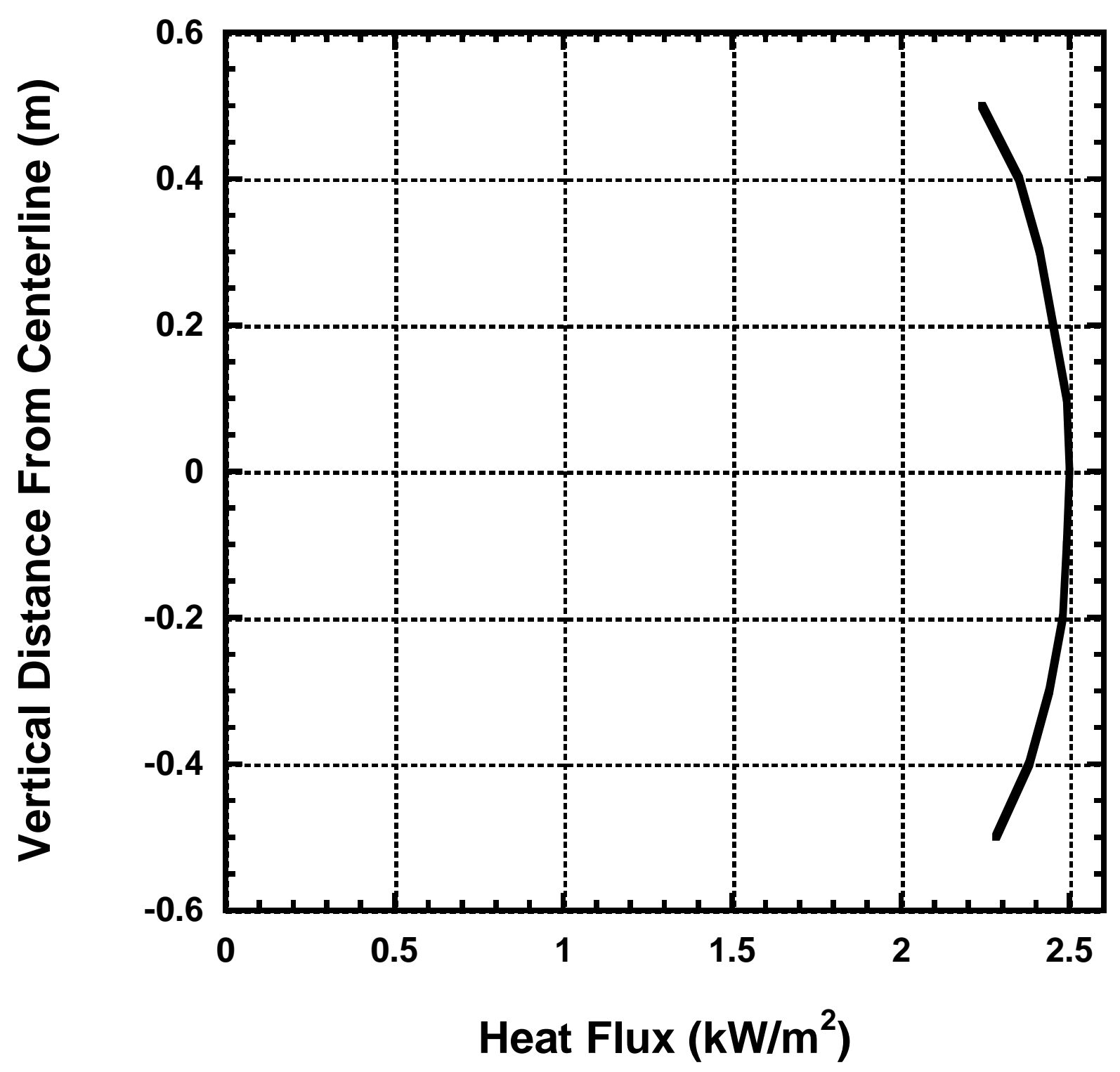

Figure 40. Graph showing the decay of the flux field with movement in the vertical direction (heat flux source on right side of graph). 


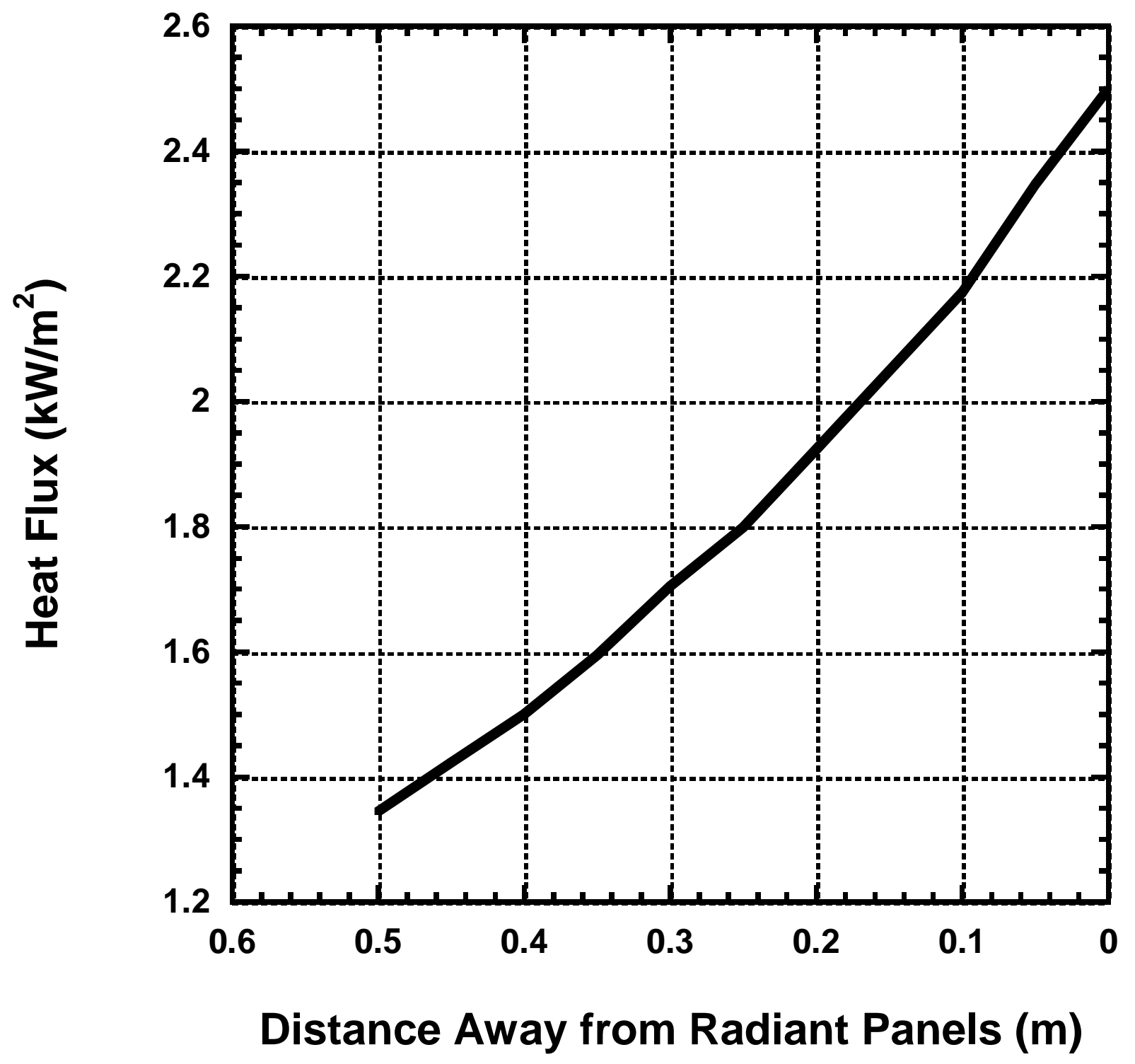

Figure 41. Graph showing the decay of the flux field with movement away from the radiant panels (heat flux source is $0.91 \mathrm{~m}$ away from the panel on right side of graph). 


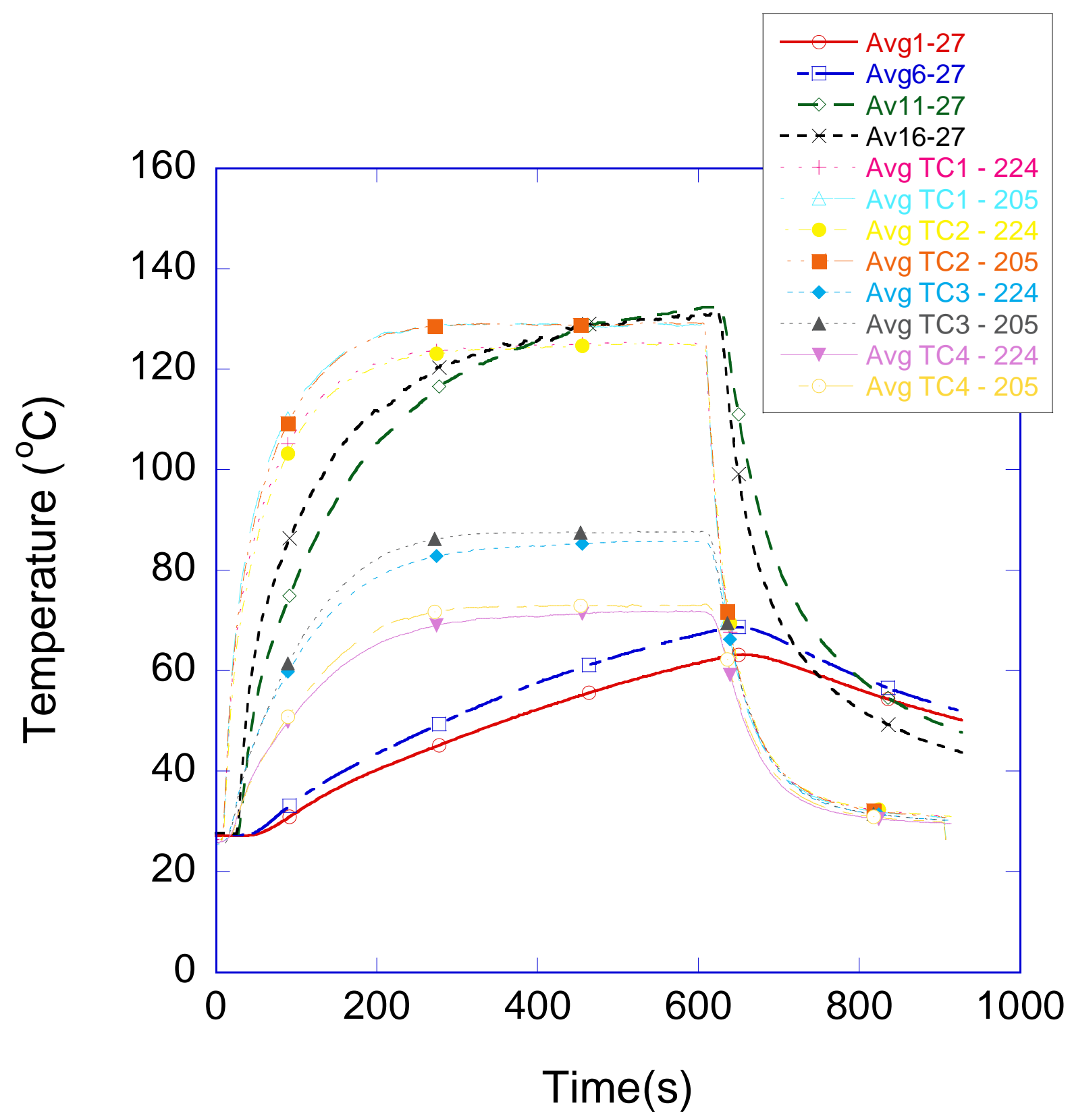

Figure 42. Graph showing comparison between temperatures measured through turnout gear at thermocouple \#16 location and data from mock-up samples in both the full ensemble test apparatus (labeled 205) and the bench scale apparatus (labeled 224). 


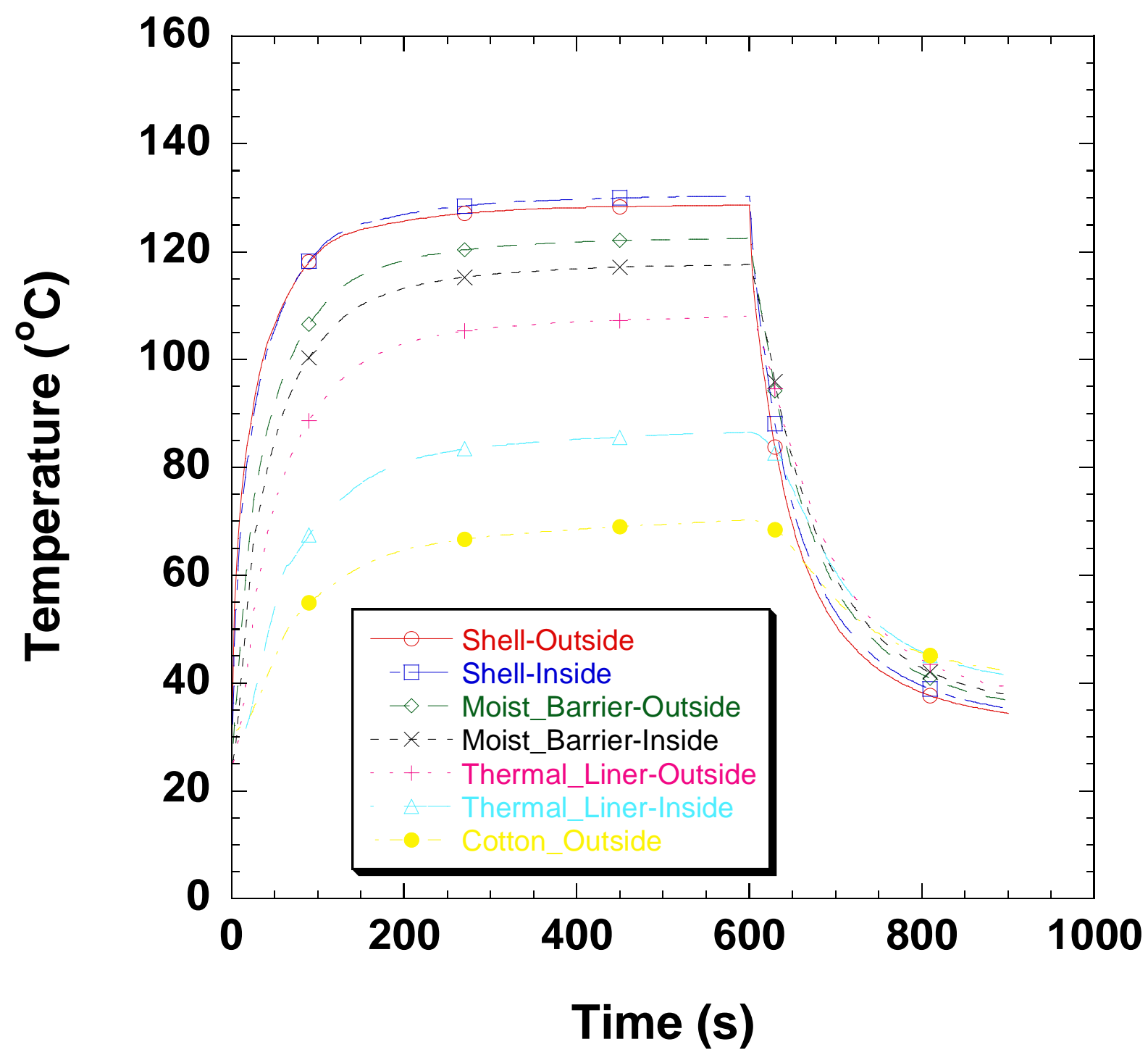

Figure 43. Graph showing calculated temperatures for a mock-up exposed to a 2.5 $\mathrm{kW} / \mathrm{m}^{2}$ heat flux using the default parameters in the heat transfer model [12]. 


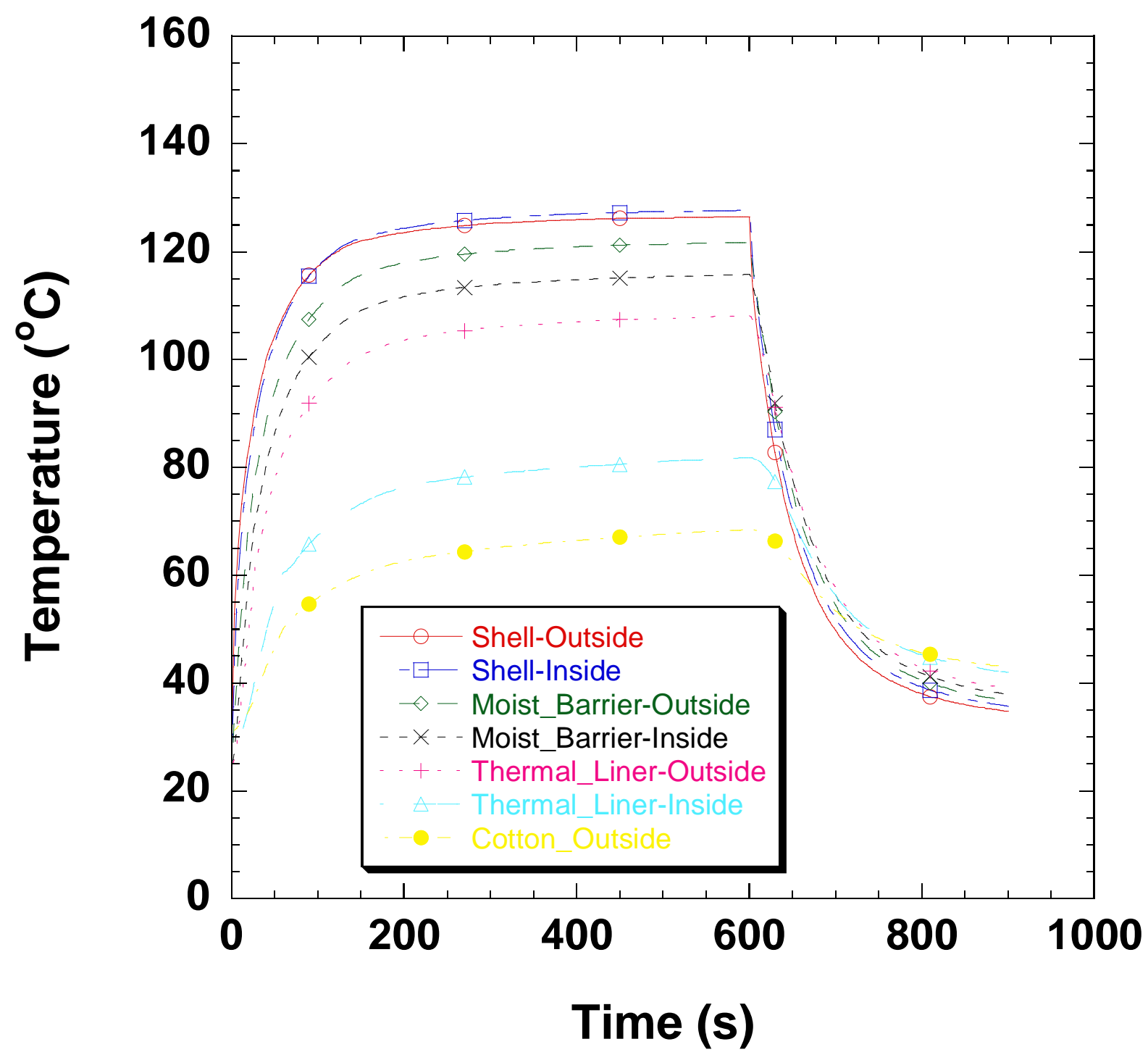

Figure 44. Graph showing calculated temperatures for a mock-up exposed to a 2.5 $\mathrm{kW} / \mathrm{m}^{2}$ heat flux using the default parameters in the heat transfer model [12] except the air gaps are half the size. 


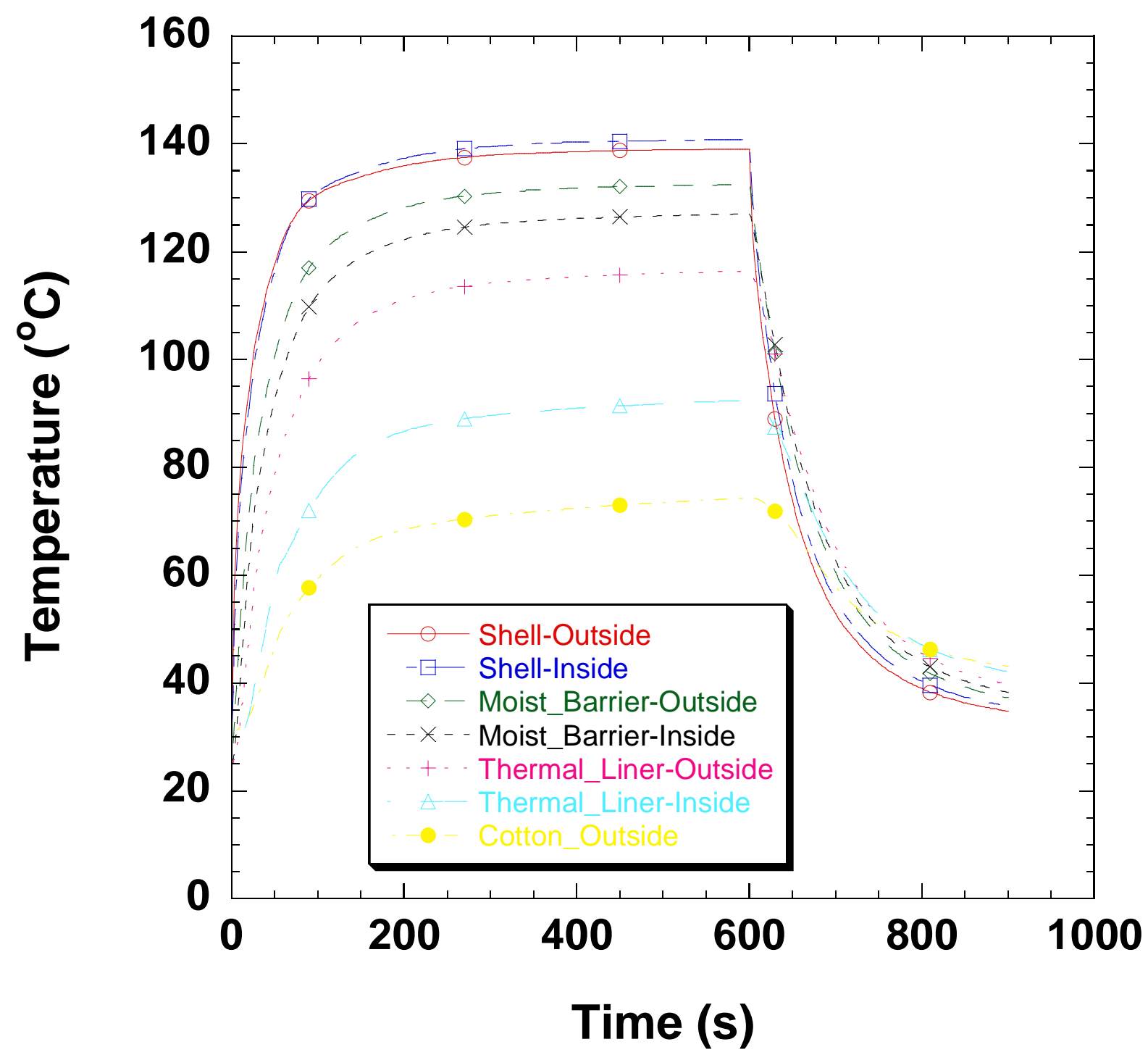

Figure 45. Graph showing calculated temperatures for a mock-up exposed to a 3 $\mathrm{kW} / \mathrm{m}^{2}$ heat flux using the default parameters in the heat transfer model [12]. 


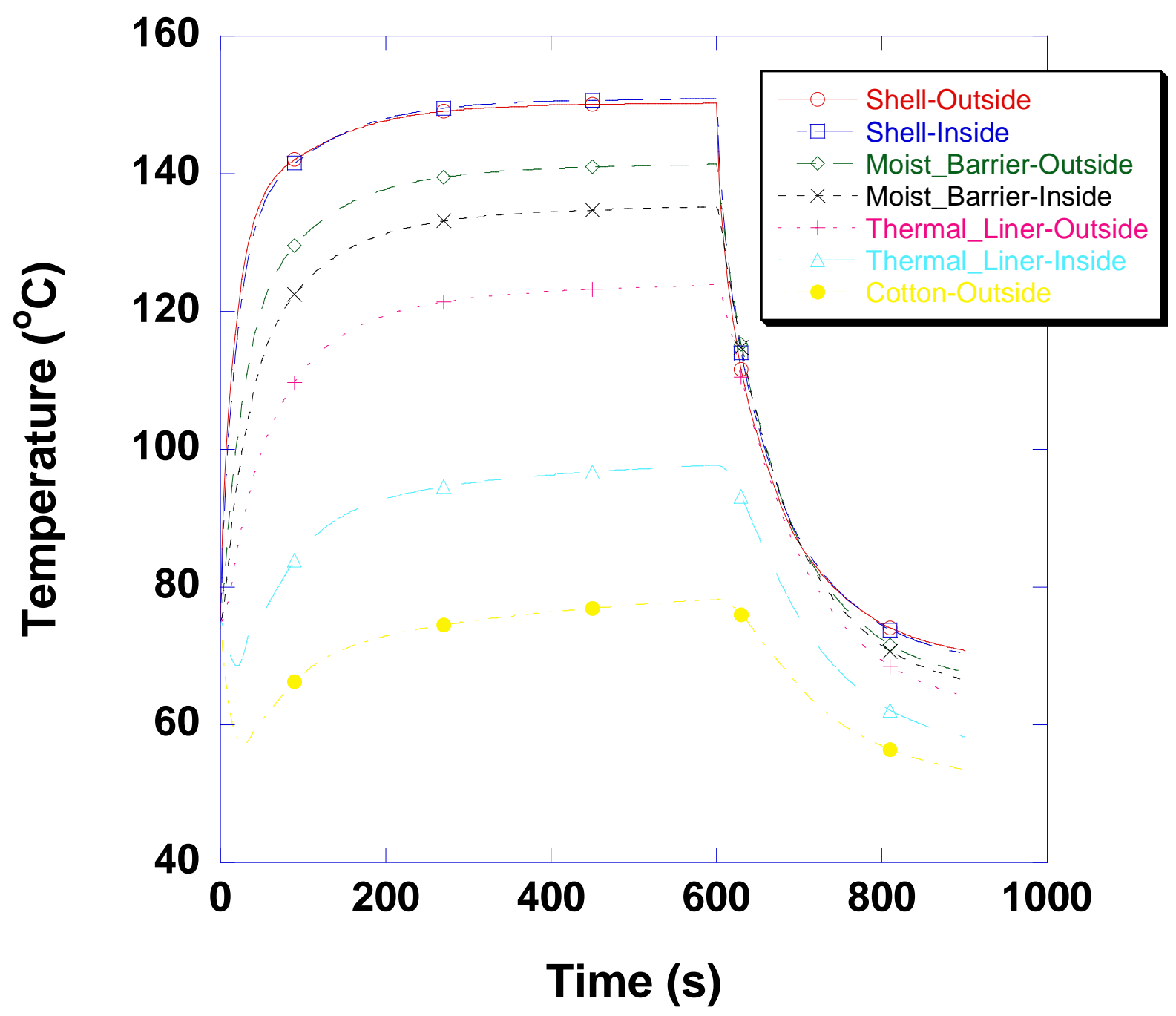

Figure 46. Graph showing calculated temperatures for a mock-up exposed to a 2.5 $\mathrm{kW} / \mathrm{m}^{2}$ heat flux using the default parameters in the heat transfer model [12] except with a $75^{\circ} \mathrm{C}$ ambient background temperature. 


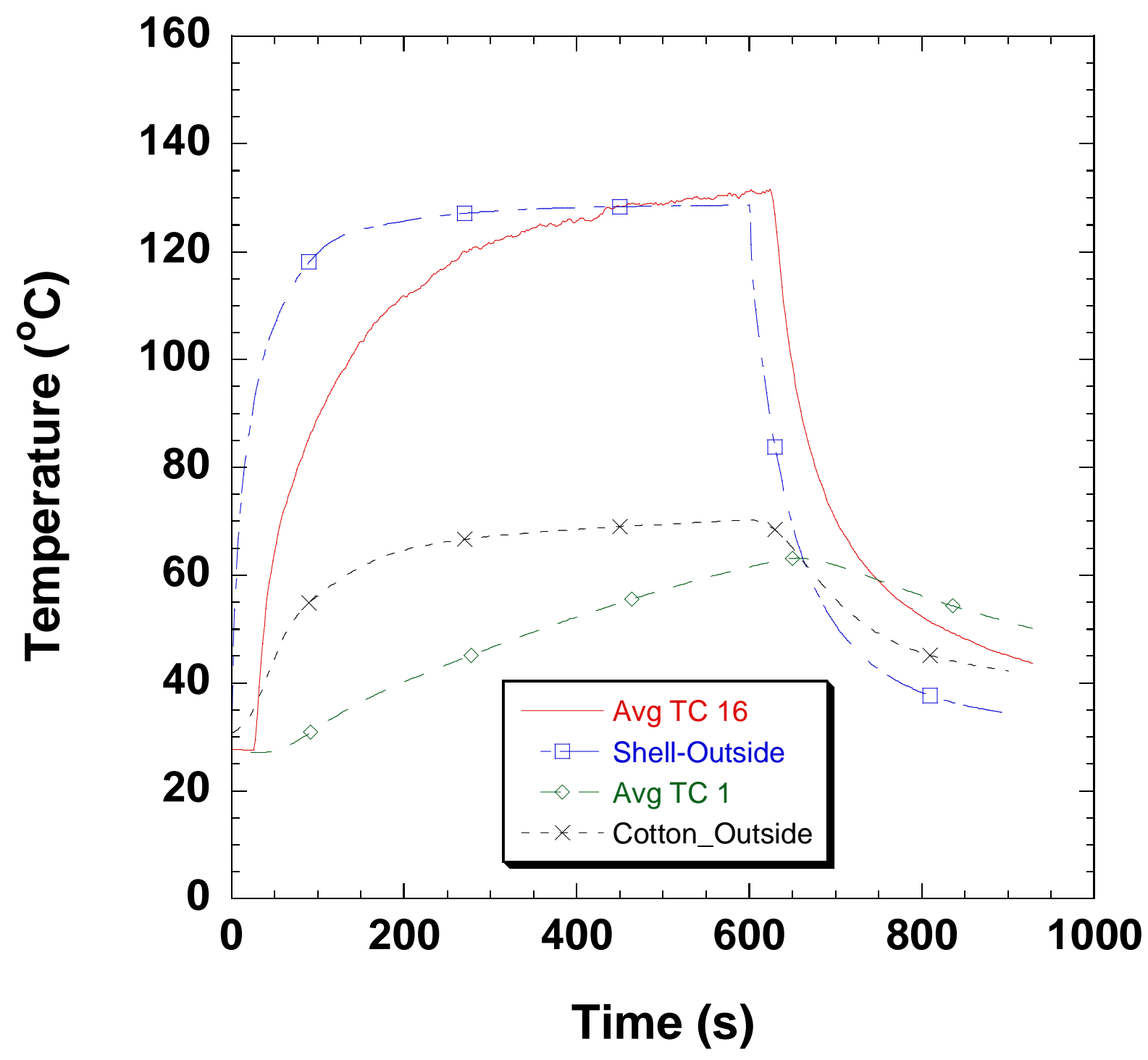

Figure 47. Graph comparing measured (Avg TC 16, Avg TC 1) and calculated temperature distributions through a turnout coat when exposed to a 2.5 $\mathrm{kW} / \mathrm{m}^{2}$ heat flux using the full ensemble test apparatus. 


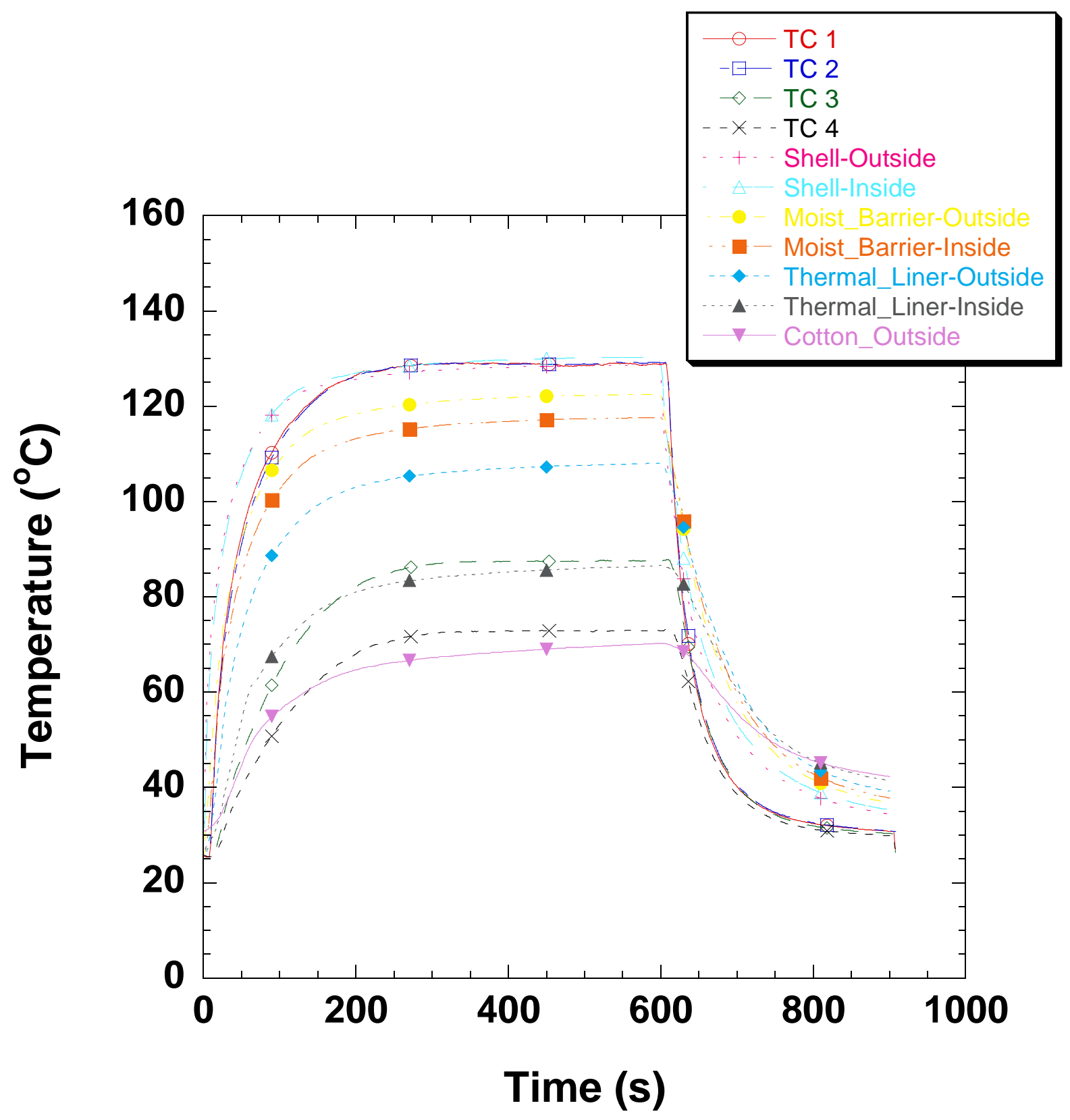

Figure 48. Graph comparing measured (TC 1, TC 2, TC 3, TC 4) and calculated temperature distributions through a mock-up assembly when exposed to a $2.5 \mathrm{~kW} / \mathrm{m}^{2}$ heat flux using the full ensemble test apparatus. 